\title{
Origin and Evolution of Earth and Life: Towards the Establishment of Astrobiology from Universe to Genome
}

\section{Shigenori Maruyama ${ }^{1,2}$}

${ }^{1}$ Affiliation: Earth-Life Science Institute, Tokyo Institute of Technology

Address, Country: 2-12-1 O-okayama, Meguro-ku, Tokyo 152-8551,

Japan E-mail: smaruyam@geo.titech.ac.jp

${ }^{2}$ Affiliation: Novosibirsk State University

Address, Country: Pirogova 1, 630090, Russia

E-mail: smaruyam@geo.titech.ac.jp

\section{Toshikazu Ebisuzaki ${ }^{3}$}

${ }^{3}$ Affiliation: RIKEN

Address, Country: 2-1 Hirosawa, Wako, Saitama, 351-0198, Japan

E-mail: ebisu@riken.jp

\section{Ken Kurokawa ${ }^{4}$}

${ }^{4}$ Affiliation: Genome Evolution Laboratory, National Institute of Genetics

Address, Country: 1111 Yata, Mishima, Shizuoka 411-8540, Japan

E-mail: kk@nig.ac.jp

This paper is comprised of 6 sections as follows.

(1) Introduction

(2) Planetary Formation Theory and Origin of Earth

(3) Origin of a habitable planet: carbon cycle

(4) Origin of the Earth’s life

(5) Evolution of the Earth's life

(6) Towards the establishment of Astrobiology

In (1) Introduction, I briefly summarized why I came to be involved in these research topics.

In (2) Planetary Formation Theory and Origin of Earth, we simply review previous researches of planetary formation theory, and introduce newly proposed Tandem model to explain the formation 
of the solar system with new factor. Then, we introduce the ABEL model as another new theory to explain how the Earth was formed. This model can explain long unsolved enigma of the origin of earth's water and solid earth. In (3) Origin of a Habitable Planet: Carbon Cycle, we try to explain the significance to unravel the carbon cycle through earth's history. And we propose a new concept of carbon cycle running from the atmosphere to mantle through earth's history and the birth of earth to present day. In addition, based on accretion and complex geology centering on Ocean Plate Stratigraphy (OPS); we propose carbon compensation depth (CCD) works as the function of $p \mathrm{CO}_{2}$ through time, which is significantly a new method to approach environmental evolution of the earth. In (4) Origin of the Earth's Life, after we review previous researches for the birthplace of life, we propose nine requirements that must be met at the birthplace of life. Then, we introduce an ideal site to emerge life is Natural geyser system on the Hadean primordial continent, which produce material circulation system to synthesize life by the combination between natural nuclear reactor and geyser. In (5) Evolution of the Earth' life, we pick up 20 biggest events in the history for the earth and life, to understand more essential and significant events to study the history of earth and life. Those events were selected considering the criterion to extract, whether the event is single and unique phenomenon to become a turning point for the earth's history. In (6) Towards the Establishment of Astrobiology, we propose the working hypothesis to push forward the present Astrobiology research. Astrobiology is the research field to unravel when, how, and where in the universe life was born. To tackle with such a big question, fundamental requirements must be clarified. The conditions to evolve to a habitable planet, which we propose here, is comprised of three groups; (1) planetary requirements to be life emerging planet, (2) nine requirements for the birthplace, and (3) requirements to evolve into planet with civilization. Totally 40 requirements are described, and each condition must be satisfied in sequence as listed. It means the emergence of life is not easy. The order and number of requirements that must be satisfied to make life very difficult even to appear, suggesting the planet with civilization might be quite rare in our Galaxy. 


\section{Introduction}

With the development of exploring technology of the universe, the number of exoplanets is now assumed to exceed 20 billion or one-order magnitude greater than our expectation. Because of overwhelming abundance of exoplanets, people think optimistically about the presence of Earth-like exoplanet and abundance of life forms in the universe. Indeed, Earth-like sized exoplanets might be common in the universe, however, it does not mean life emerged on such planets. Moreover, it is unclear whether highly civilized life forms are present.

What is life? What is conditions for the emergence of life? What is life's evolution? To answer these fundamental questions, only Earth can provide obvious evidence. Therefore, when we discuss Astrobiology, we need to understand the research for Earth's life. In this paper, we summarize the frontier of those Earth's life researches which have been progressing through our research project with 48 research organizations from 28 countries.

\section{Planetary formation theory and origin of the Earth}

The classic theory of the formation of the solar system was proposed by [1], [2], and followed by [3] proposing the formation process of planets based on N-body simulation (e.g. [4]). With the development of supercomputer, N-body simulation became able to treat more than tens of thousands of N, and more complex simulation became available (e.g. [5]). More recently, Grand Tack model was newly proposed by [6] which discuss the migration of planets in the solar system. We summarize those theories below with problems inherent in their explanation, and introduce a new model to explain the origin of the Earth which can overcome problems remaining unsolved.

\subsection{Theory of the solar system formation}

After classic formation theory of the solar system was proposed by [1], [2] and [3], [7] explained it as schematically illustrated in Fig 1, showing the process from (1) contraction of protoplanetary disk, (2) the birth of protosun and planetesimals, (3) accretion to become asteroids (from inner to outer domain of the solar system, types of asteroids were rocky asteroids, gas giants, and icy asteroids), and finally, (4) dispersion of hydrogen gas. It means that gas giants such as Jupiter and Saturn trapped hydrogen gas due to 10 Earth mass, while it remains controversial whether inner rocky planets formed before or after the dispersion of hydrogen gas.

More recently, Grand Tack model was proposed by [6] as shown in Fig 2. This model proposed that Jupiter was born at 6-7AU as first planet in the solar system. Before inner rocky planets grew up, Saturn migrated to 0.3AU (the orbit of the Mercury) with outer icy asteroids. After those icy asteroids supplied volatiles to inner rocky planets, gas giants and icy asteroids returned back to present orbital position, e.g. Jupiter at 5AU and Saturn at 10AU. [6] proposed that this process caused the gap in mass distribution between 2AU and 5AU.

These models contain serious problems because some observational facts do not support them. For example, both model explain solid earth was born with atmosphere and ocean within one million years after the primordial Earth formed. However, if the Earth was born with atmosphere and ocean, the earth should have evolved to Venus-like scorching planet, because the amount of atmospheric carbon is too much. According to geological records, at least 300 bar $\mathrm{CO}_{2}$ is being stored within the terrestrial continental crust, and another $100 \mathrm{bar} \mathrm{CO}_{2}$ is estimated to be 
stored in the mantle. Therefore, totally 400 bar $\mathrm{CO}_{2}$ are currently fixed in the solid earth. However, volatiles had been originally distributed to atmosphere when the Earth was formed. If 400 bar $\mathrm{CO}_{2}$ enveloped the Earth, there would not be an ocean due to extreme greenhouse gas effect of $\mathrm{CO}_{2}$. For the ocean to exist on Earth, the atmospheric $\mathrm{CO}_{2}$ must be less than 5 bar [8].

The reason why these models contain serious problems is that they adopted only $\mathrm{N}$ body simulation as a method. They did not consider (1) magnetorotational instability of protoplanetary disk, (2) thermodynamic features of rock forming minerals, especially for minerals including volatiles, (3) compositional differentiation observed within meteorite parent body over $200 \mathrm{~km}$ in diameter, i.e. metallic core, silicate mantle, and basaltic crust, and primordial atmosphere, caused by short-lived radionuclide like ${ }^{26} \mathrm{Al}$. If the proposed model cannot explain observational facts, such model is not comprehensive enough to accept and which leaves only the adhoc working hypothesis.

To overcome the difficulties by previous models, [9] proposed a new model of the solar system formation named "Tandem model" as illustrated in Fig 3. Their new model considers (1) magnetorotation instability and (2) compositional zoning made through the evolution of the solar system. When the bipolar flow of protosun reached to 100AU, dehydration reaction occur based on the distance from the Sun, resulting in the appearance of stagnant region where a planet will form. Icy planets form in outer domain of such stagnant region, and rocky planets form in the inner stagnant region. With time, temperature structure changes and the orbit to form a planet migrates into the inner region.

At the most inner region near the Mercury orbit, the temperature exceeds $1,000{ }^{\circ} \mathrm{C}$ where even silicate minerals evaporate. Due to this, Mercury has less silicate minerals but rich in metallic elements. According to Grand Tack model, icy asteroids are stable even in Mercury's orbit. However, in the case that temperature structure is take into consideration, even silicate minerals evaporate and volatiles are blown off to outer region of the solar system.

On the other hand, Tandem model is supported by observational facts. As illustrated in Fig. 5, chemical zonation is observed in asteroid belt according to the estimation of planetary bulk chemical composition by [10], [11] and meteorites fell on the earth.

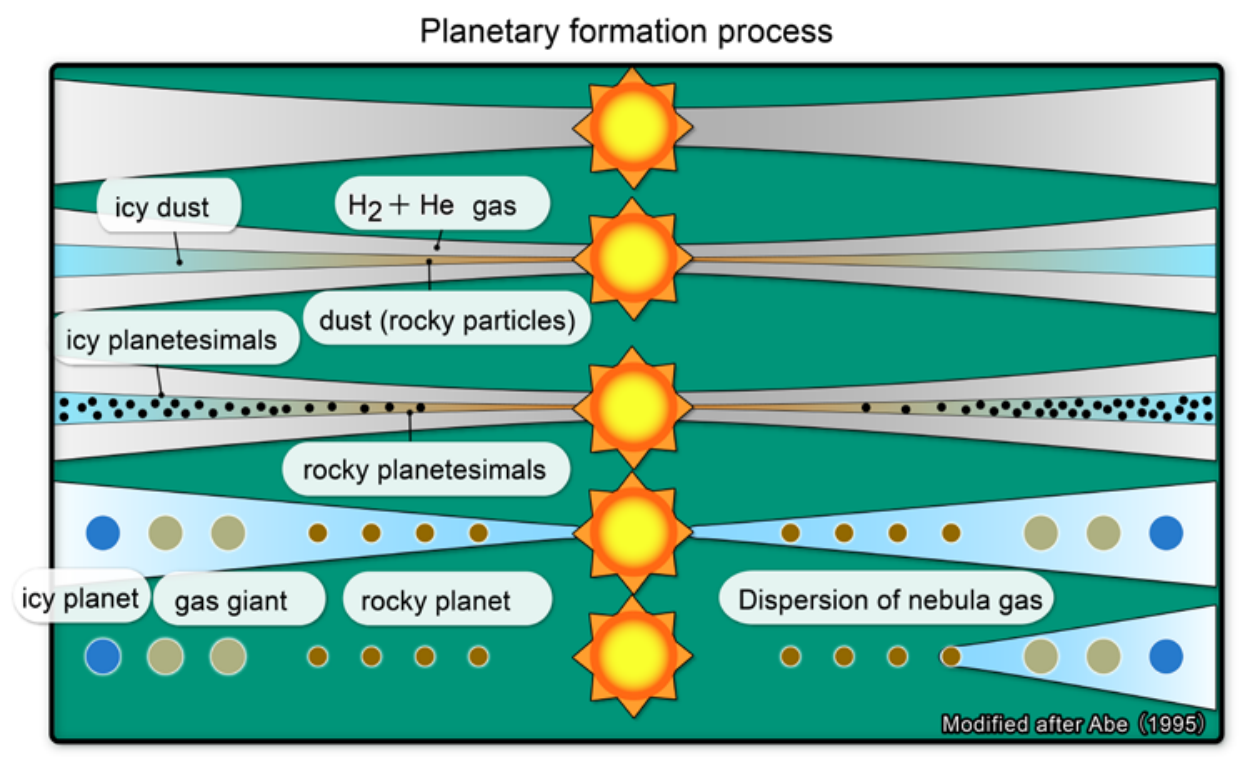


Fig 1. Model of the Solar System Formation: The solar system evolves over time from top to bottom of the illustration. Proto-planets formed from protoplanetary disk within one million years from the rotating gas nebula (top), through fine-grained mineral dust particles with chemical differentiation (middle), formation of planetesimals and their accretion to become asteroids within a gas envelope or free gas (middle bottom), and the final formation of three groups of planets (rocky planets, gas giants with ice-rock planetary core, and icy planets) as a function of distance (AU). The timing of gas dispersion is controversial. Note the difference (between the figure on the right vs. the figure on the left at the bottom) in the timing of dispersion of nebula gas. Figure was modified after [12].

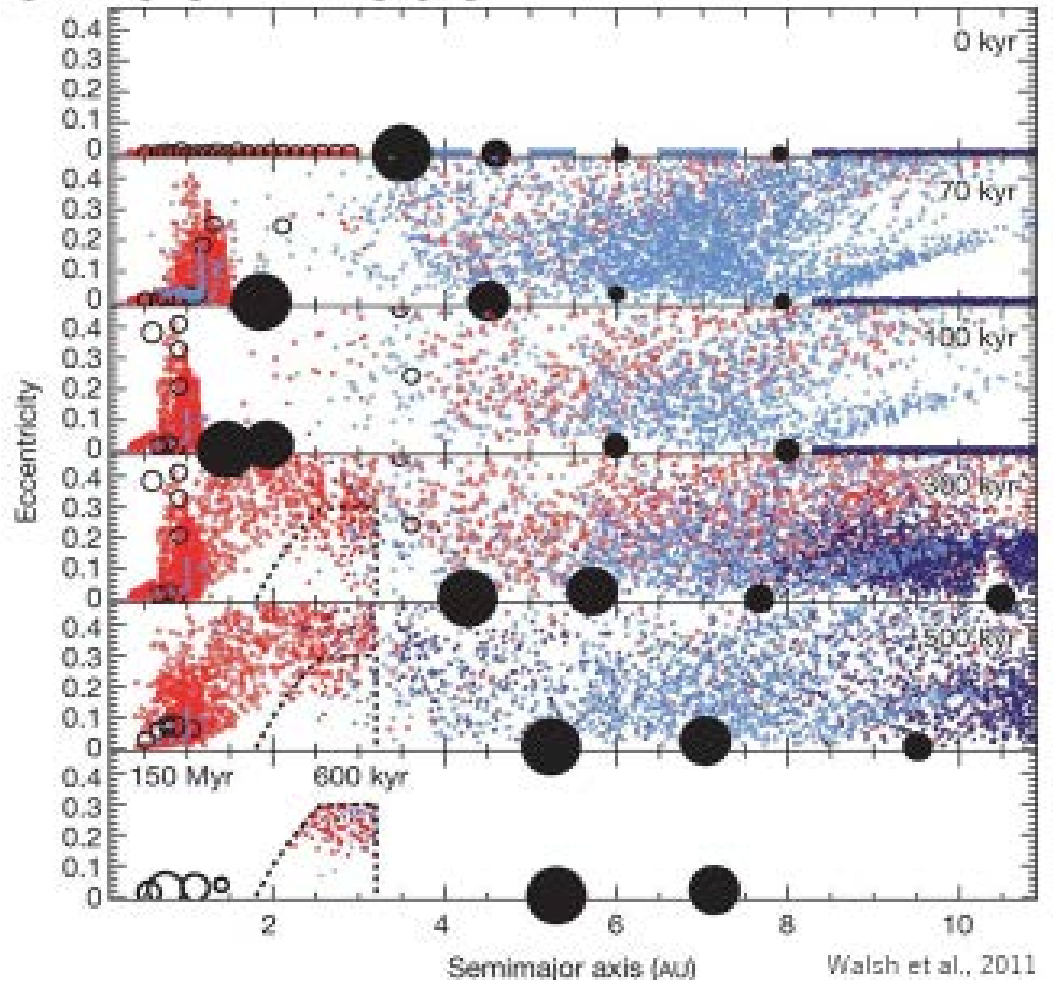

Fig 2. Grand Tack Model [6]: The time progress from top to bottom of the illustration. Jupiter was born at 3.5AU as the first planet with the biggest mass. Jupiter migrated to 1.5AU with outer icy asteroids within 70,000 years after it was born. Icy asteroids migrated to nearly 0.3AU to supply volatiles to inner rocky planets. Later, Saturn also migrated to 2AU. Both gas giants moved back to present orbital position within 500,000 years. These migration event caused the lack of mass distribution at 2-5AU [6]. 
New model: different from Grand TACK and Safronov/Kyoto models

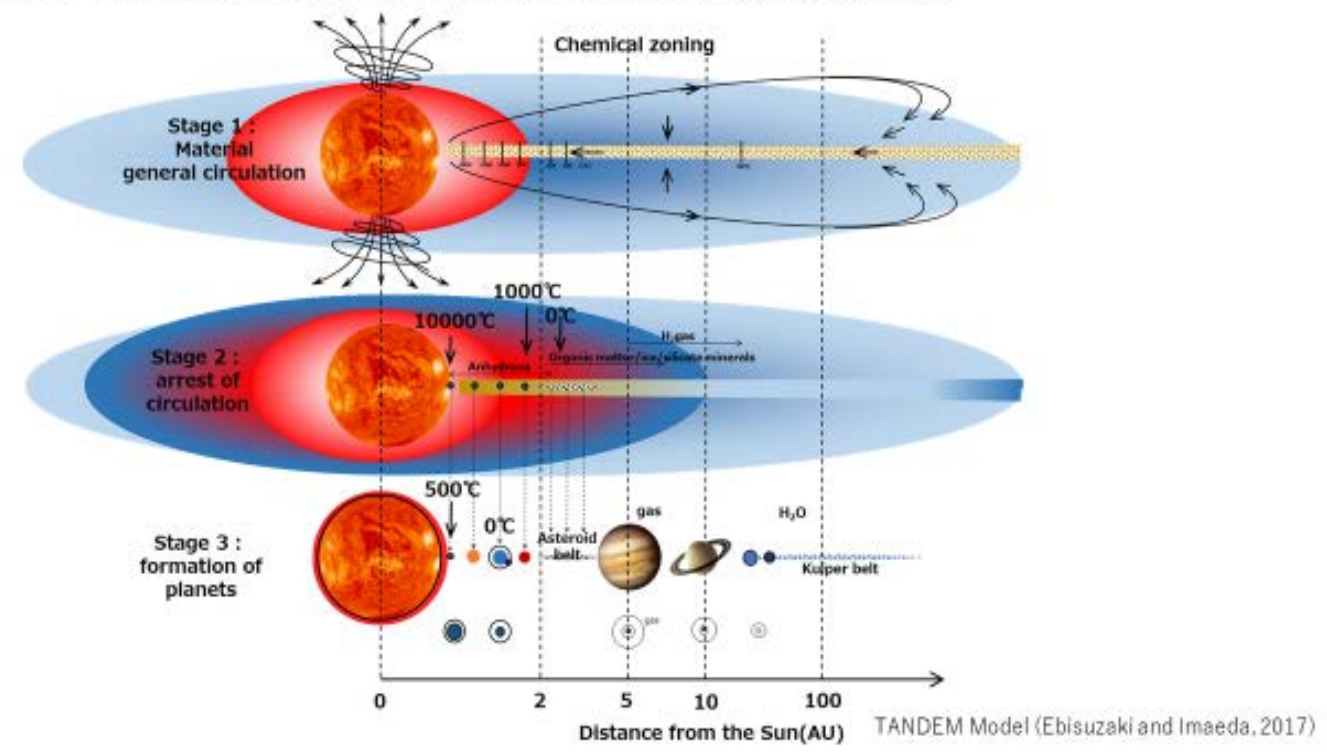

Fig 3. Tandem Model by [9]: After bipolar flow of protosun reached 100AU, material moved back along the equatorial plane. Material is concentrated on the equatorial plane of the protoplanetary disk. With increasing temperature, material accumulates at boundary between turbulent field and stability field.

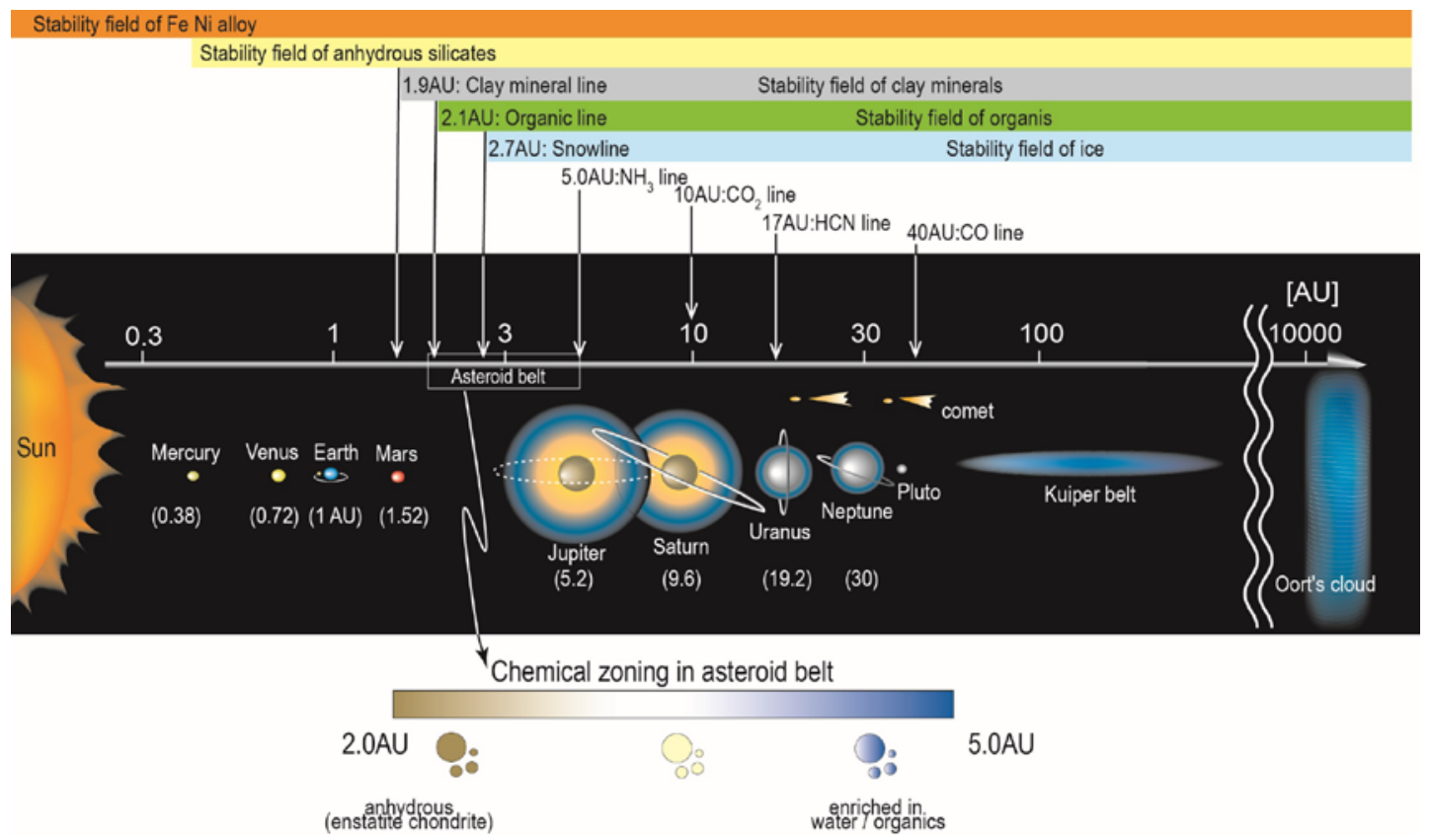

Fig 4 Progressive Chemical Zonation of the Solar System at Ca. 4.56 Ga: Progressive chemical zoning of proto-planetary mineral dusts in the nebula disc is seen as a function of distance from the Sun (AU). Organics line is at 2.1 AU [13], snowline at 2.7 AU (170 K) [14], $\mathrm{CO}_{2}$ at $10 \mathrm{AU}$, and $\mathrm{CO}$ at $40 \mathrm{AU}$ are shown [15] and [16], with a clay mineral line assumed to occur at 1.9 AU. Note that the inner stability limit of the hydrous phase is at 1.8-1.9 AU, quite far from $1 \mathrm{AU}$ where Earth was formed under a completely dry condition. The major rock type of proto-Earth was enstatite chondrite-like, as inferred from the oxygen isotope ratio, but in reality $\mathrm{Ca}$ and $\mathrm{Al}$ - and $\mathrm{Mg}$-components are also necessary additions [17]. 


\subsection{Origin of the Earth}

\subsubsection{The formation of a dry Earth without atmosphere and ocean}

Formation process of the Earth was proposed by [12] as illustrated in Fig 5. According to their model, planetesimals accreted with each other to form asteroid (400km in diameter) with time' at a later stage, proto-Earth experienced giant impact to form Earth-Moon system. In this formation model, the Earth held atmosphere as its size length reached midway between Moon and Mars. Then, the metallic core formed when Earth reached Mar's own length, followed by the differentiation from the silicate mantle.

However, as we summarized in previous section, inner domain of the solar system where the rocky planets formed experienced very high temperature, therefore, even silicate minerals evaporated and volatiles blew to the outer region of the solar system. In other words, proto-Earth could not have volatiles to form atmosphere and ocean. It indicates that all rocky planets, i.e. Mercury, Venus, Earth, and Mars, was born as a dry planet without atmosphere or ocean.

So far, Earth-Moon system is assumed to be originated from carbonaceous chondrites, because the Earth has both atmosphere and ocean. However, oxygen isotopic composition indicates the origin of solid Earth is not carbonaceous chondrite, but enstatite chondrite, as illustrated in Fig. 6. This indication is consistent with the chemical zonation in asteroid belt shown in Fig. 4. If so, the Earth was born as a dry planet without ocean or atmosphere.

On the other hand, Earth's water is assumed to have originated from carbonaceous chondrite based on the D/H of hydrogen isotope. Fig 7. shows the D/H of Earth's water which is similar to that of carbonaceous chondrites, but far from that of comets or solar wind. This

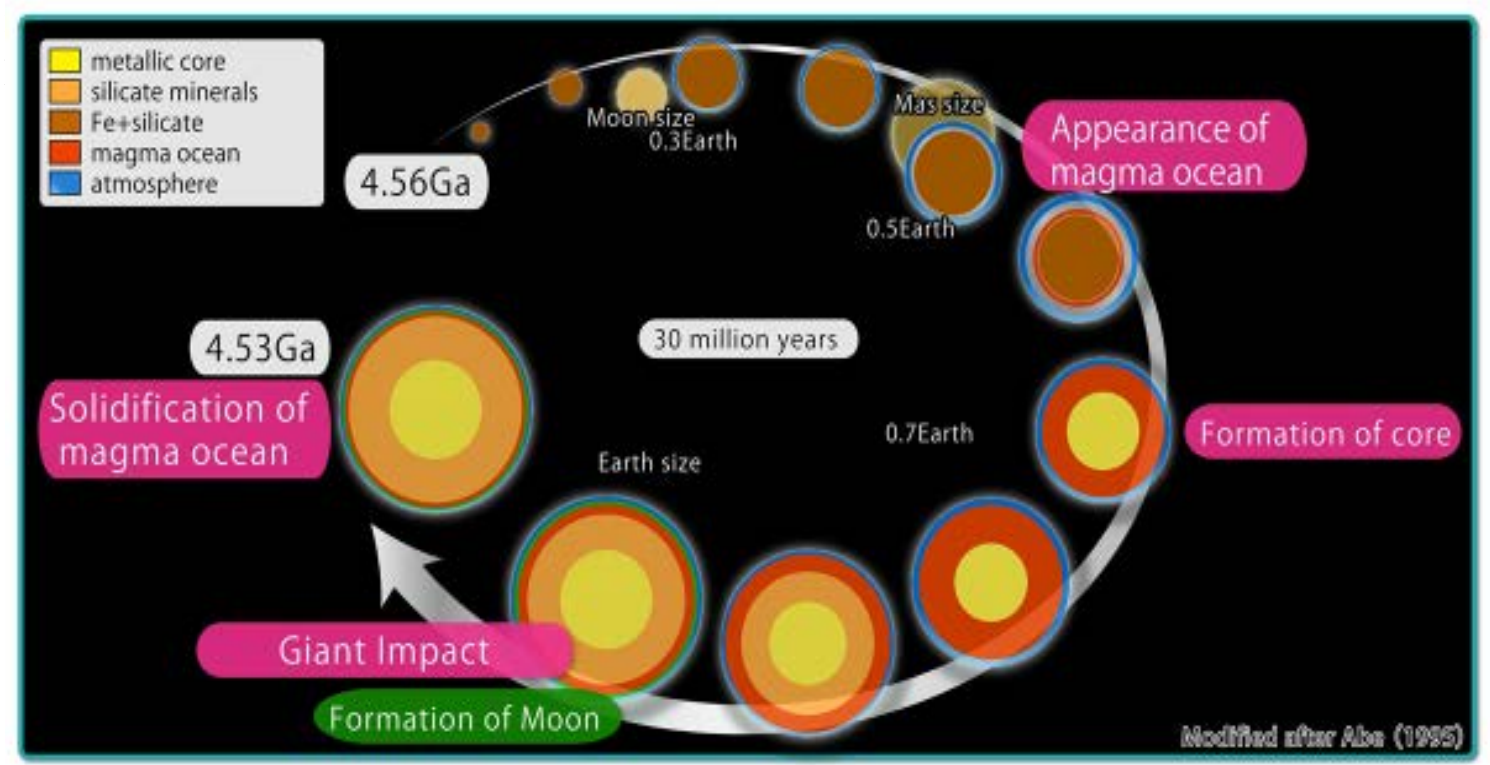

Fig 5 Evolutional Model of the Earth [12]: With time, the Earth grew through the accretion of asteroids. Primordial earth captured atmosphere when it reached Moon size. The differentiation of the core from mantle completed when it became Mars size. Finally, Mars sized asteroid collided with primordial earth to have Earth-Moon system as we see today. 

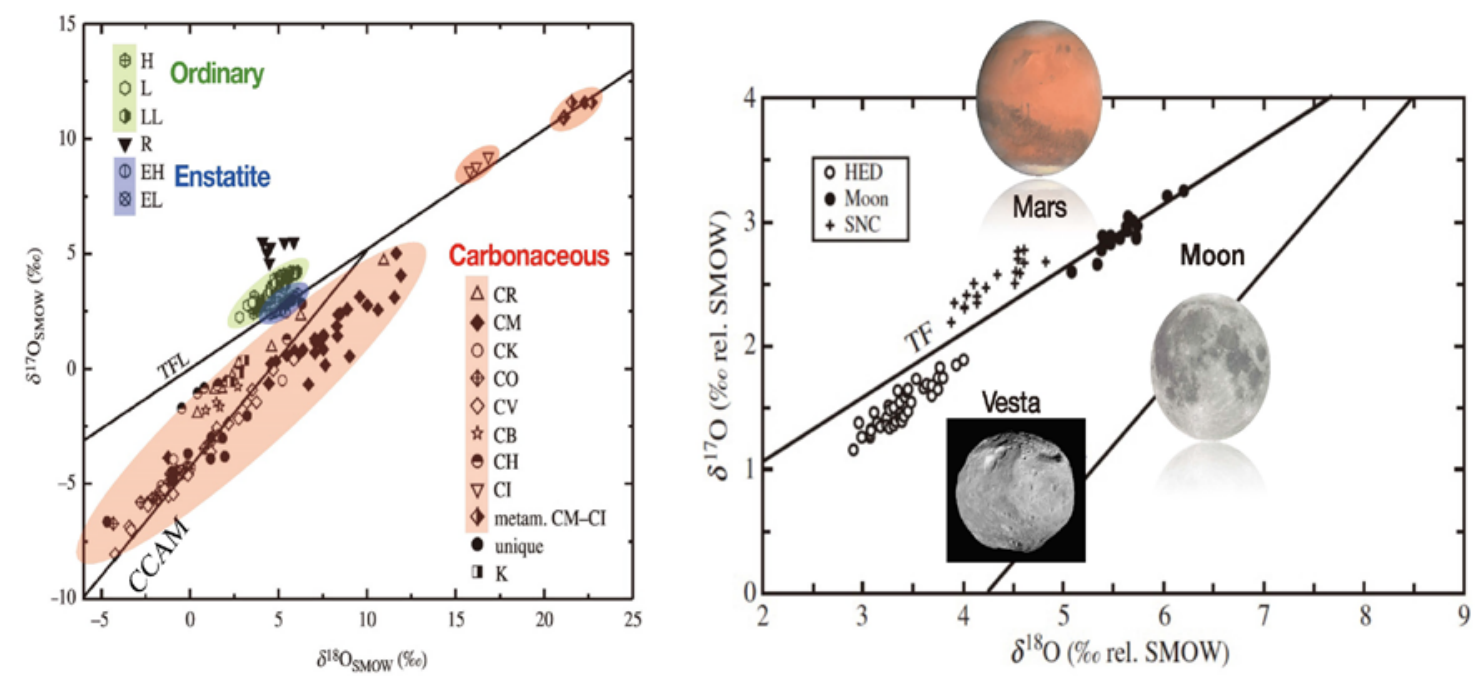

Modified after Clayton (2003), Krot et al. (2005)

Fig. 6 Oxygen Isotopic Composition: (Left) Plots of isotopic compositions of oxygen, in which case enstatite chondrite plots on the terrestrial fractionation (TF) line, while ordinary and carbonaceous chondrites do not. (Right) Plots of isotopic compositions of oxygen for Mars, the Moon, and Vesta. The Moon plots on TF line corresponding to the Earth. Figure was modified after and [18] and [19].

Terrestrial water is delivered by carbonaceous chondrites from asteroid belt

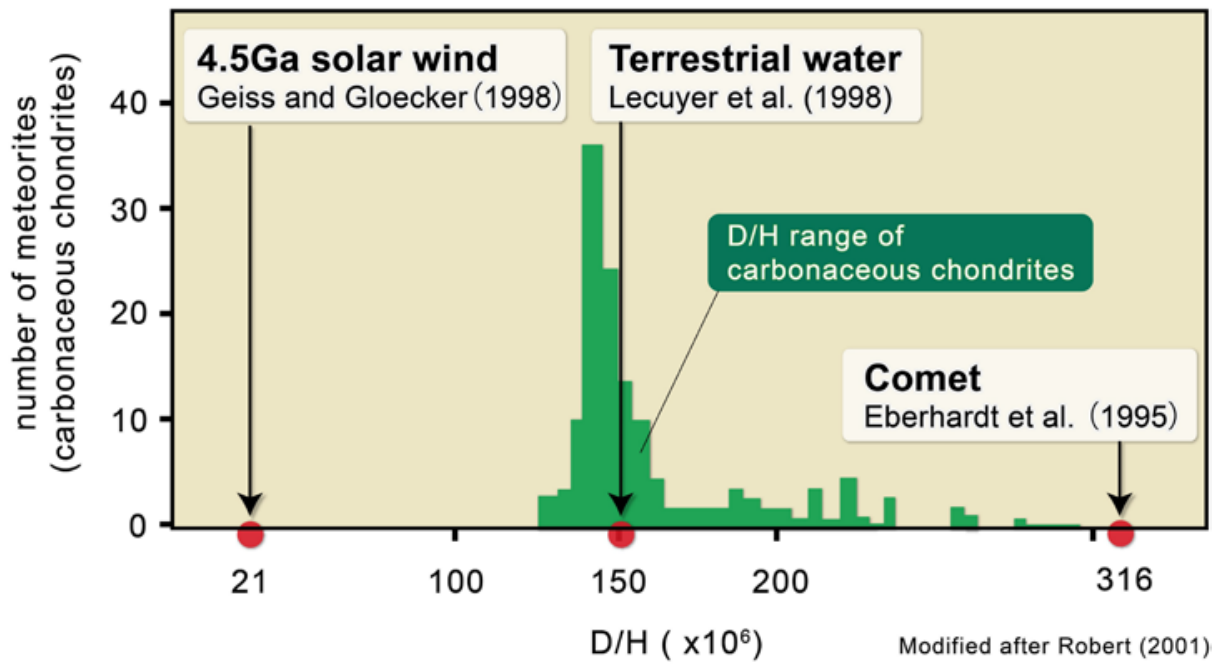

Fig 7. The origin of water on the Earth: The D/H of Earth's ocean approximates the value of carbonaceous chondrite, while distinct from the analyzed $\mathrm{D} / \mathrm{H}$ of either the solar atmosphere at 4.5 Ga or of a comet [20].

\subsubsection{When did the earth have atmosphere and ocean}

If the Earth was born as a dry planet, volatiles to form atmosphere and ocean must have been delivered secondarily. If so, when did the Earth have them? The evidence of secondary accretion of volatiles can be interpreted from lunar geological records. Moon became an almost dead 
planetary body due to its small size. Due to no atmosphere, the surface of the moon's topology and geology have remained unchanged unless bombarded by meteorites.

Through Apollo's missions, regolith and rocks around craters were collected from the Moon for dating analysis. Regolith is a layer of loose superficial deposits including sand, dust, or rocks. It is formed after meteorite bombardment with following steps; (1) If the meteorite size is over $100 \mathrm{~km}$, meteorite itself and bombarded lunar crust instantaneously evaporate by impact, (2) With cooling, evaporated minerals form glass or tektite to fall on the lunar surface. (3) Around the crater, such tektite deposit and form regolith layer. On Moon surface, $100 \mathrm{~m}$ thick regolith were formed through bombardment.

Considering the number of bombardments (over 1,000 times for 1,000-3,000km across asteroids), regolith layers were assumed to be agitated, suggesting that the zircon age distribution of lunar regolith semiquantitatively means the average of heavy bombardment age. Fig 8 shows such distribution; (A) indicates the sample sites on the nearside of the Moon, and (B) shows the zircon age distribution. According to the Fig 8 (B), the period of heavy bombardment is from 4.37Ga to $3.90 \mathrm{Ga}$, however extensive period (about $90 \%$ of bombardment) is $4.37-4.20 \mathrm{Ga}$. The important indication is regolith never shows the age before 4.56Ga when solidification of magma ocean occurred by so called giant impact. The oldest age of zircon shows 4.37Ga which is younger than the age given from base rock of lunar crust [21]. It means zircon age from regolith layer is independent from the giant impact.

These facts of bombardment are not limited on the lunar surface. Bombardment of asteroids should have occurred on the Earth as same as Moon. From this perspective, we proposed the two-step formation of the earth, called ABEL model; (1) the birth of dry planet Earth, (2) secondary accretion of volatiles (bio-elements) through bombardments of carbonaceous chondrites as illustrated in Fig 9. The bombardments delivered life constituents elements such as $\mathrm{C}, \mathrm{H}, \mathrm{O}$, and $\mathrm{N}$ onto a dry earth to form a habitable planet. In ABEL model, this bombardment event is called ABEL Bombardment, which is essentially different in definition of the event from previously proposed "Late Heavy Bombardment" or "Late veneer" models. ABEL Bombardment period is back to $4.37 \mathrm{Ga}$, continued 170 million years, and significant event to make a habitable planet with water on rocky planet. [22] redefined the bombardment event to emphasize it as one of the most important event to lead to the emergence of life, and renamed ABEL Bombardment to distinguish other models.
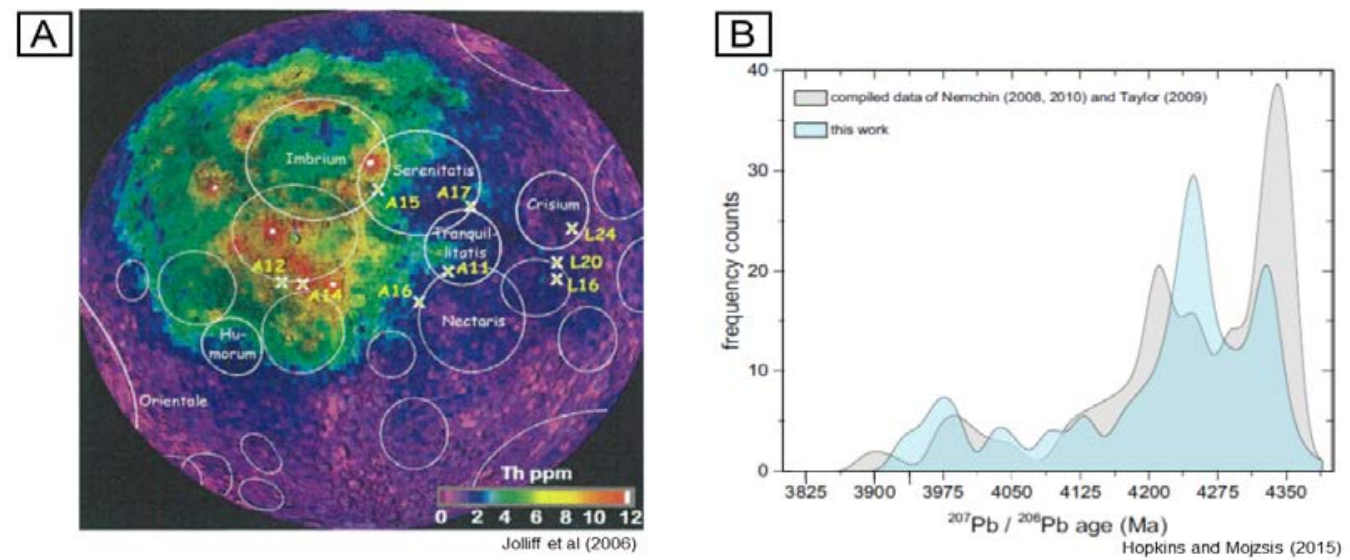

Fig 8. Thorium density distribution on the nearside of the Moon and the result of zircon dating: 
(A) The map of the Moon based on Clementine data [23]. Figure shows the distribution of impact craters, and KREEP II basalts (secondary generated KREEP basalts) largely highlighted by the elevated Th regions, with the prominent quasi-circular feature at the upper left roughly outlining the theorized Lunar Procellarum Basin first proposed by [24]. Also shown are the lunar landing sites, which includes those of the NASA Apollo and Soviet Luna programs. (B) Zircon age population diagram by [25].

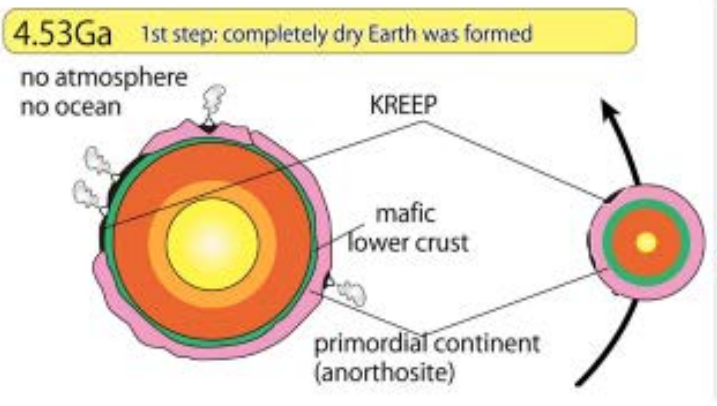

Fig 9. ABEL model [22]: ABEL means the advent of bio-elements. ABEL model is two-step formation of the earth. At first step (left figure), the earth was born as a dry planet without atmosphere or ocean. At second step (right figure), secondary accretion of icy asteroids delivers atmospheric and oceanic component on dry earth, which initiated the first metabolism to lead to the emergence of life on the Earth. Secondary accretion of volatiles must be strictly limited to appear huge landmass to satisfy the requirement of Habitable Trinity [26].

\subsubsection{The mechanism of secondary accretion}

The period of ABEL Bombardment starts from 4.37Ga, so this event is independent from the formation of the solar system. The question is what was the trigger of the ABEL Bombardment. One possible hypothesis is gravitational scattering by big three gas giants; Jupiter, Saturn, and presently missing "Black Sheep" planet. [27] and [28] suggested a possibility of such a gas giant moving with extended elliptical orbit. Or Black Sheep might have gone somewhere in the universe. However, [27] and [28] assumed that this planet returned to its original orbit within the solar system once between few thousand to several tens of thousands of years, which could be relating to the Milankovich cycle, affecting global climate change on Earth (Fig $10)$. 


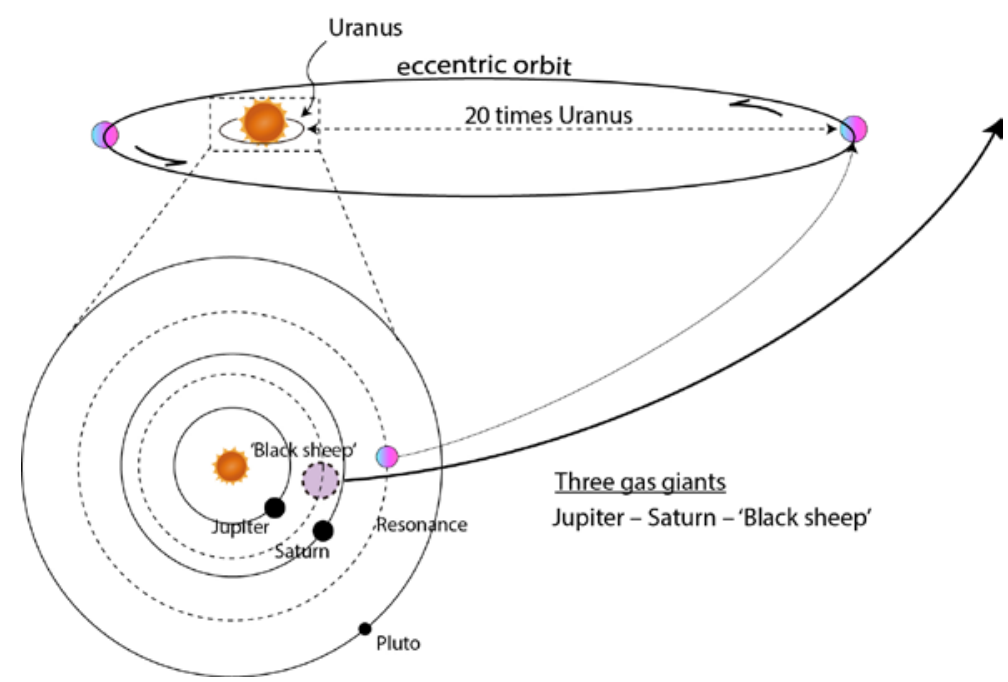

Fig 10 The trigger of the ABEL Bombardment: Theorized "Black Sheep" planet is assumed to cause an interference event with Jupiter and Saturn. After a gravitational scattering by these three gas giants, Black Sheep planet was gone and might be present in the Kuiper Belt with highly eccentric orbit [22].

\subsubsection{Hydrated mantle due to the operation of plate tectonics after the ABEL Bombardment}

The ABEL Bombardment is a critical event in the Earth history as the first event to form atmosphere and ocean on the Earth, as well as the delivery of bio-elements on a dry planet. So, is the record of the ABEL Bombardment remained on the Earth?

No Hadean rocks are remained on the present Earth, because active mantle convection and the operation of plate tectonics erased such Hadean records from the Earth's surface. However, less than $1 \mathrm{~mm}$ across tiny zircon crystals have been found from 3.0Ga layers consisting of conglomerate and sand. Those zircon shows up to 4.37Ga radioisotopic age. They have been found at about ten sites all over the world. And in addition to the zircon dating analysis, oxygen level of host granitic magma that zircon crystallized was analyzed as shown in Fig $11 . \mathrm{Ce}^{4+} / \mathrm{Ce}^{3+}$ indicates the state of oxidation of crystallized magma. Fig 11 clearly shows that Hadean magma was rather reductive and gradually oxidized between 4.0Ga and 3.5Ga. Such oxidation is thought to be the result of mantle convection after the delivery of volatiles. In other words, a dry Earth formed from enstatite-like chondrites and volatiles (bio-elements) were accreted secondary through ABEL Bombardment. After water components were given onto the Earth, it begun circulating between mantle and the surface through plate tectonics and mantle convection, resulting in the oxidation of Hadean mantle. 


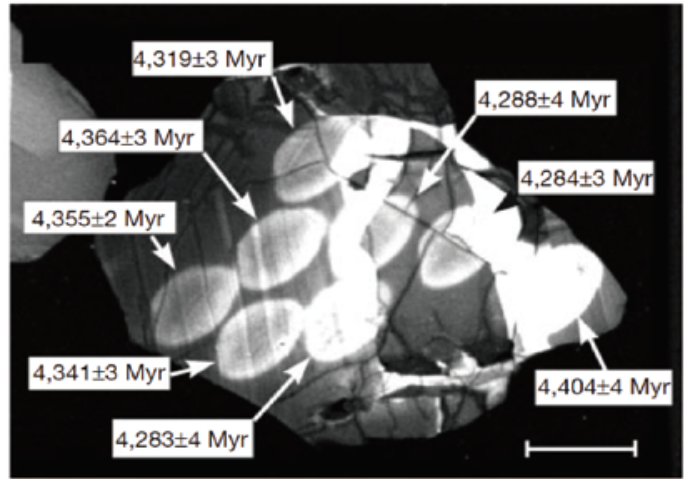

Wilde et al. (2001)

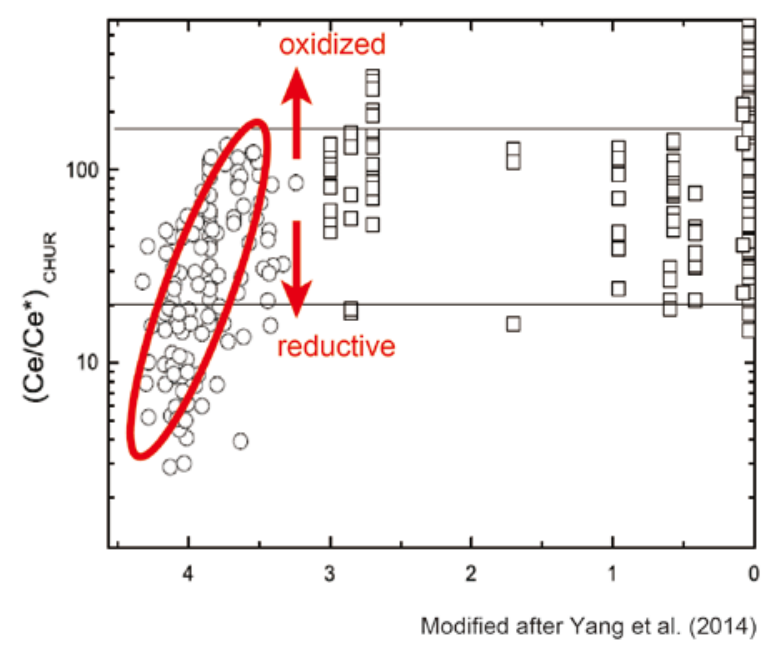

Fig 11 The evidence of ABEL Bombardment for Earth. The earth remained Early-Middle Hadean super-anoxic condition of host magma of crystallized zircons (right figure). Right figure shows the Reductive-oxidized condition measured by zircon $\mathrm{Ce}^{4+} / \mathrm{Ce}^{3+}$ ratio through time span of Hadean to the present [29]. Left figure shows the texture and measured spots of the one of the oldest zircon crystals [30].

\subsubsection{The initiation of plate tectonics by ABEL Bombardment}

After the formation of the Earth, plate tectonics had not yet operated. Stagnant lid tectonics was operated on the Earth and its surface was covered by rigid lithosphere preventing material circulation between surface environment and inner Earth [31]. By the ABEL Bombardment, stagnant lid was destroyed, and the uppermost mantle melted due to impact heating to cause the rebounding of the mantle. Mantle rebound promoted decompressional melting to generate basaltic magma to form oceanic crust. Finally, bimodal lithosphere (continental plate and oceanic plate) appeared, which initiated the operation of plate tectonics on the Earth [21].

Continued intense bombardments by icy asteroids supplied the volatiles enough to form the ocean on the earth. A cratered surfaces were to be puddles, and extensively large sized hole were created by the bombardment of large asteroid with Ceres size (about 1,000km across), where water could be stored to form ocean finally (Fig 12). 


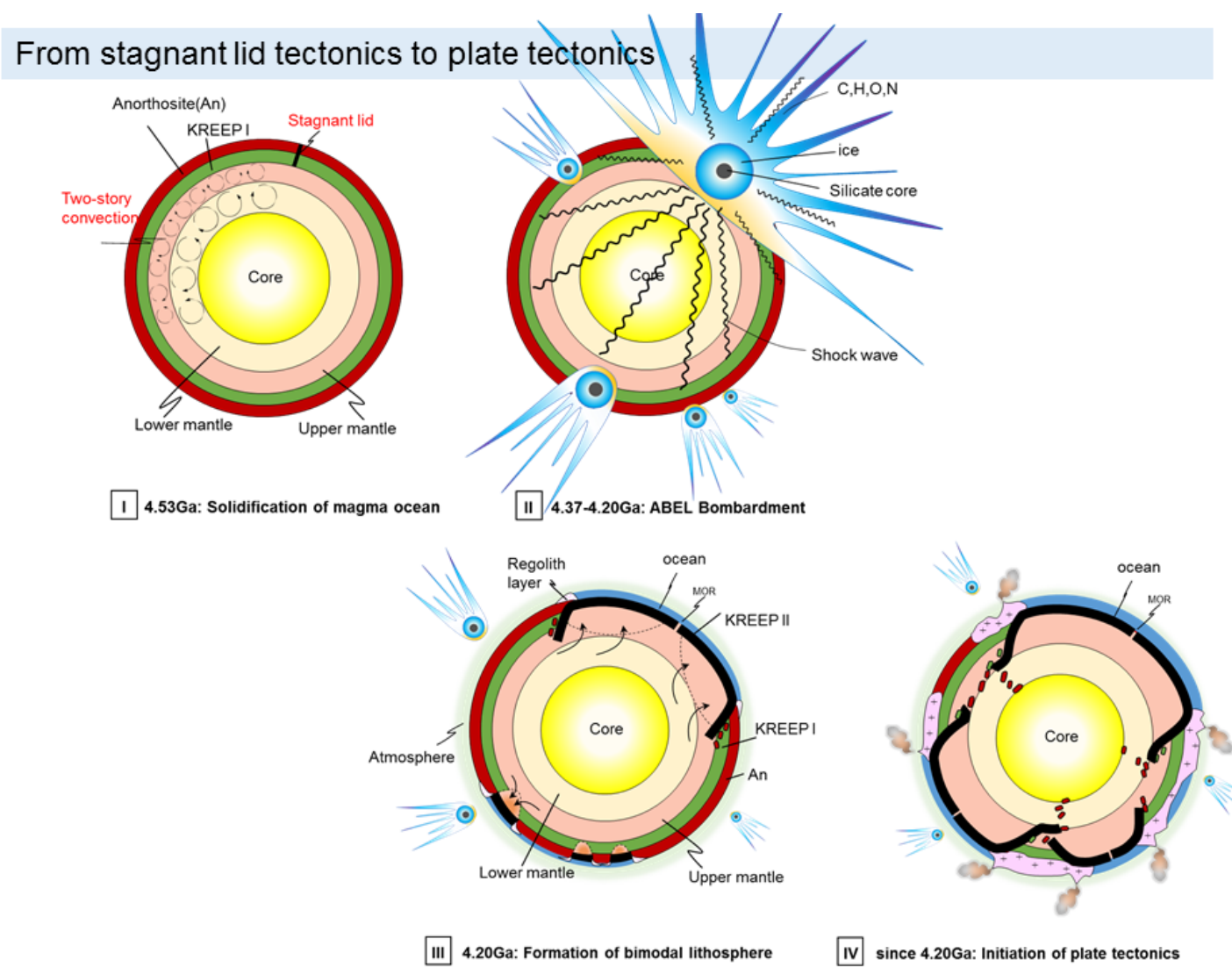

Fig 12. From stagnant lid to plate tectonics by the destroy of rigid lithosphere by Celes-class asteroid to generate ca. $10,000 \mathrm{~km}$ across tectonic depression equivalent to the modern Pacific Ocean to which water/carbon dioxide liquid from numbers of small ponds flowed into such huge tectonic depression region and accumulate water. Simultaneously, evaporation of both asteroids and continental lithosphere made the huge hole of mantle peridotite which was heated by impact energy and mantle rebound generated oceanic curst ca. $20-30 \mathrm{~km}$ thick to generate the bimodal lithosphere, same as today on the modern Earth. This led to the initiation of plate tectonics. From stage 1 Earth, stagnant lid tectonics, through stage 2 of ABEL Bombardment, to lead stage 3 of plate tectonics to generate granitic magma. At continental margin, granitic crust accumulated to increase the size of landmass (stage 4).

\subsubsection{The role of plate tectonics to create and maintain a habitable planet}

The role of plate tectonics for a habitable planet has long been discussed so far (e.g. [32]), however it is not enough to understand the importance. The Earth is the only planet to keep plate tectonics in the solar system, and the Earth is the only planet to have life, suggesting the critical correlation between the habitability and the operation of plate tectonics.

The role of plate tectonics is to enable thermal transport from inner area to the surface of the planet. Through this process, the surface temperature could be kept less than $100^{\circ} \mathrm{C}$ (in the case of 1 bar atmosphere) and necessary nutrients for life can be circulated and supplied in the surface environment. In addition to the operation of plate tectonics, the presence of huge landmass can fix carbon compound by covering with sediment, and prevent the increase in atmospheric $\mathrm{CO}_{2}$. 
Meanwhile, if plate tectonics was not operated, a planet would evolve into a Venuslike planet. The surface of Venus is covered by basaltic lava globally. According to the assumption based on cratering rate, Venus experienced mantle overturn 700Ma which accelerated active volcanic activities to supply abundant $\mathrm{CO}_{2}$ from the mantle to the surface. As a result, greenhouse gas effect made Venus a scorching planet, where the surface temperature reached $500^{\circ} \mathrm{C}$ to evaporate the ocean. Vapor dispersed to the outer space, and Venus evolved to the planet covered by 93 bar $\mathrm{CO}_{2}$. Probably, Venus could have ocean and life because this planet could have followed similar evolving scenario with the Earth, however, at some point of its history, Venus might have gone moved from the main route to evolve into a habitable planet.

\section{Origin of a habitable planet: carbon cycle}

The material circulation in the Earth system, e.g. carbon cycle, has been discussed by some experts, however, no one has recognized the long-term behavior of carbon or other bio-elements over 1,000 years. Within 1,000 years, the plate movement is only $100 \mathrm{~m}$ or so (about $10 \mathrm{~cm} /$ year). Therefore, the carriage of carbon fixed in the crust into the mantle is negligible. As a result, meteorologists have not taken into consideration the material circulation between atmosphere and ocean less than 1,000 years. However, when we think the material circulation with 200-millionyear time span, the amount of carbon cycle cannot be negligible. After 200 million years pass, oceanic plate on the Earth's surface is all subducted into the mantle (averaged age of oceanic plate is 60 million years). So we need to review the material circulation between the surface environment and inner earth.

\subsection{Carbon cycle: The estimated amount of carbon in the present continental crust}

Carbon is fixed in some types of the form, such as sedimentary rock, oil, coal, natural gas, and living organism including plants and microorganisms. The mount of fixed carbon in the continental crust has been estimated from geological records of the Earth's surface. Such surface records are basically accessible only within upper $2 \mathrm{~km}$ of the continental crust. Thanks to the development of recent technology, understanding of geological structure deeper than $2 \mathrm{~km}$ is being gained, however, estimation still include uncertainty. At present, people commonly use estimation by Russian geologist Ronov, who assumed the carbon amount in the continental crust based on sedimentary rock on Asian continent [33]. He assumed that there was no sedimentary rock in the Hadean and Archean time, but increased since the end of Proterozoic. But his assumption of generation and distribution of sedimentary rocks was wrong. We reviewed the estimated amount of carbon, based on renewed geological history of the Earth with the application of the accretionary complex geology globally [34][35]. Accretionary complex geology is able to give a detail of geological history including the amount of sedimentary rocks, because generation of sedimentary rock is closely controlled by the size and distribution of continental crust. We combined that information with the change in Sr isotopic ratio of carbonate rocks. As a result, it was assumed the fixed amount of carbon in the continental crust correspond to 300 bar atmospheric $\mathrm{CO}_{2}$. Fig. 13 shows the fixed carbon amount in solid earth. Carbon amount fixed as carbonate rock in the continental crust is about $100 \mathrm{bar} \mathrm{CO}_{2}$, that in organics (living animals, fossil, and fuel) is 200 bar $\mathrm{CO}_{2}$, therefore, total amount of carbon corresponds to $300 \mathrm{bar} \mathrm{CO}_{2}$. Present 
atmospheric $\mathrm{CO}_{2}$ is only $400 \mathrm{ppm}$, so the amount of atmospheric $\mathrm{CO}_{2}$ is negligible comparing to fixed carbon amount.

Carbon fixed within inner Earth returns to the surface as the form of $\mathrm{CO}_{2}$ through volcanic activities at mid-oceanic ridges, hot spot volcanoes, and island arc volcanoes. The total amount of $\mathrm{CO}_{2}$ supplied through volcanic activities is assumed to be 100 bar during 1 billion years (i.e. $10 \mathrm{bar} / 100$ million years). According to planetary scientists, total atmospheric $\mathrm{CO}_{2}$ must be less than 5 bar to be present Earth [8]. It means that if the atmospheric $\mathrm{CO}_{2}$ increases over 5 bars, the Earth should have evolved into Venus like burning planet due to greenhouse gas effect. However, the amount of volcanic $\mathrm{CO}_{2}$ reaches 5 bar after 50 million years by volcanic activity, suggesting the Earth could have the possibility to evolve into Venus like planet. However, the Earth has not followed such history. It indicates that the Earth's atmospheric $\mathrm{CO}_{2}$ had never exceeded 5 bars in the history. It means discharged $\mathrm{CO}_{2}$ from mantle is partly buried to be fixed in the crust, not to remain in the atmosphere.

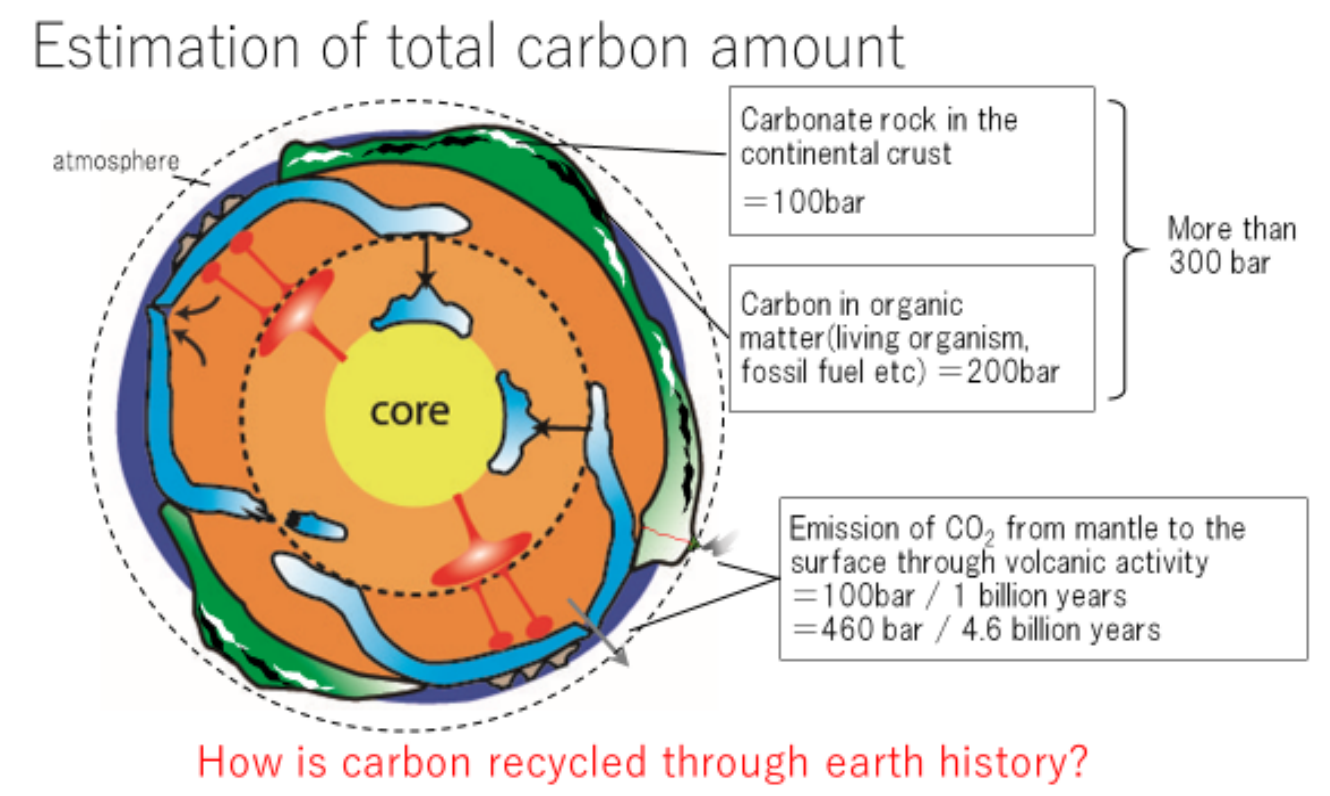

Fig 13. Estimation of Total Carbon Amount: Carbonate rock in the continental crust corresponds to 100 bar $\mathrm{CO}_{2}$ in atmosphere, and that of in organic matter on the surface environment is about 200 bar. So, totally 300bar $\mathrm{CO}_{2}$ is fixed. As the outside of this estimation, mantle could be the reservoir of $\mathrm{CO}_{2}$.

\subsection{Carbon cycle: The circulation process from the crust to the mantle}

Atmospheric $\mathrm{CO}_{2}$ reacts with rocks exposed on the surface with the help of water. Such a water-rock interaction produces carbonate minerals such as $\mathrm{CaCO}_{3}$, which is finally carried into the mantle by plate subduction and/or tectonic erosion of hanging wall rocks. Carbonate mineral is stable below $730^{\circ} \mathrm{C}$. So, if the temperature at the Moho depth along the subduction zone is below $730^{\circ} \mathrm{C}$, carbonate mineral is not decomposed, and carried into the deeper mantle (Fig 14). Since 4.4Ga, geothermal gradient at the Moho depth is less than decomposition level of carbonate minerals, so that carbonate minerals are carried into the mantle through the earth history once they are fixed in the crust on the surface. 
However, chemical composition of oceanic slab changes with time. In the Hadean, oceanic slab is dominantly komatiitic and it is possible to fix more carbonate mineral in it. After 4.0Ga, chemical composition of oceanic slab turns to basaltic [66] and lesser amount of carbon mineral can be fixed (Fig. 14). So, carriage of carbonate mineral into mantle becomes more difficult during late Hadean. On the other hand, it becomes much easier to do so through Earth's history after Archean due to secular cooling of subduction zone.

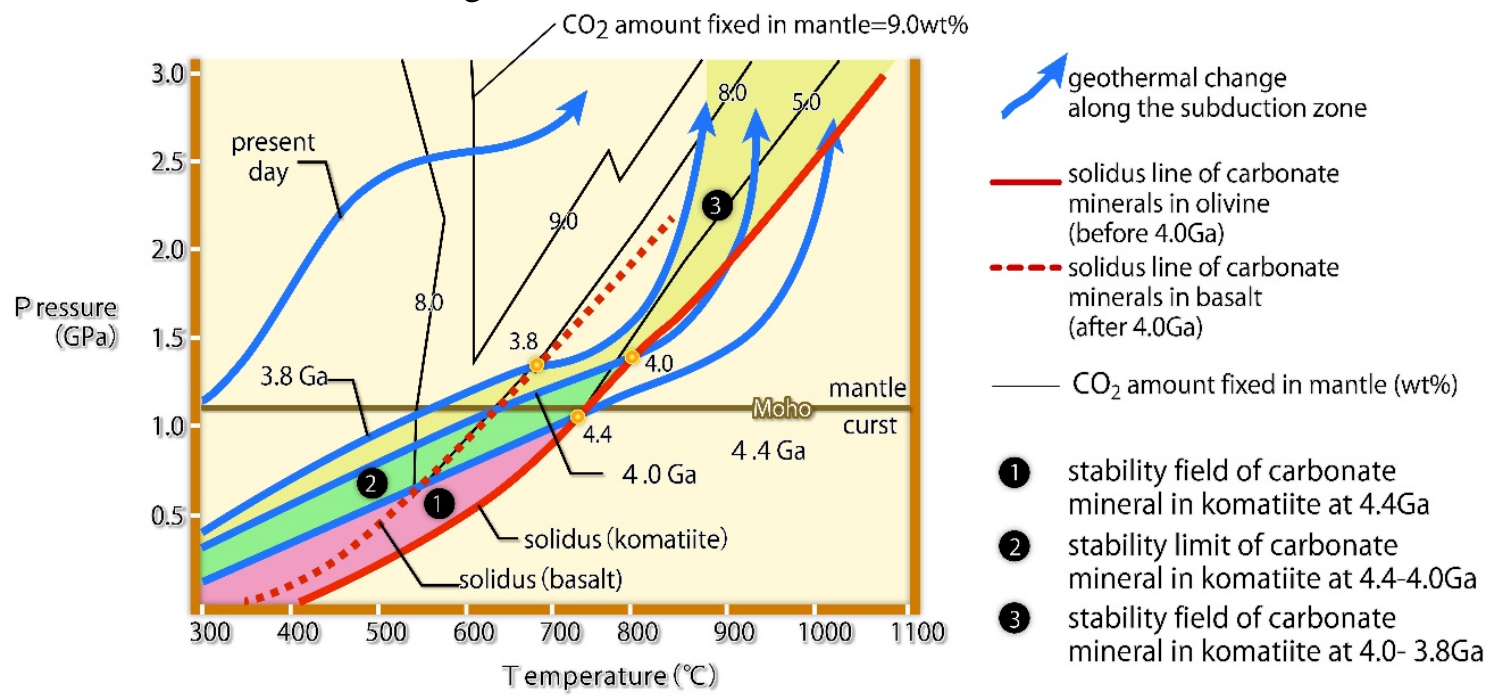

Fig 14 The Carriage of Carbonate Minerals into the Deeper Mantle: Red line is solidus line of carbonate minerals contained in komatiite. When carbonate mineral exists in lower temperature than red line, carbonate mineral is stable to be fixed. Through the subduction, fixed carbonate mineral is carried into deeper mantle whenever remaining low in temperature than solidus line. Before 4.0Ga, oceanic slab is komatiitic (olivine). The temperature at subduction zone above Moho depth is lower than solidus line, where carbonate mineral is stable in the crust. However, below Moho depth, carbonate mineral becomes unstable, therefore no carbonate mineral is carried into mantle before $4.4 \mathrm{Ga}$. After $4.4 \mathrm{Ga}$, the temperature at subduction becomes lower gradually, and it becomes possible to carry carbonate mineral into mantle, as illustrated in (2)(3). After 4.0Ga, stability field of carbonate mineral in komatiite becomes widen, indicating it is much easier to carry carbonate mineral into deeper mantle. With time, chemical composition of oceanic slab changes from komatiitic to basaltic, and carriage of carbonate into mantle becomes more easy. Red dotted line is solidus line of carbonate mineral in basalt. It is more difficult to carry carbonate mineral into mantle once chemical composition turns to basaltic from komatiitic. At the same time, the temperature of subduction zone is lowering with time, suggesting it works positive to carry carbonate mineral into mantle. For example, present day subduction zone temperature is low enough to carry carbonate mineral into mantle.

\subsection{Carbon cycle: The role of organics to fix carbon}

Oxidation of organic matter including dead bacteria release atmospheric $\mathrm{CO}_{2}$. But such $\mathrm{CO}_{2}$ is utilized by life forms again to maintain their bodies. Or photosynthesis consumes the atmospheric $\mathrm{CO}_{2}$ and fix it as organics again, so carbon in atmosphere is consumed through the activity of life. This is the basic carbon cycle related to life on the Earth. Carbon cycle driven by plate tectonics plays an important role to buffer atmospheric $\mathrm{CO}_{2}$, however, if life did not fix atmospheric CO2 in parallel, the Earth could not be maintained as a habitable 
planet over 4 billion years.

\subsection{Water cycle and nitrogen cycle: other bio-elements than carbon}

Water component is carried into deeper mantle as the form of hydrated minerals. Before Archean time, rock type produced on the earth is komatiite. The stability field of komatiite is the region shallower than $60 \mathrm{~km}$ depth in the uppermost mantle (Fig 15). After 4.0Ga, produced rock type changes from komatiite to basalt due to the change in chemical composition at mid-oceanic ridge. Mid-oceanic ridge basalt (MORB) is consisting of hydrated silicate minerals, which cannot be carried into the mantle until the temperature at the Moho depth becomes lower than $650^{\circ} \mathrm{C}$. During the temperature at the Moho depth is around $650-1,000^{\circ} \mathrm{C}$, going-down basaltic crust is partially melted to produce granitic magma including fluid. Granitic magma moves upwards with fluid.

The lowering of the temperature at Moho depth begin around 1,000-600Ma [34][35]. In this period, the temperature at Moho depth becomes lower than $650^{\circ} \mathrm{C}$, and hydrated minerals move down to deeper mantle. And this process is continuing until now to carry surface water (ocean) into upper mantle as the form of hydrated minerals.

Nitrogen is not partitioned to rock component or water component. So basically, almost all nitrogen remains in the atmosphere. Therefore, at the beginning of the Earth's history, all nitrogen existed as $\mathrm{N}_{2}$ in the atmosphere. However, through chemical reaction, nitrogen can be fixed as amino acid, protein, or macromolecular organic compound. Those organic matter is buried in sediment, and they are carried into deeper mantle as well as slabs through tectonic erosion processing along the subduction zones. When underground temperature is over $100-200^{\circ} \mathrm{C}$, those organics are decomposed and nitrogen return to the surface as gas. However, there are cases that some nitrogen could be taken into mica when it crystallizes (e.g. muscovite, biotite, Na-mica, or Ca-mica). In this case, very limited amount of nitrogen can be carried into mantle, but it is almost negligible. So the nitrogen does not circulate between inner Earth and the surface. However, not small amount of nitrogen is fixed as organics and buried in sediment. Through the emergence and evolution of life, the total amount of atmospheric nitrogen should have decreased in proportion to total biomass. 

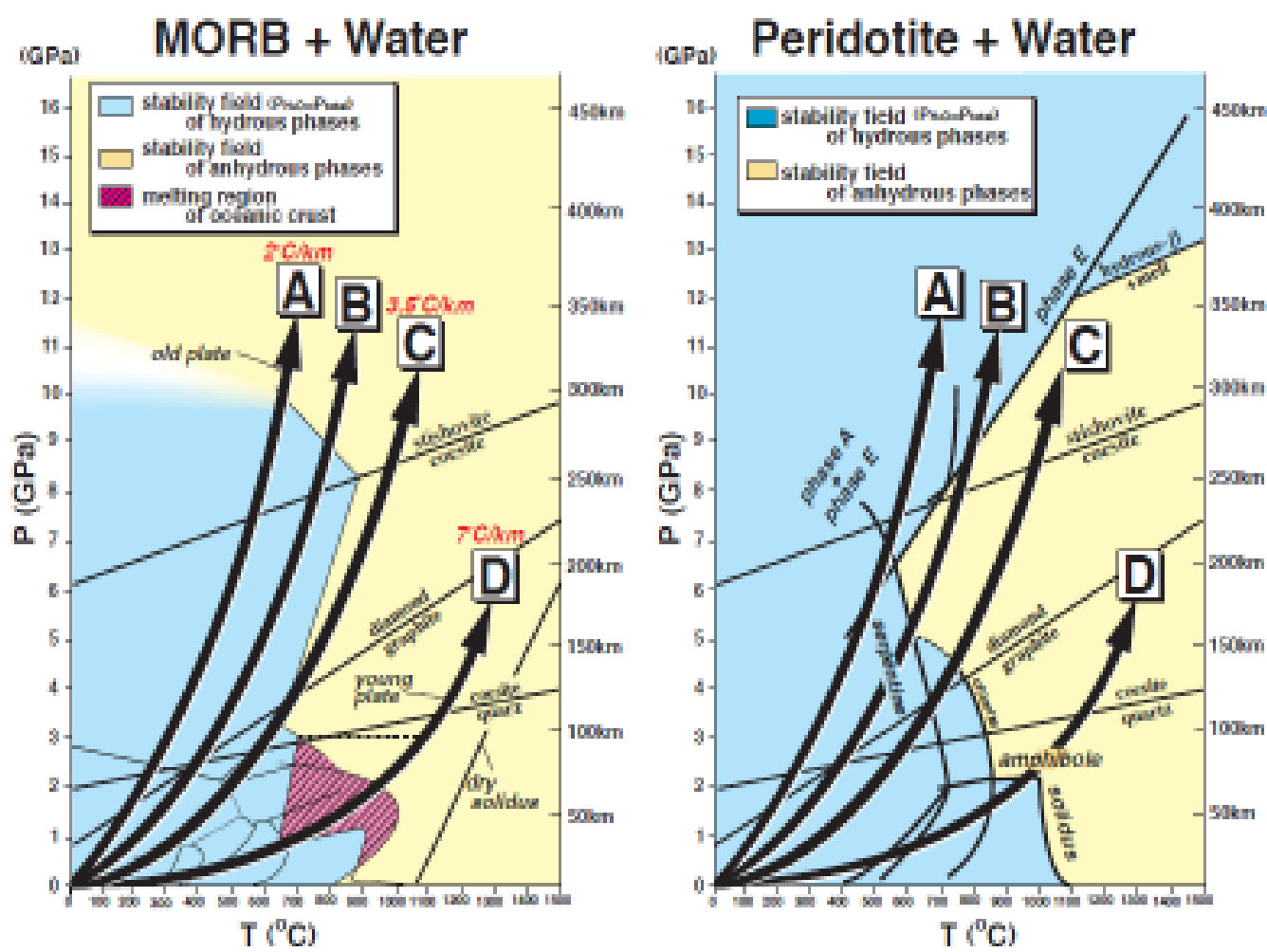

Fig. 15 Stability field of hydrous silicates of MORB composition. Blue region is the stability field of hydrous silicates, whereas yellow is the region of anhydrous silicates. Hadean-Archean subduction zone geotherms correspond to $\mathrm{D}$, whereas the modern geotherm to A. Under the Hadean earth, water cannot be delivered into mantle [35].

\subsection{Carbon cycle through Earth history: $\mathrm{CCD}$ is the function of $\mathrm{pCO}_{2}$}

According to the ABEL model, volatiles including carbon were delivered to the earth mainly through the ABEL Bombardment during from 4.37Ga to 4.20 Ga 170 million years. During the bombardment period in the Hadean, carbon was assumed to be fixed in the crust through water rock interaction. After plate tectonics initiated, fixed $\mathrm{CO}_{2}$ in the crust was carried into the mantle, spending over 200 million years (Fig 16).

In the Archean, supply of volatiles (including carbon) from the universe to the earth stopped due to ABEL Bombardment period ended. It means there is no more supply of carbon in the earth's history. Most part of given $\mathrm{CO}_{2}$ through the bombardment had been carried into deep mantle, however, volcanic activity returns carbon from mantle to atmosphere. Around 2.7Ga, mantle overturn (overturn between upper mantle and lower mantle) occurred, which released back huge amount of $\mathrm{CO}_{2}$ into the surface environment. In spite of catastrophic increase in the atmospheric $\mathrm{CO}_{2}$, the Earth did not turn to Venus-like planet. It is because the ocean works as the buffer.

Since the end of Archean, total area of exposed land gradually increased, and Nuna supercontinent appeared around 2.0Ga in Paleoproterozoic time. By this time, life evolved into eukaryotic organism, 1 million times larger than prokaryotic life, to fix more carbon for their life activity. In the late Proterozoic, more carbon was fixed as organic carbon. 
At the onset of the Phanerozoic time, large multicellular life emerged on the earth. They consumed and fixed more carbon with their body. And dead bodies were buried in the sediment on the crust to be carried in to mantle. Decomposition of organics through subduction of the crust release carbon into the surface.

Getting a quick overview of carbon cycle, most part of given $\mathrm{CO}_{2}$ in early Hadean was cycled between mantle and surface environment. With the emergence of life, carbon was utilized by living organism within the surface environment.

Carbon cycle has not yet been well investigated as we could not have evidence of $p \mathrm{CO}_{2}$. However, we found that Carbon Compensation Depth (CCD) could be the function of $p \mathrm{CO}_{2}$ in a large sense (e.g. increase in $\mathrm{pO}_{2}$ with some ten times, or hundreds of times). CCD refers to the specific depth of the ocean at which calcium carbonate minerals dissolve in the water quicker than they can accumulate. CCD is controlled by physical factors such as temperature and pressure, and also by deep-sea living organisms. Basically, CCD is controlled by temperature, pressure, $\mathrm{pH}$ and other chemical factors, and it reflect various environmental factors. However, it is still possible to use it as the index of pCO2 approximately. Therefore, to overview historical pCO2, we look into CCD under simple environmental condition such as constant temperature, pressure, or other parameters.

For this approach, accretionary complex geology can provide us CCD to figure out the amount of pCO2. Accretionary complex exposed along the plate convergent boundaries, which conserves Ocean Plate Stratigraphy (OPS). OPS consists of a set of stratigraphy, which is formed during plate spreading from mid-oceanic ridge to the trench. OPS is consisting of (1) MOR basalt, (2) chert (pelagic), (3) mudstone (semi-pelagic), (4) trench turbidite composed of mudstone and sandstone. These stratigraphy is formed at the bottom of ocean. If CCD is less than $1 \mathrm{~km}$ like present Earth, OPS does not contain any carbonate layers. If OPS contains carbonate layers, it means CCD is deeper than ocean floor.
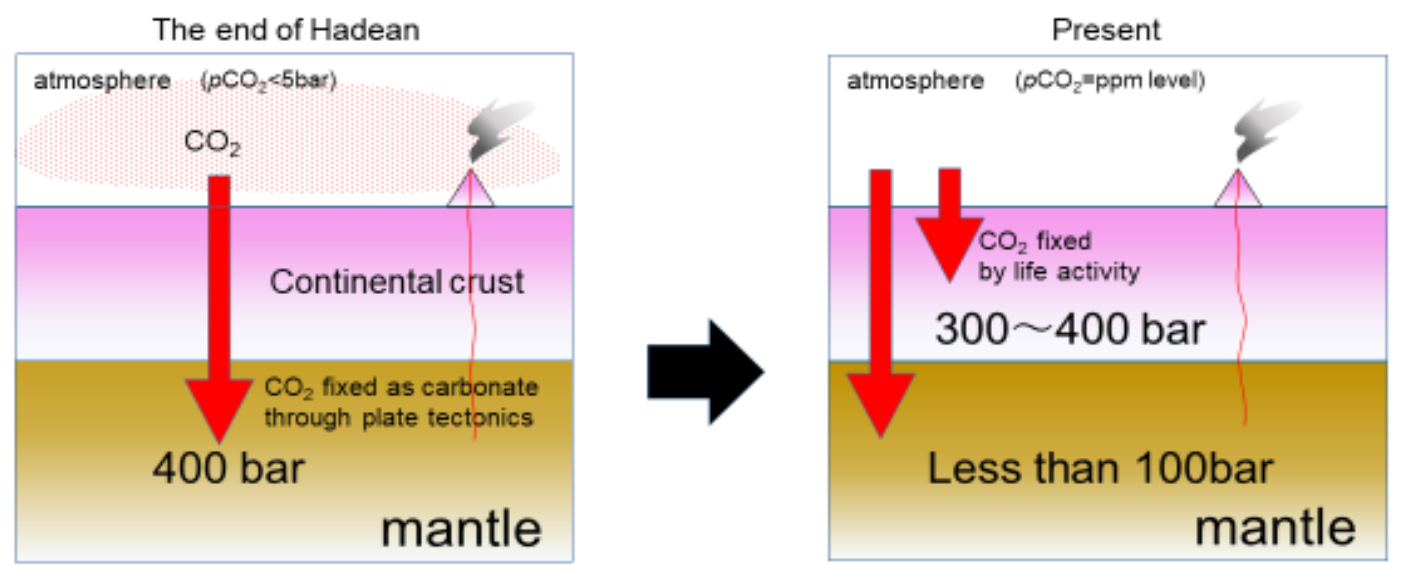

Fig 16 Carbon cycle: (Left) Almost all carbon was fixed in the continental crust as carbonates, and carried into mantle through plate subduction. Fixed carbon in the mantle is released to the surface environment through volcanic activity. (Right) Estimated carbon storage in the crust and mantle is given. If initially given carbon amount corresponds to 400bar atmospheric $\mathrm{CO}_{2}$, carbon remains in the mantle is less than 100 bar. 


\subsection{Maximum and minimum value of carbon amount to be a habitable planet}

The presence of atmospheric $\mathrm{CO}_{2}$ is critical to evolve into a habitable planet. If atmospheric $\mathrm{CO}_{2}$ is absent, life cannot emerge. If the amount of atmospheric $\mathrm{CO}_{2}$ is too much (over 5 bar), a planet evolves into Venus-like planet which cannot be habitable. How did the Earth evolve not to be Venus like planet through time?. The answer is schematically shown in Fig 17.

After the delivery of volatiles from outer asteroid belts to the earth, given carbon was carried into mantle through plate subduction and tectonic erosion. Huge amount of $\mathrm{CO} 2$ should have carried into inner earth, however, it does not mean all the amount of CO2 was transported to mantle. Some of them remained in atmosphere and some part of them is dissolvable in ocean, which is reflected as CCD (carbonate compensation depth).

From early to middle Hadean, primordial ocean is assumed to be extremely toxic due to high salinity, enriched in heavy metals, and extreme acidity, which prevent forming carbonate in ocean. In other words, fixing of $\mathrm{CO} 2$ in this period is limited on the primordial continent. However, with time, water-rock interaction neutralizes oceanic composition. By the end of Hadean, ocean should have been almost neutral [36], except for salinity and carbonate could be formed on the bottom of ocean.

It is assumed that $\mathrm{CO}_{2}$ amount of habitable planet have to be maintained between 5 bar (maximum limit) and 100ppm (minimum limit). Maximum limited is given from [8], and minimum limit is given by the life's activity. Through the earth history, there were two crises at 2.7-2.5Ga and 1.4Ga. At 2.7-2.5Ga, mantle overturn released huge amount of carbon from the mantle into surface environment. The reason why atmospheric $\mathrm{CO}_{2}$ did not reach the critical level for the planet is that life fixed carbon more actively than emission in this period. At 1.4Ga, stagnation of plate tectonics occurred. Carbon could not be carry into the mantle effectively, but volcanic activity released carbon constantly, which disrupted the balance in atmosphere.

\section{New model of carbon cycle}

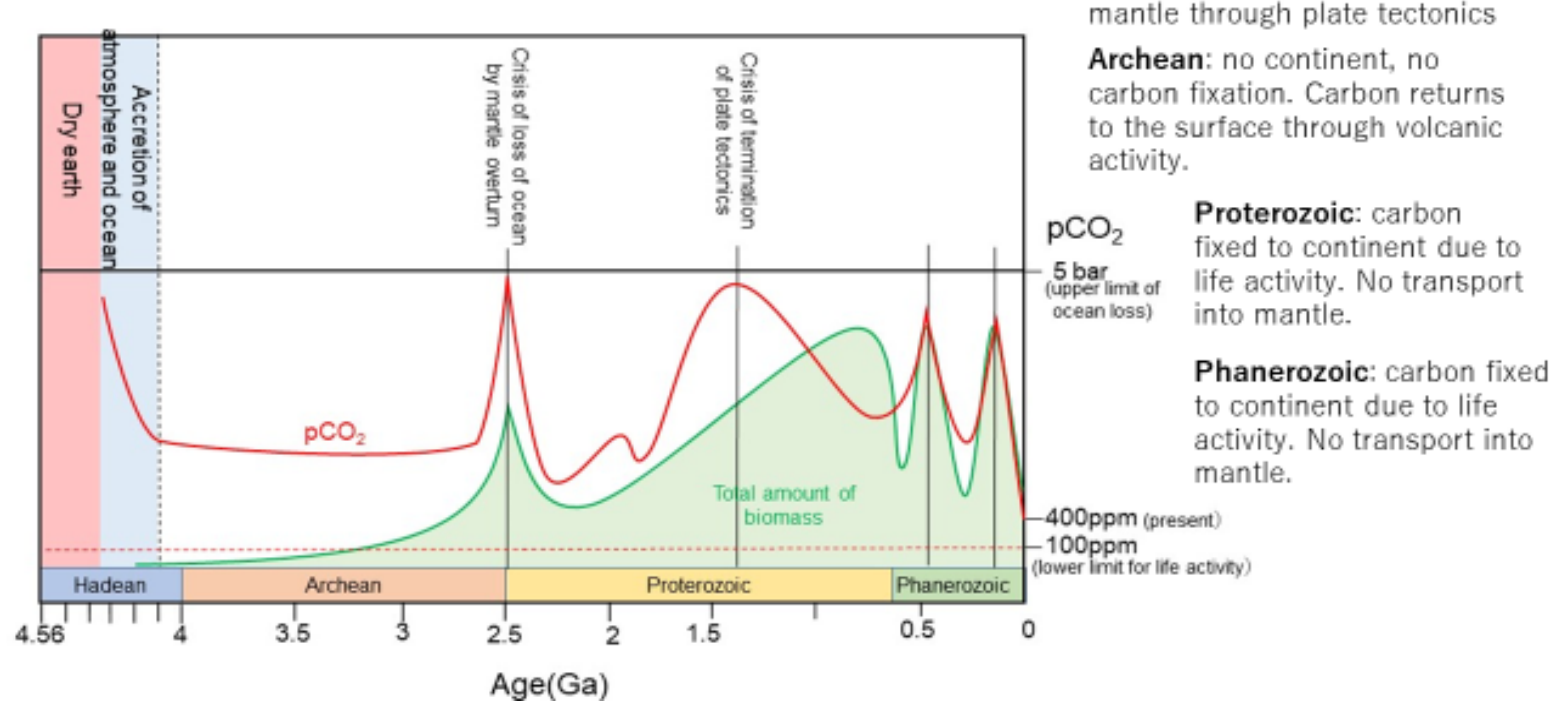

Fig 17. Fluctuation of carbon amount in atmosphere: Red line means atmospheric $\mathrm{CO}_{2}$ through time, while green amount means the amount of biomass through time. If the total amount of atmospheric $\mathrm{CO}_{2}$ excess 5 bar, Earth evolves into Venus-like planet. Through the earth's history, there were two crises due to increase in $p \mathrm{CO}_{2}$, which occurred at around 2.5Ga and 1.4Ga. 


\subsection{Beyond habitable zone concept}

The concept of habitable zone is widely known as the range of orbits in which liquid water can exist on the surface of the planet. Habitable zone is affected by the type of central star, suggesting habitable zone of F-type star (larger than Sun) is farther from a central star, aversely, smaller central star has habitable zone in nearer orbital range (Fig 18). Looking into the solar system, the Sun is categorized G-type star, and three planets are within habitable zone; e,g, Venus (0.8AU), Earth (1AU), and Mars (1.5AU). The earth locates in central part of habitable zone, which is $150,000,000 \mathrm{~km}$ far from the Sun. In spite of the location within habitable zone, the surface temperature of Venus reaches $550^{\circ} \mathrm{C}$ and there is no ocean on the surface. Likewise, Mars do not have ocean. This observational fact indicate planetary habitability cannot be determined by the distance from the central star, because the amount or composition of planetary atmosphere causes greenhouse gas effect, which can destroy the habitability. In the case of the Earth, the surface is covered by liquid water (ocean), but not all the time. 2.2-2.3Ga and 600-800Ma, the earth experienced snowball earth. At that time, the surface was frozen [37][38]. Therefore, we should reconsider which factors can determine the planetary habitability.

One important factor is carbon cycle. If the amount of carbon is too much on the planetary surface, greenhouse gas effect makes a planet inhabitable. If the amount of carbon is too small, life cannot emerge. The planetary must keep enough carbon on the surface through circulation. To circulate carbon, plate tectonics must be operated, which indicates the coexistence of ocean and landmass. It means a planet must have Habitable Trinity environment [26] to become habitable. The concept of Habitable Trinity is one of the most significant index to explore habitable exoplanet.

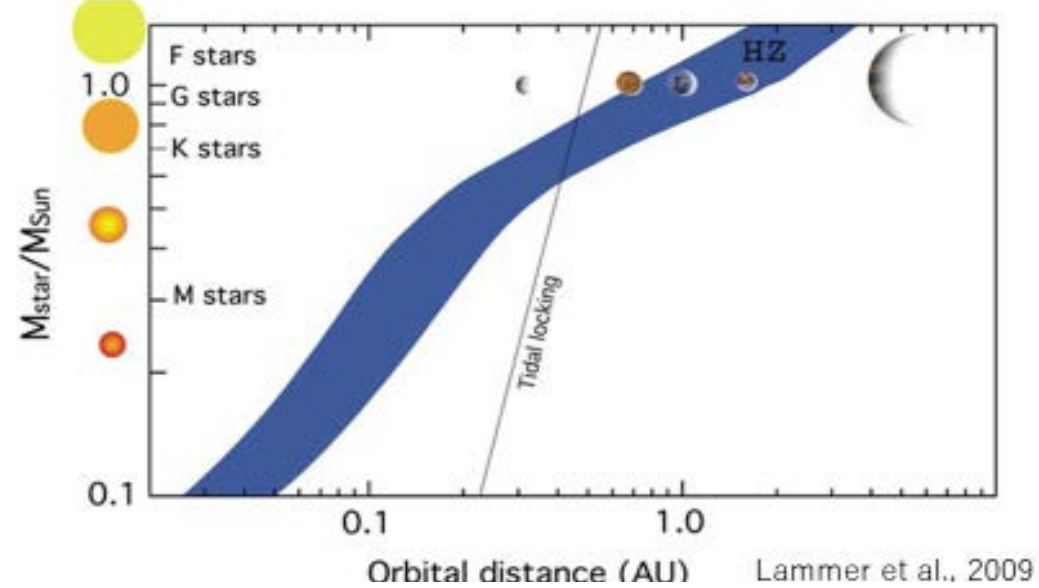

Fig 18 The problem of the concept of habitable zone: Habitable zone concept cannot be fixed only by the distance from the central star. The concept of habitable zone must be reconsidered.

\section{Origin of the Earth's life}

Since Darwin's time, the origin of life research is one of the most difficult topic in science. For the emergence of life, necessary conditions of environmental setting has long been discussed. However, previous discussions remained not enough to provide reasonable scenario for life's origin. We summarize the necessary conditions for birthplace of life based on the review of previous multidisciplinary studies ranging from biological to astronomical viewpoints. Based on these, nine requirements for the emergence of life on a planet are identified in 5-2. 


\subsection{Hypotheses for the birthplace of life}

Hypotheses of birthplace of life have been proposed since Darwin's time. These include the following: (1) the classic concept of 'Darwin's warm little pond', involving an organic soup either on-land or in tidal flats [39][40][41], (2) the panspermia model that explains life as arriving from the extraterrestrial Universe [42] and Neo-panspermia as succession model of Panspermia [43], (3) the idea that life was originated from Mars [44], (4) the proposal that life was initiated in a mid-oceanic ridge hydrothermal system [45] or in an alkaline hydrothermal vent [46], (5) the idea that life was born under island arc volcanic environments related to a primordial continent [47], and (6) the recently proposed nuclear geyser model that life was born at geyser environment driven by a natural nuclear reactor on the Hadean primordial continent [48](Fig.19).

In previous studies, conditions to bear life have not yet clearly defined. Most people vaguely think that life could emerge if there are water, wet-dry cycle, and reducing environment. Then, with the birth of first life, free oxygen accumulated through time, evolved to present earth and life. However, the emergence of life is not such a simple process. The birthplace should have had requirements to have life.

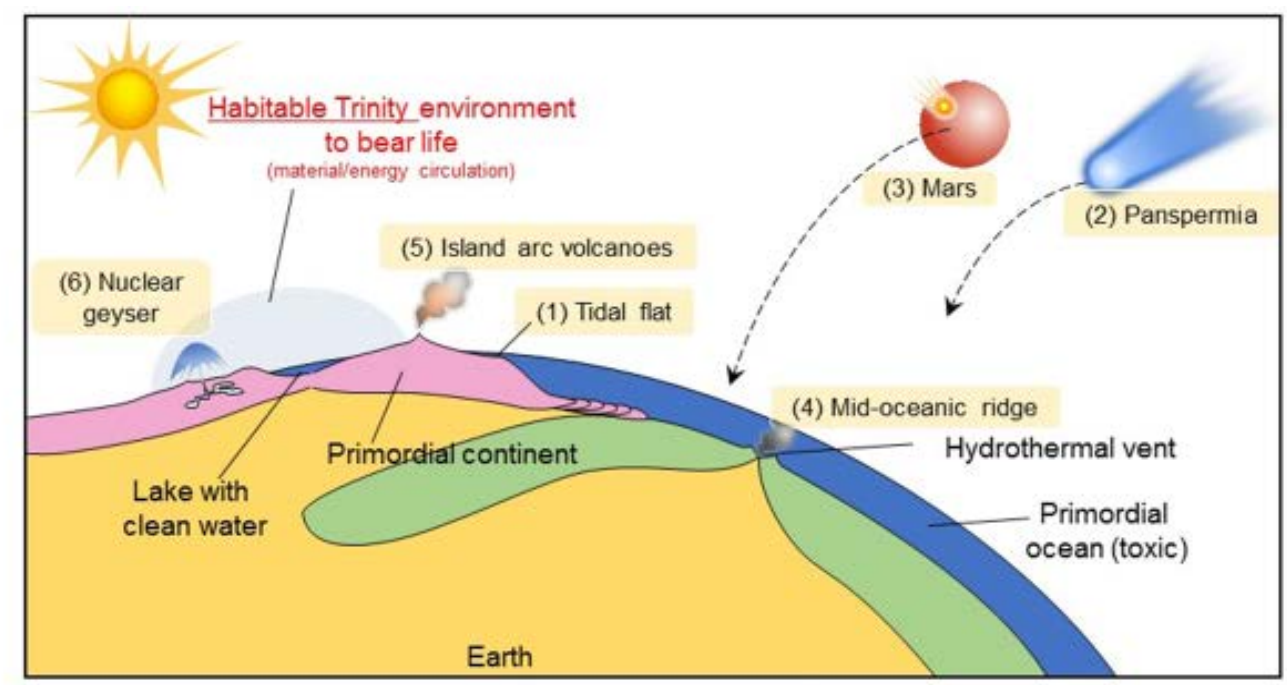

Fig 19. Hypotheses of the birthplace of life. There are several hypotheses for the birthplace of life. (1) the classic concept of 'Darwin's warm little pond', or in tidal flats [39][40][41], (2) the panspermia model [42] and Neo-panspermia as succession model of Panspermia [43], (3) Mars [44], (4) Mid-oceanic ridge hydrothermal system [45] or in an alkaline hydrothermal vent [46], (5) Island arc volcanic environments [47], and (6) Nuclear geyser model [48].

\subsection{Nine requirements for the emergence of life}

Based on our review for previous research about the origin of life, the birthplace would have to met following nine requirements at least. (1) an energy source (ionizing radiation and thermal energy); (2) a supply of nutrients (P, K, REE, etc.); (3) a supply of life-constituting major elements; (4) a high concentration of reduced gases such as $\mathrm{CH}_{4}, \mathrm{HCN}$ and $\mathrm{NH}_{3}$; (5) dry-wet cycles to create membranes and polymerize RNA; (6) a non-toxic aqueous environment; (7) Na-poor water; (8) highly diversified environments, and (9) cyclic conditions, 
such as day-to-night, hot-to-cold etc (Table 1).

\begin{tabular}{|c|c|c|c|c|c|}
\hline & Environmental factors & $\begin{array}{l}\text { Nuclear geyser } \\
\text { system }\end{array}$ & $\begin{array}{l}\text { Hydrothermal } \\
\text { system }\end{array}$ & Mars $^{3}$ & Universe ${ }^{4}$ \\
\hline 1 & Energy source (ionizing radiation+ thermal energy) & Yes & No & Yes & Yes \\
\hline 2 & Supply of nutrients ( $P, K, K R E E P$ etc) & Yes & $? 1$ & Yes & No \\
\hline 3 & Supply of life constituent elements ( $\mathrm{CHON}$ ) & Yes & $?^{1}$ & Yes & Yes \\
\hline 4 & Concentration of reducing gas & Yes & No & $?^{2}$ & No \\
\hline 5 & Dry/wet cycle & Yes & No & Yes & No \\
\hline 6 & Na-poor water & Yes & No & Yes & No \\
\hline 7 & Non-toxic water environment & Yes & No & $?^{2}$ & No \\
\hline 8 & $\begin{array}{l}\text { Diversified environments (Ocean: } \mathrm{pH} \text {, salinity, heavy } \\
\text { metals, Atmosphere: Temperature \& Pressure, Continent: } \\
\text { varied geology) }\end{array}$ & Yes & No & $?^{2}$ & No \\
\hline 9 & Cyclic change & Yes & No & No & No \\
\hline
\end{tabular}

Table 1. Nine requirements for the birthplace of life: For the emergence of life, birthplace must meet nine environmental requirements at least. If even one requirement is satisfied, life cannot emerge.

\subsubsection{An energy source (ionizing radiation and thermal energy)}

To synthesize organic compounds, $\mathrm{N}_{2}$ has to react with other material in spite of very strong triple bonding. To break this triple bonding, the Haber-Bosch process was invented, utilizing high temperatures $\left(500-600^{\circ} \mathrm{C}\right)$ and high pressures $(200-1,000 \mathrm{~atm})$ to facilitate reactions of $\mathrm{N}$ by overcoming a high activation energy barrier. In nature, however, such conditions cannot be maintained to facilitate the necessary reactions of $\mathrm{N}$ to produce building blocks of life (BBLs). The only reasonable energy source is radioactive non-thermal energy during uranium disintegration, this is the only one solution to destabilize $\mathrm{N}_{2}$ as well as $\mathrm{H}_{2} \mathrm{O}$, and $\mathrm{CO}_{2}$ to facilitate chemical reaction (Fig. 20). Through a continuous supply of aqueous electrons and active chemical products, numerous kinds of simple or macromolecular organic compounds can be produced. A natural nuclear reactor is only one supplier of high energy enough to facilitate production of BBLs on Hadean earth. Comparing the energy source as illustrated in Fig 21, the nuclear reactor is the only supplier of necessary energy density. 


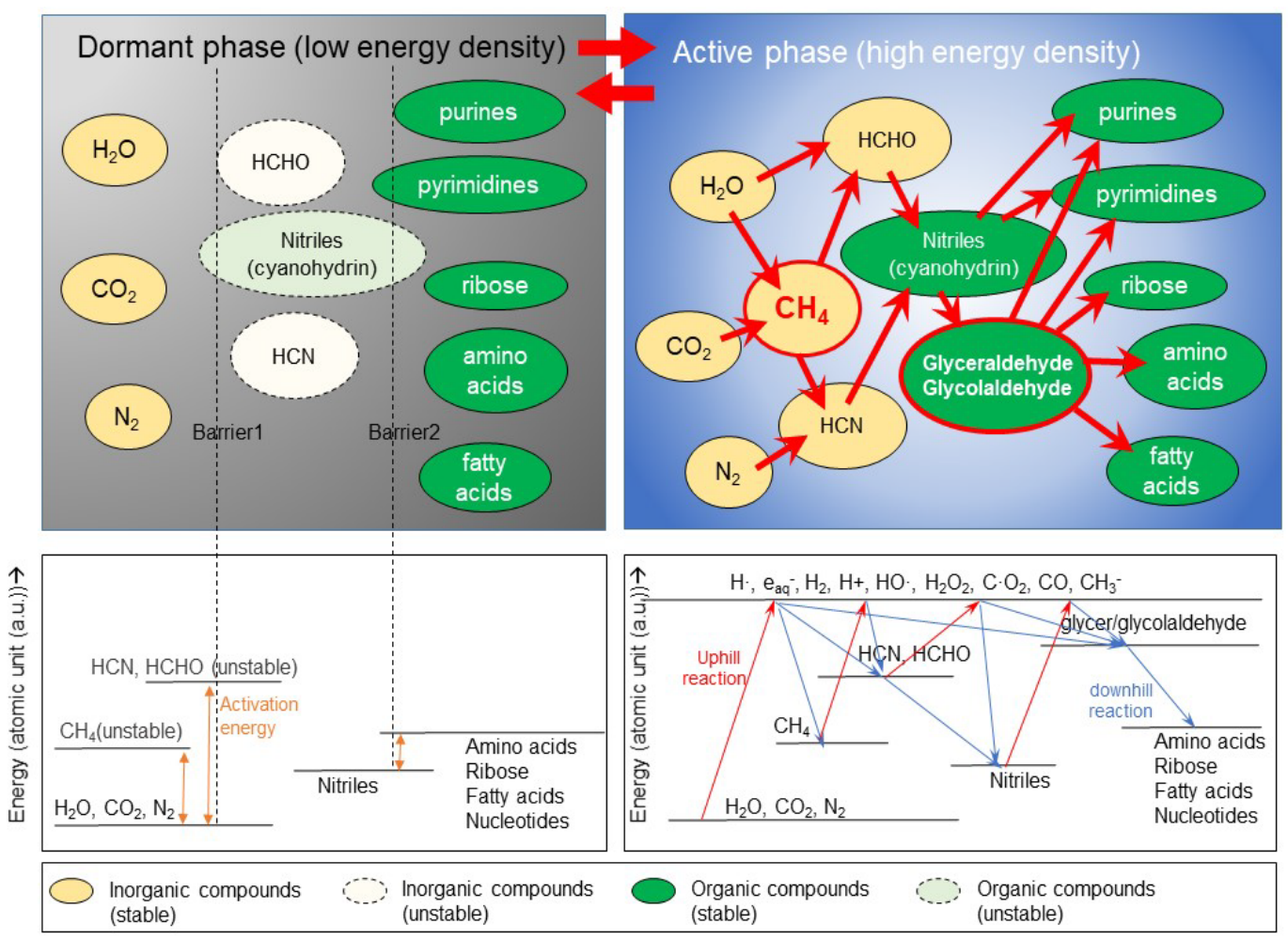

Fig 20. The importance of high energy particle to overcome the energy uphill problem: Without high energy particle like aqueous electrons, chemical reaction does not proceed, because material remain stable. With the supply of high energy particle, stable $\mathrm{H}_{2} \mathrm{O}, \mathrm{O}_{2}$, and $\mathrm{N}_{2}$ can react with each other to produce intermediate material such as HCN, KCN.

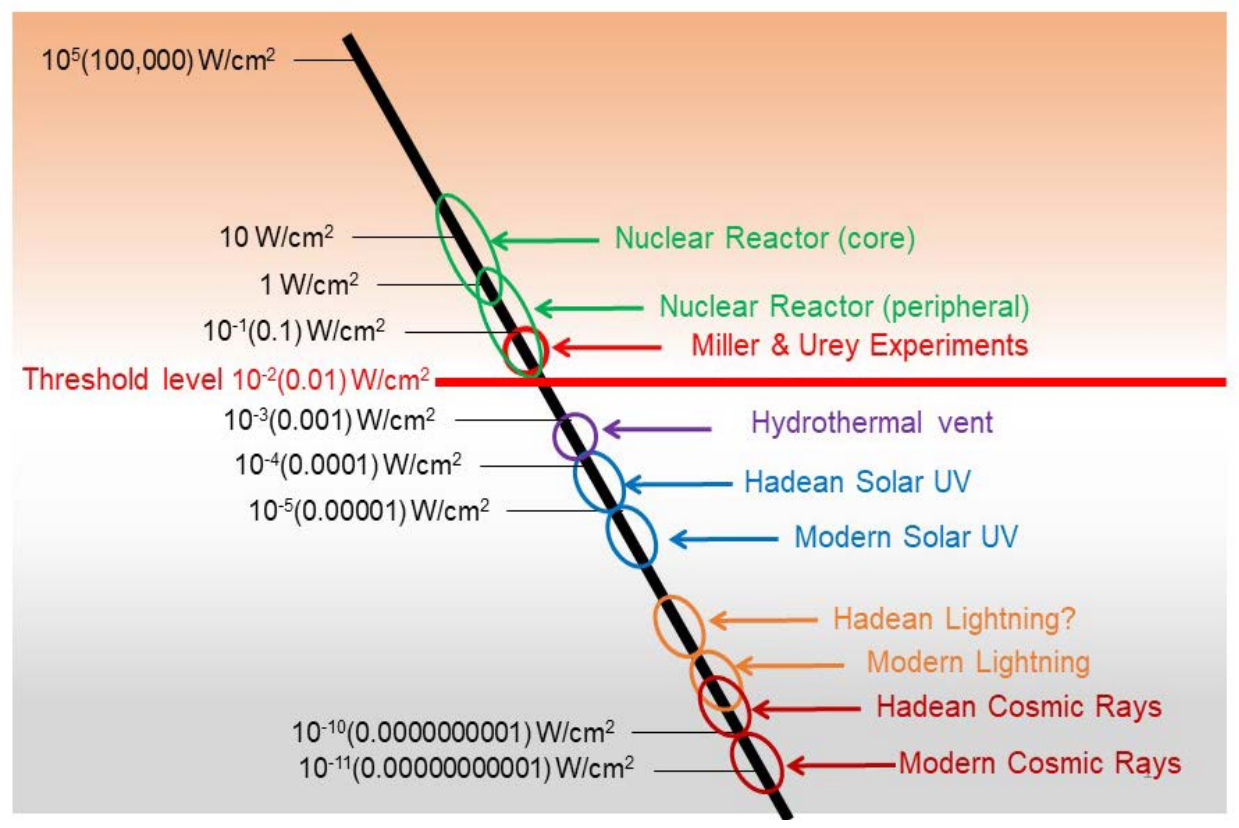

Fig 21. Comparison between energies: To produce organic compounds, Miler and Urey experiments used higher energy than most energy sources such as hydrothermal vent, solar UV, cosmic rays etc. In other words, the birthplace requires such high energy to emerge life. The only candidate is the energy supplied from nuclear reactor. 


\subsubsection{A supply of nutrients ( $P, K, R E E$, etc.)}

$\mathrm{C}, \mathrm{H}, \mathrm{O}$, and $\mathrm{N}$ make up 95\% of living organisms, and the remaining 5\% is made up by nutrients such as potassium (K), phosphorus (P), iron (Fe), calcium (Ca) and magnesium (Mg). Although nutrients are minor constituents, living organisms cannot emerge without them.

\subsubsection{A supply of life-constituting major elements}

More than 95\% of individual body of living organism is composed of $\mathrm{C}, \mathrm{H}, \mathrm{O}$, and $\mathrm{N}$. Therefore, no one has questions about the necessity of $\mathrm{C}, \mathrm{H}, \mathrm{O}$, and $\mathrm{N}$ for life. Combined with the supply of nutrients (K, REE, P etc.) as stated in 5-2-2, the supply of life-constituting elements (C, $\mathrm{H}, \mathrm{O}$, and N) is critical to sustain life. A concept of the "Habitable Trinity" [26] simply shows such a condition, which holds that the co-existence of suppliers of all necessary elements; i.e. the atmosphere, ocean, and landmass, and the supplying system is driven by the Sun, promoting material and energy circulation (Fig. 22). Most planetary scientists adhere to a prevailing concept of the habitable zone, focusing on the presence of liquid water. They regard this concept as the most important condition for the potential presence of life, however, living organisms cannot survive with only water. The presence of the Habitable Trinity conditions must be emphasized in considering the emergence and survival of life.

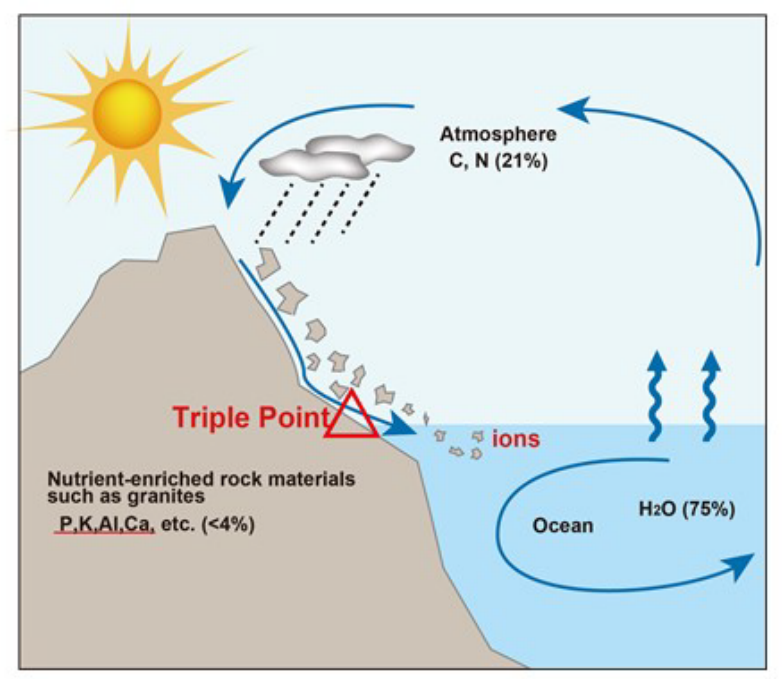

\begin{tabular}{|c|r|r|c|}
\hline Element & Weight(kg) & $\mathbf{W t} \%$ & compose of \\
\hline $\mathrm{O}$ & 45.50 & 65.00 & All \\
\hline $\mathrm{H}$ & 7.00 & 10.00 & ocean \\
\hline $\mathrm{C}$ & 12.60 & 18.00 & atmosphere \\
\hline $\mathrm{N}$ & 2.10 & 3.00 & atmosphere \\
\hline $\mathrm{Ca}$ & 1.05 & 1.50 & landmass \\
\hline $\mathrm{P}$ & 0.70 & 1.00 & landmass \\
\hline Minor $^{*}$ & 1.05 & 1.50 & landmass \\
\hline Total $^{*}$ & 70.00 & 100.00 & \\
\hline
\end{tabular}

-Minor elements: $\mathrm{K}, \mathrm{Na}, \mathrm{S}, \mathrm{Cl}, \mathrm{Fe}, \mathrm{Cu}, \mathrm{Zn}, \mathrm{Mo}, \mathrm{Cr}, \mathrm{Co}, \mathrm{Gs}, \mathrm{Se}, \mathrm{I}, \mathrm{Si}, \mathrm{F}, \mathrm{Cd}, \mathrm{Bg}, \mathrm{Sn}, \mathrm{Hg}, \mathrm{Ni}, \mathrm{V}$

Fig 22 Habitable Trinity is the new concept to explore a habitable planet: For emergence of life, water is necessary but water itself cannot produce any life. Necessary elements; life constituent major elements $(\mathrm{C}, \mathrm{H}, \mathrm{O}, \mathrm{N})$ and minor elements such as phosphorus and metallic elements, must be supplied constantly. To make it possible, a habitable planet has to maintain the coexistence of atmosphere, ocean, and landmass under the driving force of the material circulation, which is the habitable trinity concept.

\subsubsection{A high concentration of reduced gases such as $\mathrm{CH} 4, \mathrm{HCN}$ and NH3;}

To promote the synthesis of amino-acids to lead to the origin of life, the presence of reducing gases, such as $\mathrm{H}_{2}, \mathrm{CO}, \mathrm{CH}_{4}, \mathrm{NH}_{3}$ and $\mathrm{HCN}$ is necessary [43] [49] [50]. However, major difficulties arise in the mechanism to accumulate these gasses in nature. Gas is diffused into open atmosphere or ocean, which is the case at mid-oceanic ridges or surface environment. To overcome this 
problem, an underground cave is an ideal site, because the reducing gas produced could be accumulated over time on the ceiling of the cave.

\subsubsection{Dry-wet cycles to create membranes and polymerize RNA}

Dry and wet cycle is necessary for the emergence of life, as exemplified by a series of diverse prebiotic chemical reactions including polymerization of amino acids to peptides and synthesis of RNA from nucleotides by repeated dehydration-hydration, that has been repeatedly emphasized (e.g. [40][41][51][52][53][54]).

\subsubsection{A non-toxic aqueous environment}

For life, water must be moderately clean, which we call non-toxic water environment. The reason why we emphasize it as one of requirements is that Hadean ocean was too toxic to live. As explained in the ABEL model, earth's atmosphere and ocean was secondary accreted by icy asteroids, which are composed of not only large amounts of $\mathrm{H}_{2} \mathrm{O}$, but also $\mathrm{CO}_{2}, \mathrm{~N}_{2}, \mathrm{SO}_{2}$, halogens such as $\mathrm{Cl}$ and $\mathrm{F}$ [55]. Therefore, initially appeared ocean was extremely toxic with ultra-high acidity and salinity, as well as a high abundance of heavy metallic elements. In such water chemistry, life could not emerge. So non-toxic water environment is necessary for life.

\subsubsection{Na-poor water}

Modern cell cytoplasm is extremely poor in $\mathrm{Na}^{+}$, while conversely it is enriched in $\mathrm{K}^{+}$, and also enriched in $\mathrm{PO}_{4}{ }^{3-}$. This indicates that the first cells are originated from highly reduced conditions that were highly depleted in $\mathrm{Na}^{+}$ions and conversely enriched in $\mathrm{K}^{+}, \mathrm{Zn}^{2+}$ and $\mathrm{Mn}^{2+}[47]$. Therefore, the birthplace of life would be poor in $\mathrm{Na}^{+}$.

\subsubsection{Highly diversified environments}

The process to generate building blocks of life is truly complex. It needs reducing material and oxidizing material at the same time, for example. To allow such variety of reactions, the varied environment is necessary, which can provide different $\mathrm{pH}, \mathrm{pO}_{2}$, temperature, salinity and chemical conditions related to the catalytic minerals, even contrasting conditions, e.g., oxidized vs. reduced, or acidic vs. alkaline, at the same time at different place. To make it possible, the presence of a highly diversified surface environment on the Hadean Earth is necessary, and it can provide the sole solution. The highly diversified surface environments of the Hadean Earth should have large primordial continents, composed of anorthosite (called PAN, MAN, and FAN), KREEP basalts filling in cratered basins created by ABEL Bombardments, serpentinized Mg suites (komatiites), newly formed andesite volcanic rocks and their plutonic equivalents at subduction zones, U-ores associated with minerals such as schreibersite $\left(\mathrm{Fe}_{3} \mathrm{P}\right)$, and a variety of rock-forming minerals of Fe-oxides, Ni-Co alloys, $\mathrm{Zn}, \mathrm{Cu}, \mathrm{Pb}, \mathrm{Mn}$, native iron, oxides, sulfides, molybdenite $\left(\mathrm{MoS}_{2}\right)$ and other key minerals to generate the necessary metallic proteins. In addition to a variety of rocks and minerals, topological diversity is also provided, such as highlands, lowlands, tropical area, glaciated area, deserts, wetlands, lakes, swamps, and rivers on land. They can provide different conditions according to site both physically and chemically, e.g. temperature, humidity, and 
chemical composition of lakes or rivers. Weathering, erosion, and transportation promoted by climate can provide various nutrients to surrounding region with complex chemical composition (Fig 23).
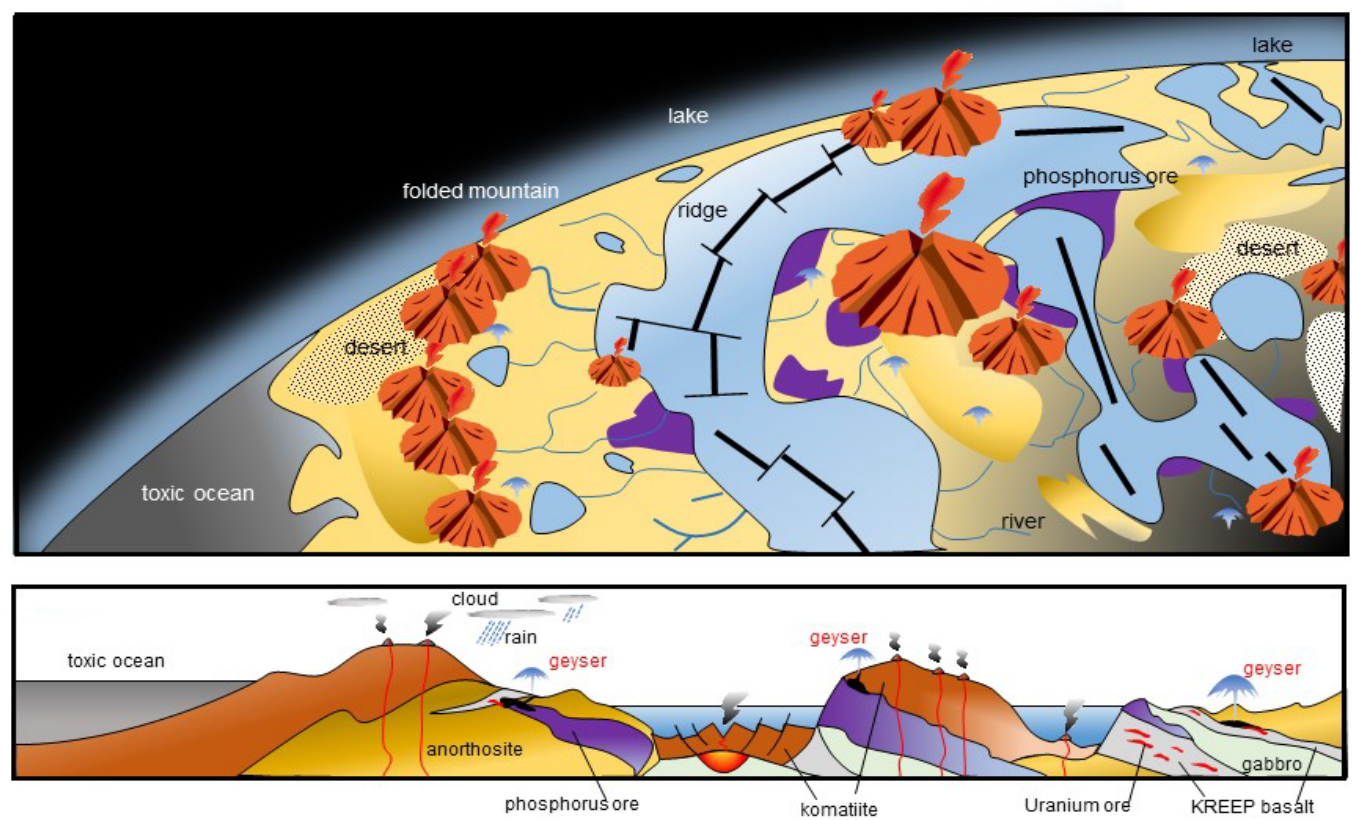

Fig 23 Highly diversified environment: Hadean surface environment should have been highly diversified. In addition to a variety of rocks and minerals on the continent, topological diversity is also provided, such as highlands, lowlands, tropical area, glaciated area, deserts, wetlands, lakes, swamps, and rivers on land, which enable chemical reaction between numerous kinds of building blocks of life through material circulation.

\subsubsection{Cyclic conditions, such as day-to-night, hot-to-cold etc}

Cyclic changes provide an important factor for maintaining life cycles, as seen in the fundamental processes in which life is associated with periodic fluctuations (e.g. [56][57]). Periodic environmental change, such as temperature, $\mathrm{pH}$, inorganic/organic ions and anions, must have affected the earliest steps of the life-forming process, e.g., low-temperature conditions result in regular crystallization of specific organic compounds, whereas high-temperature conditions promote random orientation of the crystalized organic compounds, with $60^{\circ} \mathrm{C}$ as the critical transition temperature. This temperature fluctuation may be related to the folding-unfolding of DNA, fragmentation-reconnection, and several steps for self-replication processes in the RNADNA world. It is assumed that the cyclic changes in the surrounding water chemistry would affect the fundamental processes of pre-biotic chemical evolution, and functions coded in genes may provide a kind of "fossil" of environmental cyclic changes.

\subsection{The nuclear Geyser model as the most probable birthplace}

As the ideal place to meet nine requirements, [48] proposed the Nuclear Geyser model. The advantage of this model is the presence of a natural nuclear reactor as a supplier of high energy particles which can promote chemical reaction between thermodynamically stable substances such as $\mathrm{N}_{2}, \mathrm{H}_{2} \mathrm{O}$, and $\mathrm{CO}_{2}$. 
In addition, the importance is the combination of a nuclear reactor and geyser which generate a system to maintain material/energy circulation. The combination between a geyser and natural nuclear reactor construct the perfect system that would meet several critical conditions to bear life. The advantages of nuclear geyser system are as follows. (1) Formation of highly reduced volatiles such as $\mathrm{H}_{2}$, $\mathrm{CO}, \mathrm{CH}_{4}, \mathrm{NH}_{3}$ and even $\mathrm{HCN}$ through water-rock interaction between wall rocks and inflow of surface water into the caves, in spite of oxidized atmospheric composition of the surface environment (Fig. 24). (2) The reduced gasses generated are concentrated on the ceilings of geyser cave, which maintains the locally reduced environment. (3) With the flow of water into geyser cave, reduced gas, high energy particles, intermediate activated organic matters, and other products react among one another through ionizing radiation to form more complex organic compounds. Amino-acids and peptides can be progressing with increasing distance from the natural reactor. (4) Periodic splash of geyser system caused by phase change of water/vapor 1:1,000, brings BBLs to the surface to be exposed to oxidizing environment. (5) In a small lake on the surface (Darwin's warm little ponds), wet-dry cycle would polymerize amino-acids to proteins and finally to RNA or form membranes through evaporation by strong tidal forces. The most fruitful water-site for life forms was lacustrine environment on primordial continent, such as lakes, rivers, wet lands like swamps [58], which was provided through global hydrological cycle driven by climate system [35]. The materials produced on the surface oxidized environment are then brought down into the geyser cave again in the process of material circulation. (6) Inside of geyser lacks high-temperature condition above $100^{\circ} \mathrm{C}$, because of periodic eruption of boiling water and vapor. Therefore, nuclear geyser system would prevent the synthesized RNA and DNA from being destroyed, which provides unique characteristics as a birthplace. Also, periodic splashing sustains cyclic nature within the nuclear geyser system, which can be advantageous to change the water chemistry, because solubility of inorganic ions, anions and organics depends on temperature. This would help the evolution from RNA to DNA world.

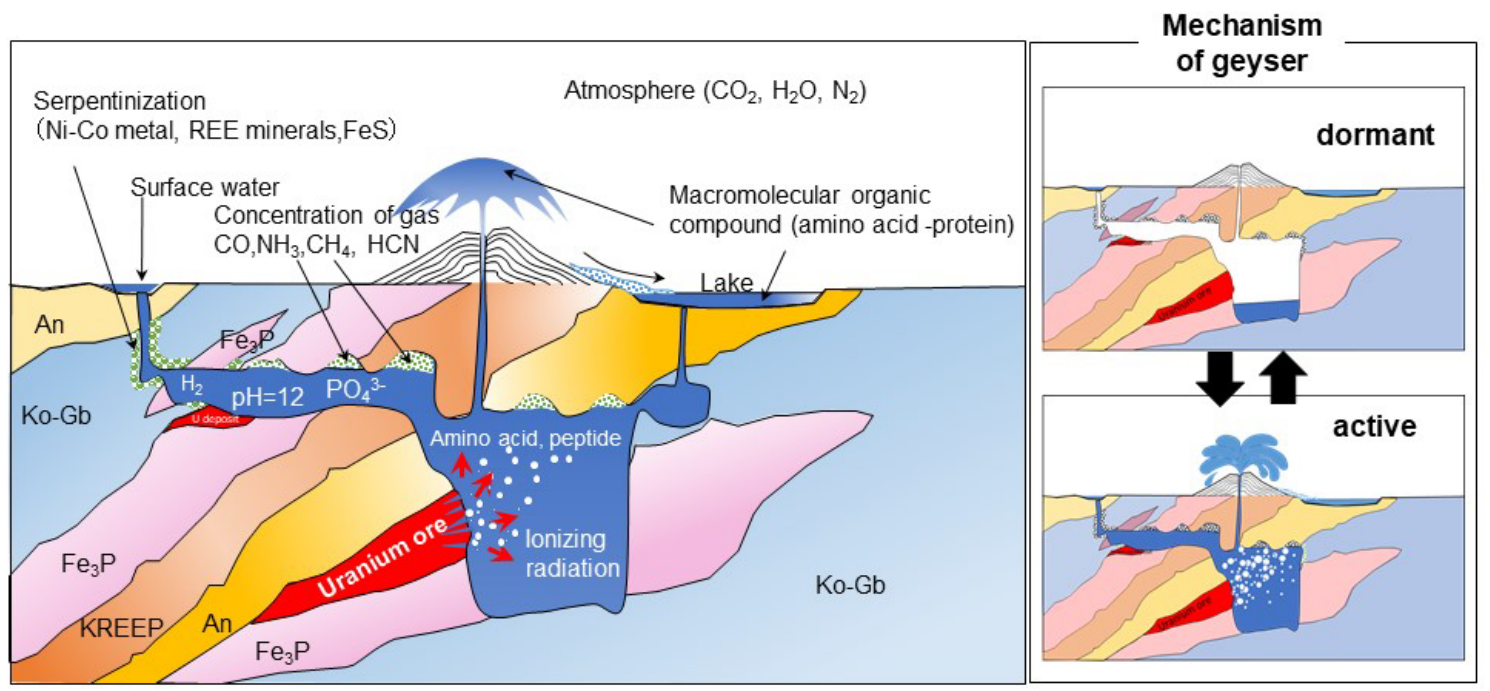

Fig 24. Nuclear Geyser Model: As the most ideal place for the emergence of life, [48] proposed the Nuclear Geyser model. Combination between a natural nuclear reactor and geyser provide the system to circulate material to promote pre-biotic chemical evolution. 


\subsection{Three step model for the emergence of life}

Charles Darwin explained life evolved to adapt to the changing environment. Which means life does not evolve or change if the environment is stable and remains unchanged. In other words, environmental factors trigger the evolution of life. Based on this concept, Maruyama proposed the three step evolution to emerge first life.

Maruyama's new idea to explain how the first life was generated from inorganic environments, suggests three-step model for life's emergence at its most probable birthplace, centering on a nuclear geyser system. In this model, he hypothesizes that prebiotic chemical evolution progresses with three-step. At first stage, first proto life appeared as ectosymbiont, then after the drastic environmental change, second stage proto-life emerges (second proto-life). Finally, another environmental change forces second proto-life to evolve into third stage protolife (third proto-life), which is the first cell life.

Before to begin the scenario of pre-biotic chemical evolution of primordial life, the surface environment of Hadean earth should be emphasized. Initial Earth was totally dry and did not have ocean or atmosphere. On the surface of the Earth, schreibersite $\left(\mathrm{Fe}_{3} \mathrm{P}\right)$ was crystallized from the final residue of dry magma under extremely dry condition. $\mathrm{Fe}_{3} \mathrm{P}$ is highly reduced mineral of metallic phase without oxygen or hydrogen. If initial magma was hydrous, struvite $\left(\mathrm{NH}_{4} \mathrm{MgPO}_{4}-\right.$ $6 \mathrm{H}_{2} \mathrm{O}$ ) and apatite appeared as a hydrous phosphorus mineral, and schreibersite was not appear. Struvite is stable under oxidized condition, so hydrous struvite cannot be a source of $\mathrm{P}$ to create life forms, because solubility of $\mathrm{PO}_{4}{ }^{3-}$ is extremely low under oxidized condition. To enable $\mathrm{P}$ to react with other materials, the presence of schreibersite under highly reductive environment is critically important. If there was no schreibersite, function of metabolism cannot begin.

Associated with P-bearing minerals, uranium ores must have been present commonly to have natural nuclear reactors on the surface or sub-surface of primordial continents as the supplier of high energy particles. After the ABEL Bombardment occurred at 4.37Ga [22], meet-up between highly reduced P-bearing minerals and water components from icy asteroids initiated the chemical reaction as a precursor of metabolism. Since then, natural nuclear reactor played a key role to produce numerous amounts of BBLs by ionizing radiation, and circulate them between reduced underground and oxidized surface environment which is driven by geyser. Uranium ore, forming a natural nuclear reactor, worked as a driving force to circulate material and energy.

\subsubsection{The emergence of first proto-life}

Fig 25 (top figure) shows the schematic illustration of Hadean surface environment including nuclear geyser, which is divided into five domains based on the role of respective site; Domain I: surface environment with clean water and oxidized atmosphere of $\mathrm{CO}_{2}-\mathrm{H}_{2} \mathrm{O}-\mathrm{N}_{2}$, Domain II: underground space with wall rocks dominated by komatiite or Mg-suites (kind of plutonic rocks) enriched in olivine (60 modal\%), Domain III: geyser main room in combination with natural nuclear reactor in the presence of schreibersite ore, KREEP basalt, anorthosite, and serpentinized komatiite or Mg-suites, where periodic splashing occurs. Domain IV: lacustrine environment on the surface where wet-dry cycle is maintained. Domain V: incubation room to emerge first stage proto-life. In next section, detailed process within in each domain are described. 


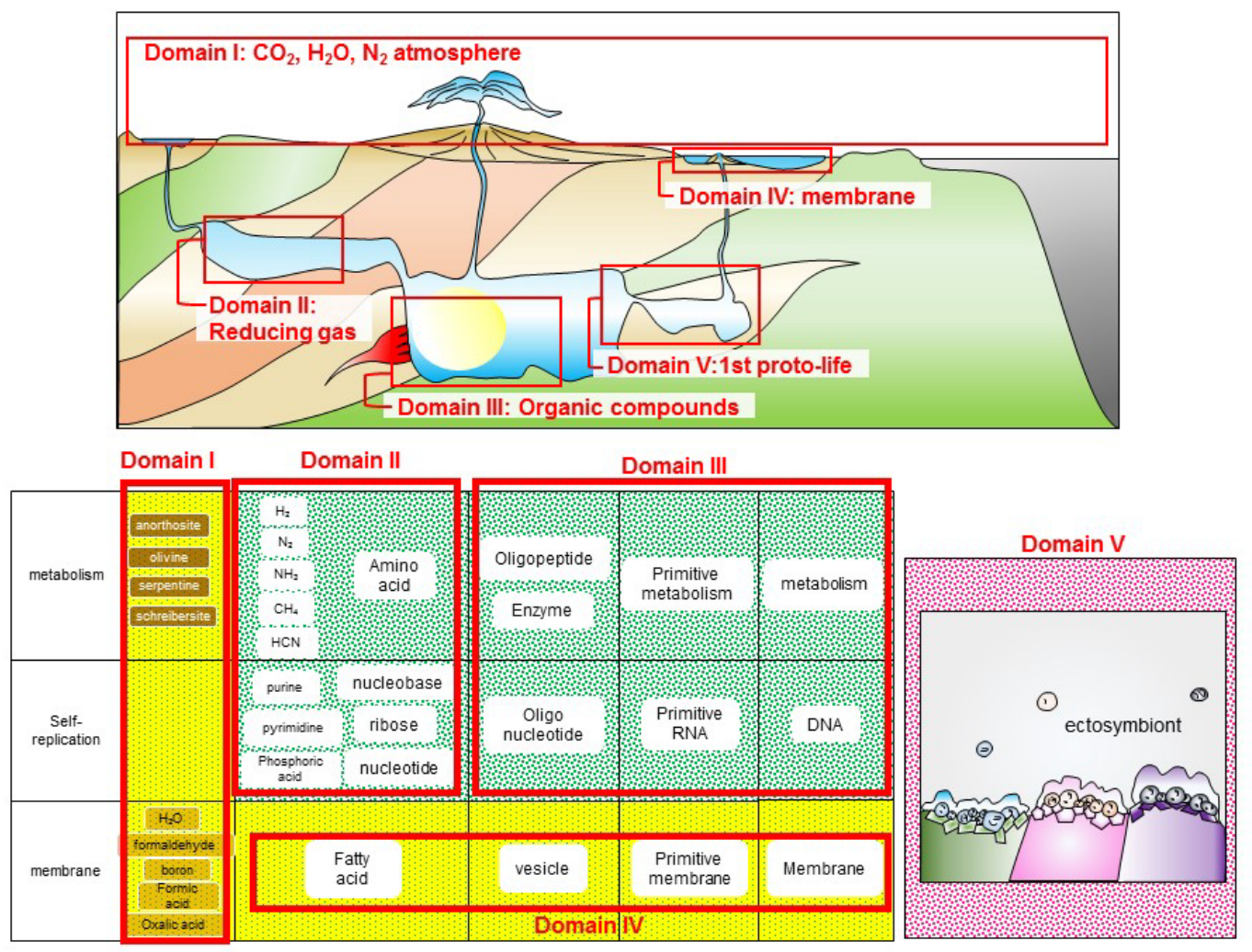

Fig.25 Top. Cross-sectional depiction of a nuclear geyser system, showing its division into five domains related to their roles. Domain I supplies the starting material of $\mathrm{H}_{2} \mathrm{O}, \mathrm{CO}_{2}, \mathrm{~N}_{2}$, etc. that are necessary for the emergence of life. Domain II produces highly reduced gasses, including HCN, and amino acids, through water-rock interaction. Domain III is the powerful factory that produces more complex BBLs. Due to periodic splash of geysers, these BBLs are tossed on to the surface environment. Domain IV is lacustrine environment around the geyser where dry-wet cycle is maintained due to strong tidal forces generated by a then-very-close Moon. Material from this surface environment is re-circulated into the interior of the nuclear geyser system. Domain V is the most moderate and optimal site for the emergence of the first proto-life, where all the necessary material accumulated.

\subsubsection{Domain I: Inorganics}

Domain I supplies starting inorganic material to synthesize BBLs. About $10 \%$ of the oxidized atmosphere of $\mathrm{CO}_{2}-\mathrm{H}_{2} \mathrm{O}-\mathrm{N}_{2}$ can be soluble in water, although it depends on various conditions such as $\mathrm{pH}, \mathrm{pO}_{2}$, and temperature. Particularly, $\mathrm{N}_{2}$ is difficult to be soluble in water, but if highly reduced minerals such as native $\mathrm{Fe}$ and $\mathrm{Fe}_{3} \mathrm{P}$ are available as catalytic nutrients, $\mathrm{NH}_{4}{ }^{2-}$ can be enriched in water.

\subsubsection{Domain II: From inorganic to organic}

Surface water was incorporated into the geyser cave (Domain II) through river to react with wall rocks dominated by komatiite or Mg-suite of plutonic rocks to produce $\mathrm{H}_{2}$, which reacts with $\mathrm{CO}_{2}$ to increase $\mathrm{CO}$, also reacts with $\mathrm{N}_{2}$ and nutrients such as $\mathrm{K}$ (sourced from KREEP basalt) and P (from schreibersite) to yield $\mathrm{CH}_{4}, \mathrm{HCN}$ and $\mathrm{KCN}$. $\mathrm{N}_{2}$ reacts with $\mathrm{H}_{2}$ to produce $\mathrm{NH}_{3}$ or 
HCN. If K is available, even KCN can be generated. When anorthosite is available, Na-poor environment could be provided to enable water to react with altered low-temperature minerals derived from igneous minerals to yield variable metallic ions and anions in water. If brucite $\mathrm{Mg}(\mathrm{OH})_{2}$ is formed through serpentinization, brucite is dissolved easily due to high solubility in water, hence water turns into alkaline around $\mathrm{pH}=12-13$ by the increase of $\mathrm{OH}^{-}$in water. Then, $\mathrm{pH}$ gradient is generated from the serpentinized surface, hence electron density gradient appears. If these reactions occur on the surface, those gasses would disperse right away into atmosphere, but in the underground geyser system, gasses would accumulate and being concentrated on the irregular ceilings of the cave to make basic BBLs such as amino acids (Fig. 26). Under this condition, cyanohydrin, glyceraldehyde, glycolaldehyde and other important organic compounds can be produced with the help of high energy particles derived from natural nuclear reactor (Fig 24).

With the presence of HCN, another very important organic compound to lead to synthesis of RNA can be also formed in Domain II. Under very low $\mathrm{pO}_{2}$ condition, schreibersite exposed on the geyser wall is 105 times more soluble in water than oxidized condition (e.g. [47]), so after phosphate $\left(\mathrm{PO}_{4}{ }^{3-}\right)$ is supplied into water, which would generate glyceraldehyde 3-phosphate (G3P), or combine with 2-aminooxazole [43] to produce phosphoimidazole which will play critical role to synthesize RNA in Domain II/III and complete first proto-life in Domain V.

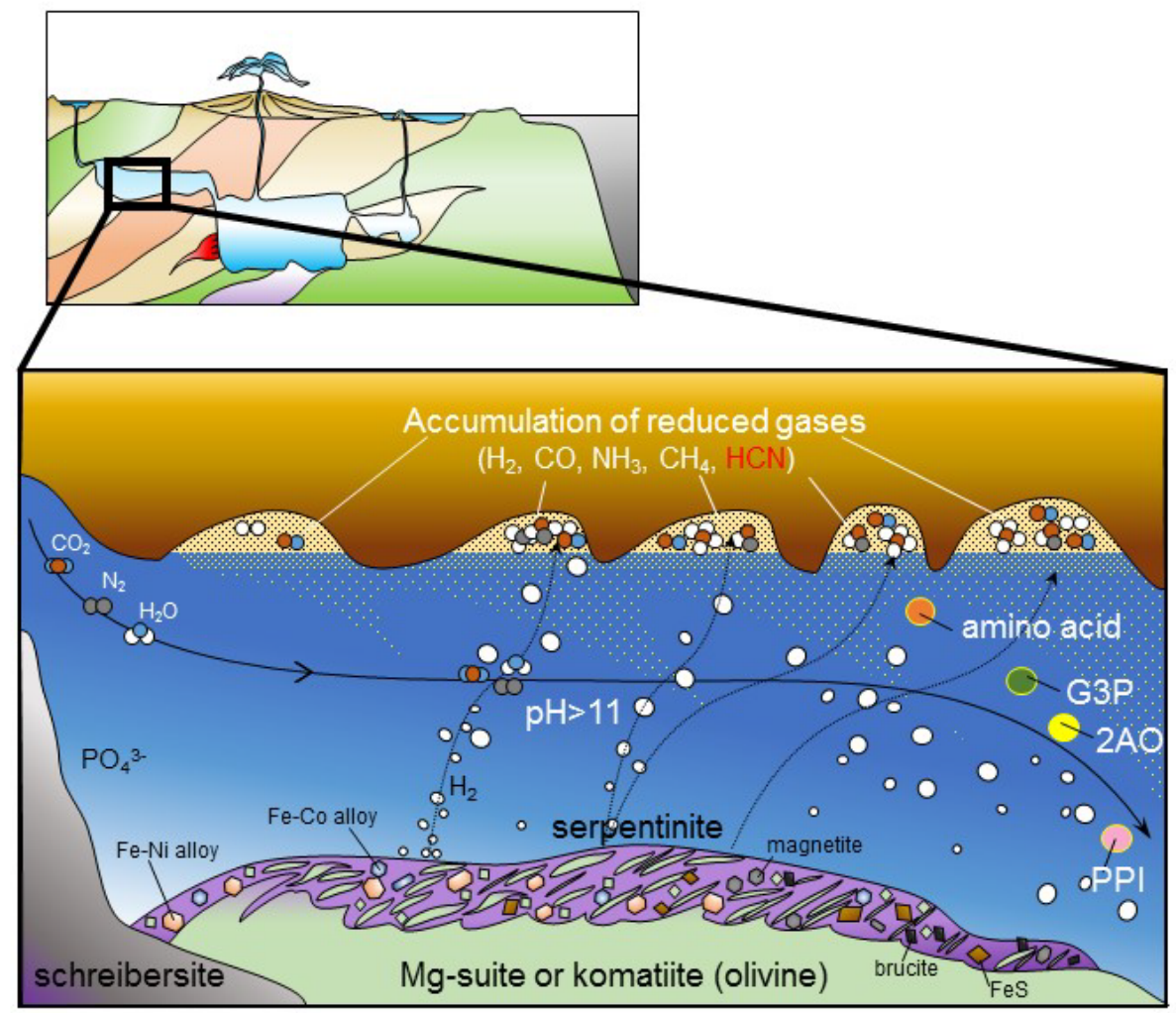

Fig 26 Domain II of the nuclear geyser system. Birth of highly reduced gasses $\left(\mathrm{H}_{2}, \mathrm{CO}, \mathrm{NH}_{3}, \mathrm{CH}_{4}\right.$, $\mathrm{HCN}$ ) through water-rock interaction between komatiite and neutral $\mathrm{pH}$ water in the underground cave. Note that the concentrated HCN promote synthesis of even complex organic compounds such as glyceraldehyde 3-phospate and 2-aminooxazole. 


\subsubsection{Domain III: Production of more advanced BBLs}

Various BBLs, from simpler amino acids to more complex 2-aminooxydazole, which produce in Domain II, move along with the flow to go into Domain III, which is a main room of the geyser system, combined with a natural nuclear reactor, as the powerful factory of BBLs, where enormous amount of high energy particles such as abundant aqueous electrons is supplied to generate further advanced BBLs, such as nucleobase, nucleotide, myriad proteins, RNA and so on (Fig. 27). A series of biofilms could be formed naturally right on the secondary minerals through the water-rock interaction at low temperature less than $100 \mathrm{C}^{\circ}$ (Fig. 27), which seems slightly far from the reactor's core to keep away from intense radiation effect. More than several tens of ectosymbionts are formed within biofilms on the minerals such as Fe-Ni alloy, Fe-S, $\mathrm{Fe}_{3} \mathrm{O}_{4}, \mathrm{Mg}(\mathrm{OH})_{2}$ on serpentinite, $\mathrm{Fe}-\mathrm{S}, \mathrm{TiO}_{2}, \mathrm{MoS}_{2}, \mathrm{MnS}$, (Zn, Fe)S, $\mathrm{Cu}_{2} \mathrm{~S}$, REE-bearing minerals such as allanite, monazite, clay minerals, and variety of zeolites or carbonates on meta-KREEP basalts, and Ca-, Mg- or CaMg carbonates on meta-anorthosite. As a result, host rock (serpentinite, anorthosite, and KREEP basalt) could produce mainly three different colonies comprised of biofilm-like ectosymbionts, but those colonies would be mixed together through geyser eruption, and encountered millions of steps of chemical reaction within nuclear geyser system with different conditions.

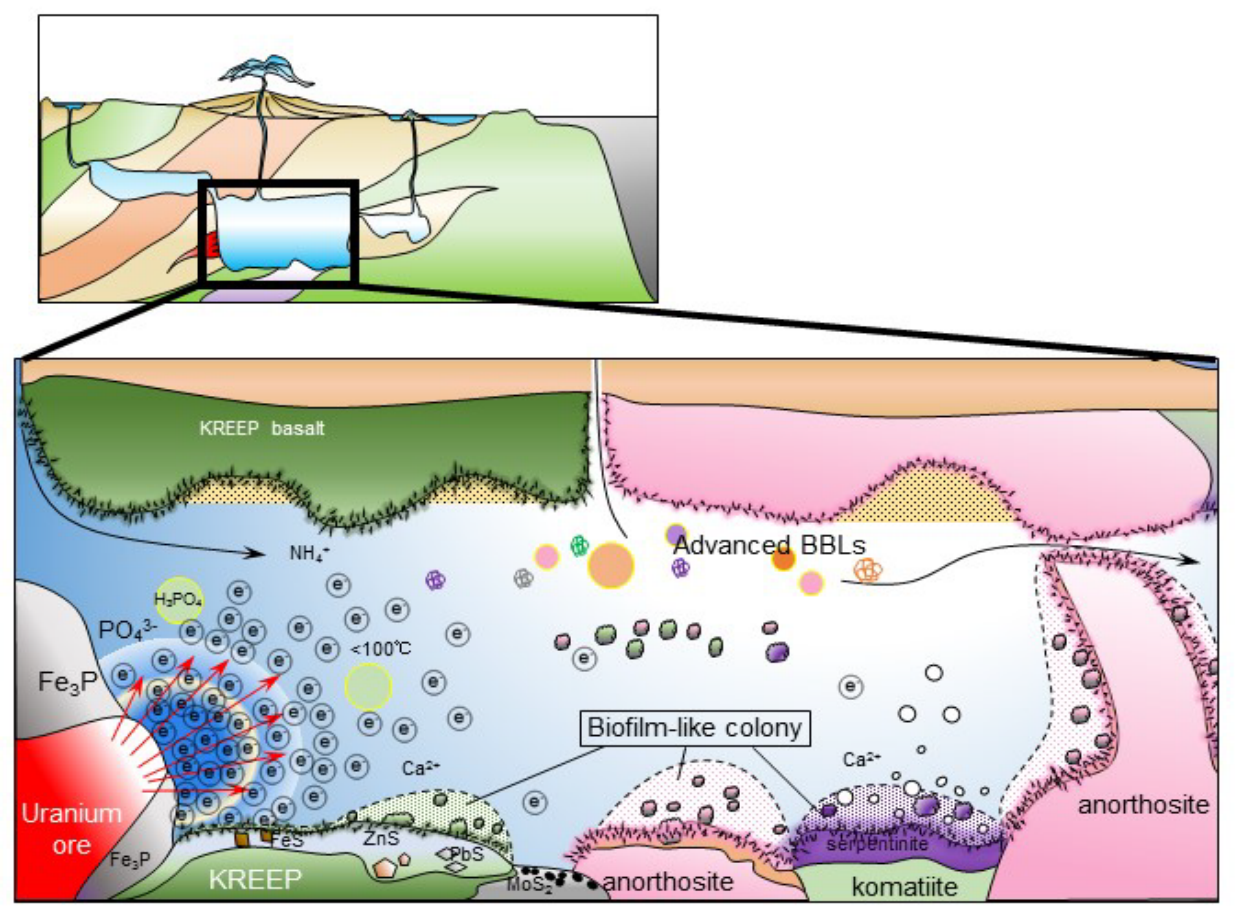

Fig 27. Domain III of the nuclear geyser system. The natural nuclear reactor, together with $\mathrm{Fe}_{3} \mathrm{P}$, promotes the production of advanced BBLs by ionizing radiation. Simultaneously, water-rock interactions develop biofilm-like colonies on the surfaces of wall rocks.

\subsubsection{Domain IV: Production of BBLs in an oxidizing wed-dry surface environment}

With the time, BBLs, formed within nuclear geyser, are splashed out on the surface environment, e.g. Domain IV, which were exposed to UV from the Sun (1,000 times of present one) and enormous galactic cosmic rays (GCR) because it was the peak of starburst period in our 
galaxy. Amino acid or highly complex organic compounds turned to tar to remain to be nonreactive. However, these tars could go into geyser cave as a part of material circulation, which can react again with other chemical material thanks to the ionizing radiation by natural nuclear reactor.

Domain IV is basically oxidized environment which is opposite to underground Domain II and III. At this time, Moon's orbit was at $128,000 \mathrm{~km}$ from the Earth (one-third of present MoonEarth distance; $384,000 \mathrm{~km}$ ), causing a severe tidal force to produce dry-wet cycle at lacustrine environment around the geyser, where hydration-dehydration of amino acid was promoted. It could lead to the synthesis of proteins, fatty acids, nucleic acids, and also vesicles and membranes (e.g. [54][59]). Fatty acids could easily form from schreibersite $\left(\mathrm{Fe}_{3} \mathrm{P}\right)$ with ionizing radiation, however, if polycondensation progressed in a small pond, it turned to coacervate or vesicle to evolve into primordial cell membrane [53] which would become possible through material circulation centering on the nuclear geyser system (Fig. 28).

And amino-acids are progressively polymerized to peptides and proteins, or RNA with the help of ZnS-bearing enzymes. Through material circulation, almost all of them are recirculated into the geyser caves again and again, toward to bear first proto-life in Domain V.

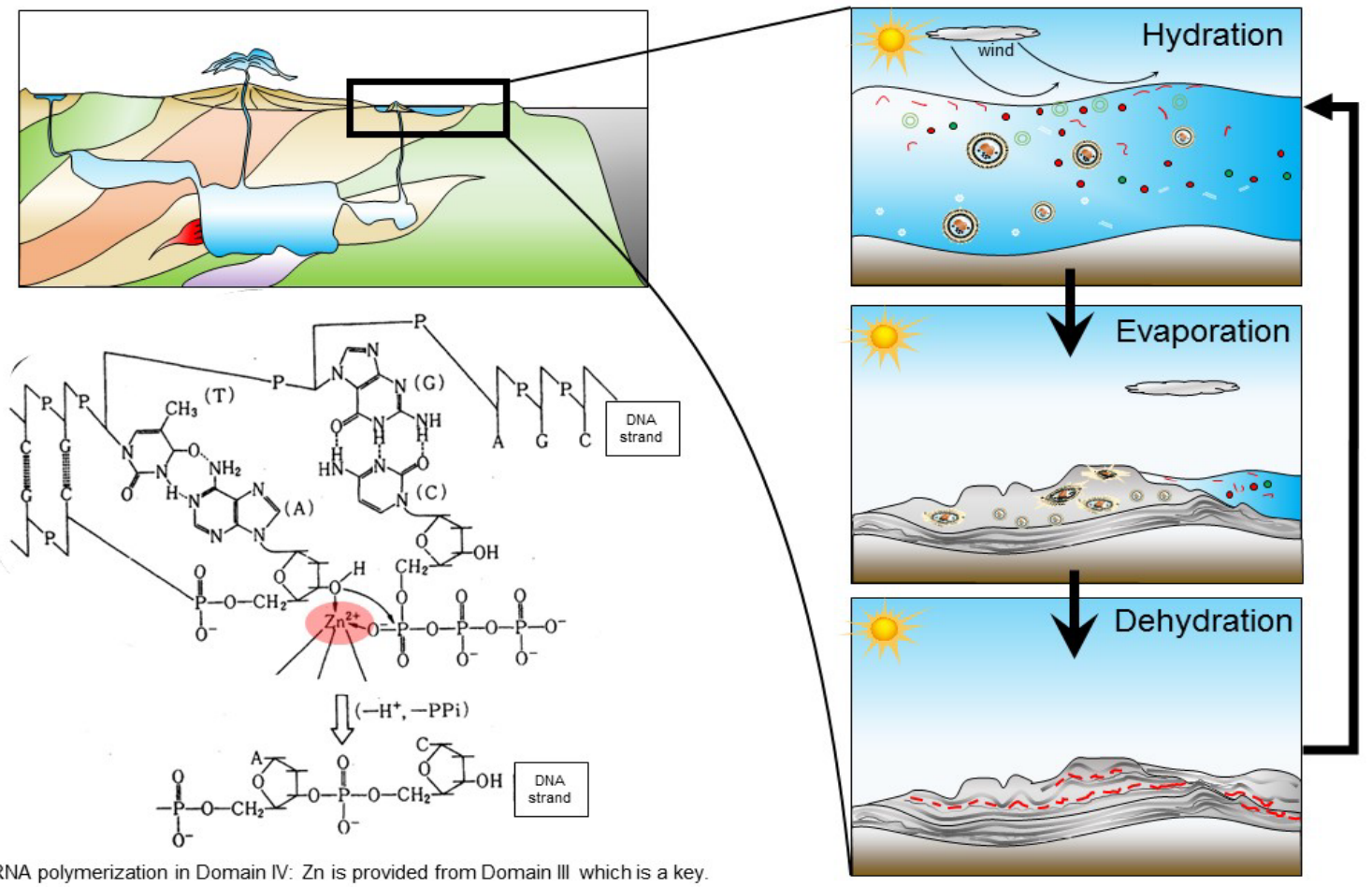

Fig 28 Domain IV of the nuclear geyser system. Along the lakes, tidal fluctuation provided drywet cycle under oxidized condition, where membranes were formed through repeatedly occurring hydration-dehydration process. RNA polymerization is also progressing in Domain IV in which Zn play a key role. Zn is provided from wall rocks of Domain III.

\subsubsection{Domain V: Birthplace of the first proto-life}

Finally, first proto-life emerges in Domain V or outer margin of Domain III where the energy density is moderate to save primitive life (Fig 29). The appearance of first proto-life is due to almost infinite mixing of numerous number and kinds of complex organic compounds within 
nuclear geyser system, which periodically circulated advanced BBLs between reduced underground and oxidized surface environment. By splash of the geyser, underground materials were carried onto the surface for further reaction with BBLs produced under oxidized environment such as vesicle or membrane. Through repeated material circulation, source material of membrane and nucleotides polymer were carried to underground to bear first proto-life. Also numerous organic molecules created in Domain III were developing through mixing.

First proto-life is thought to be very primitive with insufficient functions and live as ectosymbiont to exchange electrons or necessary ionic elements with adjacent proto-life forms, while the primary source of electrons is still natural nuclear reactor. Nutrients were all supplied from wall or host rocks, such as $\mathrm{Mg}^{2+}$ and FeS from serpentinite, $\mathrm{Ca}^{2+}$ from anorthosite, and $\mathrm{MoS}_{2}$, ( $\mathrm{Zn}, \mathrm{Fe}) \mathrm{S}$, and $\mathrm{TiO}_{2}$ from KREEP basalt. The outer edge of each rock has a different type of ectosymbiont, presumably forming three colonies (Fig 29, Fig 30). Then, those first proto-life in colonies were splashed out to the surface to be hybridized through the process of material circulation to adapt to environment which would be the life utilizing Sun radiation.

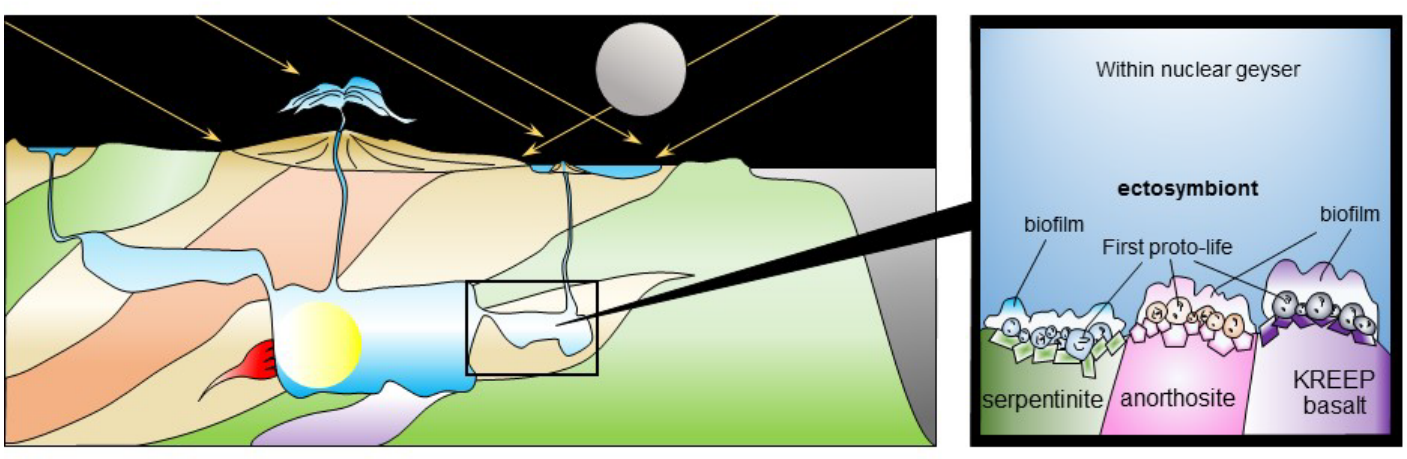

Fig 29 Domain V of the nuclear geyser system. First proto-life was born as the form of ectosymbiont on the three types of host rocks (serpentinite, anorthosite, and KREEP basalt) forming biofilm-like colonies. They still depend on the natural nuclear reactor as the energy source, and all necessary nutrients were supplied by wall or host rocks.

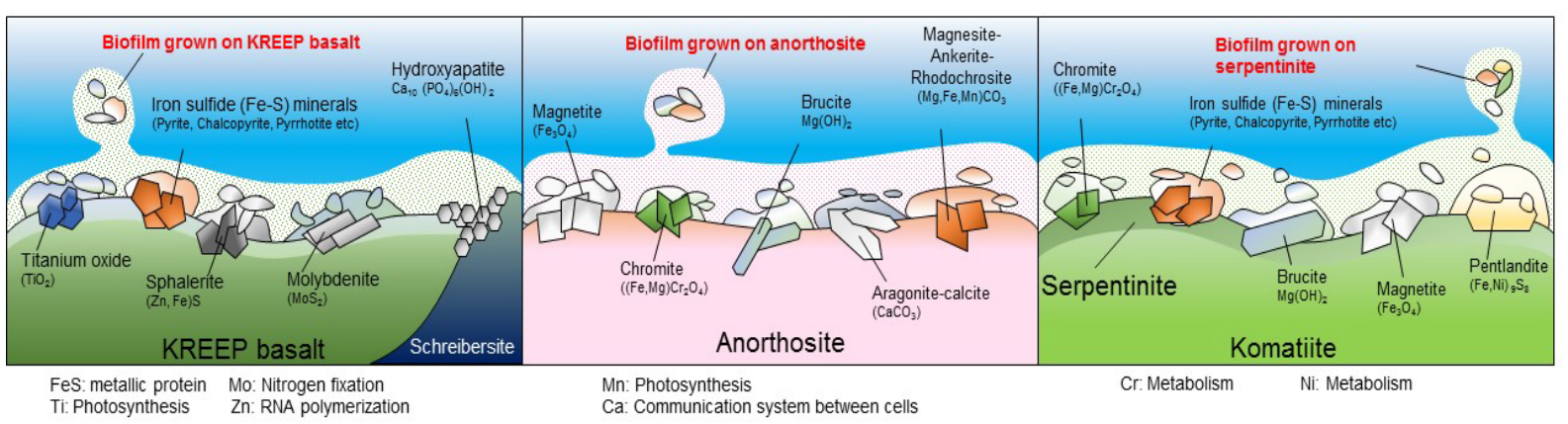

Fig. 30 Three types of colony of first proto-life as ectosymbiont in form of biofilm, which develop right above the secondary minerals through water-rock interactions. Colonies were formed on the surface of altered KREEP basalt, anorthosite, and komatiite. These three different microbial communities are splashed out to the surface and mixed altogether. Most of them die to be tar due to no continuous energy supply as well as nutrients. 


\subsubsection{Utilization of metallic proteins}

It is assumed that metallic proteins have been utilized in this early stage to stabilize the proto-life chemically. Under the extremely low $\mathrm{pO}_{2}$ with $\mathrm{H}_{2}$-producing environment like Hadean surface environment, ferredoxin was expected to be a key metallic protein which contains Fe-S bearing activate center. Fig. 31 shows the redox potential for non-metallic and metallic redox systems [60][61]. Metallic proteins are classified into three types with different colored letters, (1) metalloprotein, (2) iron-sulfur (Fe-S) protein, and (3) non-protein metal complex. It should be noted here that the metallic redox system is a function of increasing $\mathrm{pO}_{2}$ through time, which is from Fe (III/II, Hadean-Archean), through Mn (III/II, Proterozoic) to Cu (II/I, Phanerozoic). In the Hadean geyser system, stable metallic protein must be ferredoxin, because of the lowest redox potential (Fig. 31). Ferredoxin uses redox potential of Fe (III/II) coupled with sulfur, and played the most important role for the metabolism for the first proto-life.

To synthesize ferredoxin, Fe-S minerals formed through water-rock interaction is a key. Rock type to be effective for synthesis of ferredoxin should be komatiite. Moreover, water in nuclear geyser must be enriched in $\mathrm{PO}_{4}{ }^{3-}$ which was $10^{5}$ times more comparing to the modern oxidized water [47].

Among non-metallic proteins, Acetyl hydroxide $\left(\mathrm{CH}_{3} \mathrm{COOH}\right) /$ Acetaldehyde $\left(\mathrm{CH}_{3} \mathrm{COH}\right)$ shows the lowest redox potential, and $\mathrm{S}_{2}{ }^{2-} / 2 \mathrm{~S}^{2-}$ is the second lowest value as electron transfer system.

From the Domain IV on the surface, membranes of mono-layer phospholipid or its bi-layer provide to the Domain V or III, because of constant material circulation in the whole system, or directly from IV to Domain V where the birthplace of first proto-life, because membranes and precursor RNA must have been synthesized by dry-wet cycle on the surface environment with help of mineral enzyme (e.g., (Zn,Fe)S) and brought into Domain V.

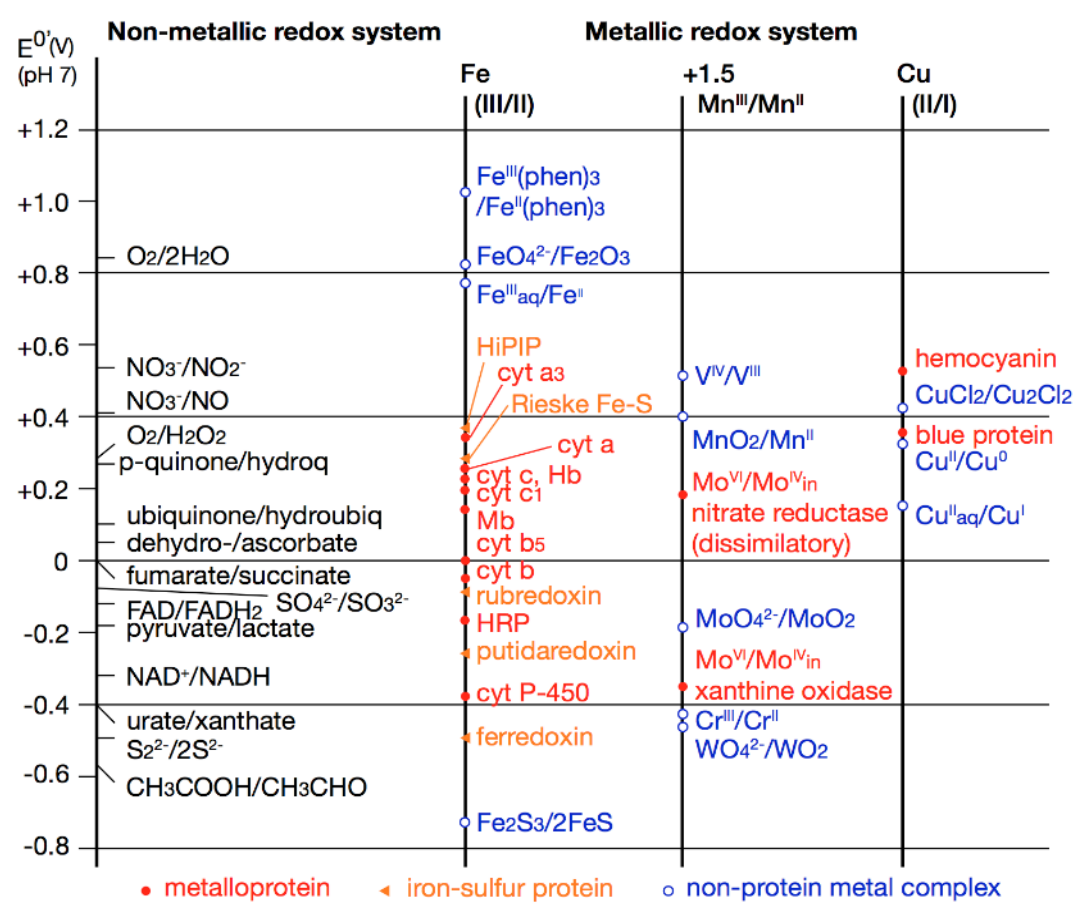

Fig. 31 Redox potential in terms of non-metallic and metallic redox system. With the increase of pO2 through time, metallic redox system evolved from Fe, then $\mathrm{Mn}$, to $\mathrm{Cu}$ [61]. 


\subsubsection{The emergence of second proto-life}

\subsubsection{Drastic environmental change from Step 1 to Step 2}

Early Hadean Earth seemed to have no geomagnetic field, which is thought to be generated by the convection of liquid outer core. The appearance of liquid core and generation of geomagnetic field seems to be around 4.20Ga [62]. Fig. 32 shows the schematic cross section of Hadean Earth. At 4.53Ga, dry magma ocean was solidified through the cooling of primitive Earth, and stagnant lid tectonics operated [21]. After 4.37Ga, ABEL Bombardment delivered water components on dry Earth and formed atmosphere and ocean, initiating the operation of plate tectonics. With time, anorthositic-KREEP primordial continent was subducted into the bottom of upper mantle at $660 \mathrm{~km}$ depth, then accumulated there. After that, stagnant slab of primordial continent dropped onto core mantle boundary (CMB) and heated up solid core. As a result, outer margin of solid core melt to have liquid core. By 4.2Ga, liquid outer core could generate strong geomagnetic field and protected the surface environment from UV and GCR from the outer space. UV and GCR are dangerous for primitive life as it can break its body. Therefore, protection by geomagnetic field is important factor to prepare the nicer place for proto-life.

At that time, first proto-life were periodically and repeatedly splashed out onto the surface environment through material circulation centering on the nuclear geyser system. Despite of appearance of geomagnetic field, the surface environment was still dangerous for proto-life born in underground space. There were two critical environmental problems for first proto-life when they moved from inside of geyser to the surface environment. First problem was the energy source to survive on the surface. While primitive first proto-life was in underground cave, they were given enough material and energy from natural nuclear reactor. On surface environment, the Sun is the only one energy source, however, it is too weak for them to survive. Also, they have no energy source during night time, which is more critical to maintain metabolism. Second problem is oxidant, generated by photochemical reaction. On the surface of Hadean Earth, $\mathrm{TiO}_{2}$ and $(\mathrm{Zn}, \mathrm{Fe}) \mathrm{S}$ were common, which were formed through water-rock interaction of KREEP basalt at low temperature. As these semiconductor minerals are known for artificial photosynthetic modern technology to produce $\mathrm{H}_{2}$ and $\mathrm{O}_{2}$ through decomposition of water, they were source minerals of oxidant. Presumably, semipermeable membrane of first proto-life was easily damaged by such oxidants.

Due to enforced change in habitat from geyser to surface environment, first proto-life should have experienced mass extinction and almost all of them turned to be tar, dead end products. So, what is the biological response to adapt to this environment? 


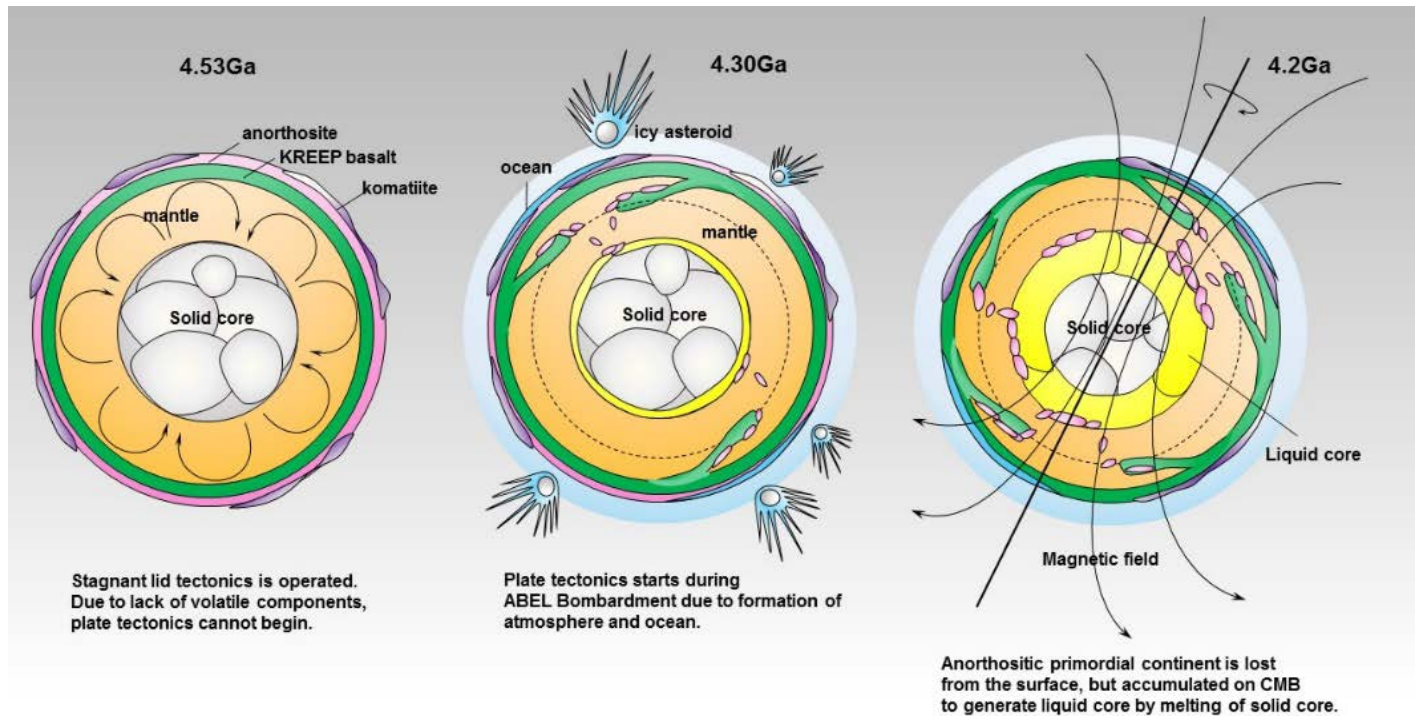

Fig. 32 Appearance of the geomagnetic field of the Earth. Early Hadean Earth seemed to have no geomagnetic field due to the absence of liquid outer core. After ABEL Bombardment (4.37-4.20Ga), Earth's atmosphere and ocean were formed on a dry planet Earth, initiating the operation of plate tectonics. Plate tectonics carried primordial continents into the core mantle boundary (CMB) and heated up solid core. As a result, outer margin of solid core melt to have liquid core. By 4.2Ga, liquid outer core could generate strong geomagnetic field and protected the surface environment from UV and GCR from the outer space.

\subsubsection{Biological response from Step 1 to Step 2}

Critical environmental change necessitated first proto-life to reform its function to survive, which led to the evolution of first proto-life to second proto-life. One of the largest difference in metabolizing system between first proto-life and second proto-life is assumed to be the function to take in the energy from sunlight. Solar energy density is extremely weak, which is $10^{-3}$ times of natural nuclear reactor (Fig 21). Also, sun energy cannot be given during night time. Therefore, second proto-life had to develop more efficient metabolizing system which could utilize very weak Sun energy, also store and reuse the energy during night time when no energy is supplied. Then, new metabolizing system is assumed to acquire adenosine triphosphate (ATP) to enable transporting chemical energy within a proto-cell, and it could supply energy during even night time (Fig. 33).

Another important factor is metallic proteins such as ferredoxin containing Fe-S cluster to play a role as excellent electron transfer system. These kinds of metallic protein were numerously created in Domain III/V of nuclear geyser cave where serpentine, anorthosite, and KREEP basalt could provide necessary metallic elements, which was taken into the part of proto-life. Photosynthesis is thought to be the function which started to be invented in this period. Primitive photosynthesis (anoxygenic) utilized redox potential of ion-sulfur or hydrogen as electron donor in electron transfer system. Chloroplast-type ferredoxin should have developed on the surface after initial type of ferredoxins were synthesized within nuclear geyser. Then, they took in chlorophyll molecule to successfully absorb sunlight and transfer energy. With time, this function has been developed to oxygenic photosynthesis (combination of photosystem I (PSI) and photosystem II (PSII)) which was completed by 2.9Ga, followed by quick $p \mathrm{O}_{2}$ increase [63][64] 
at 2.6-2.5Ga (Great Oxidation Event I) and at 2.3-2.2 Ga (GOE II) which transformed the Earth atmospheric composition to more oxidized which caused the evolution to Eukaryote.

Another change of function occurred in membrane. On the surface environment, solar energy could generate oxidant through photochemical reaction, which should have broken primitive semipermeable membrane formed in geyser environment. To survive, membrane should have evolved. The structure of membrane had to be strengthened and its structure got more complexity. Complex structure prevents material from transporting between inside and outside. Therefore, import of proton pumps, aquaporins, and aquagrlceroporins were repeatedly attempted to improve the membrane's permeability. Also, to handle osmotic pressure, second proto-life was assumed to invent active material transportation using ATP.

Through above adaptive evolution to the surface environment, second proto-life was born and gradually expanded their habitat globally. Differently from inside of geyser, the surface region was vast, and the environment was varied; second proto-life is exposed to daily climate change (from sunny to rainy), seasonal physical changes (from winter to summer), differences in surface geology (from sedimentary rocks to volcanic rocks), which had not occurred within the geyser cave, and they adapted themselves to such an environmental situation gradually. As a result, second proto-life could have evolved a lot kinds of different ecosystems here and there on the Earth. However, they are thought to live as ectosymbiont as well as first-proto-life.

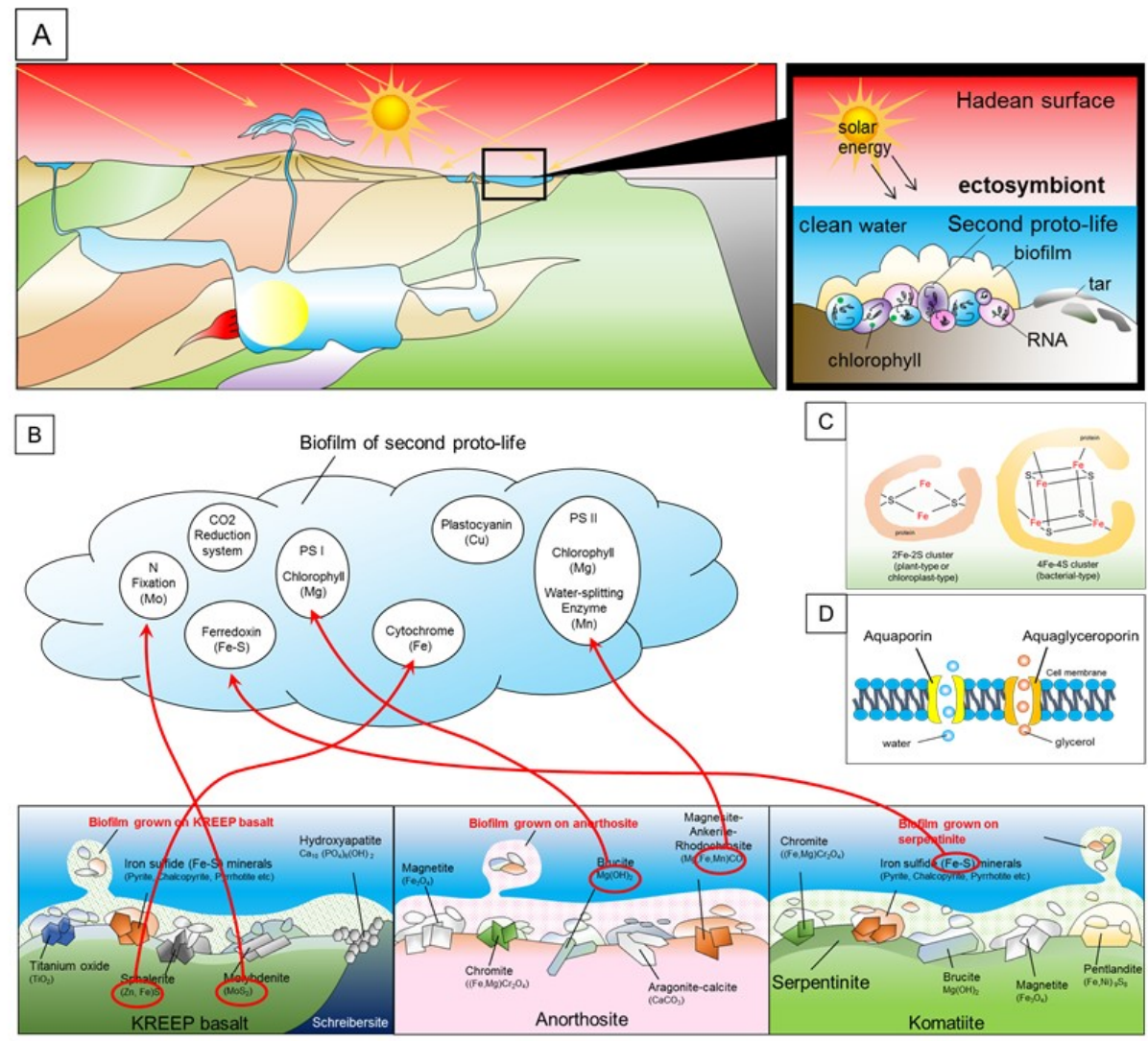

Fig 33 Birth of second proto-life using solar energy on the surface. (A) After splashed out from geyser cave onto surface environment, first proto-life reformed its function to fit to new environment, and evolved into second proto-life, using Sun energy. (B) The birth of photosynthesis using solar energy to get ATP by improving the oldest protein, ferredoxin and 
related protein born in the geyser cave. (C) Ferredoxin and its structure with Fe-S cluster. (D) The structure of bi-layer membrane with aquaporin and aquaglyceroporin.

\subsubsection{The emergence of third proto-life, prokaryote}

\subsubsection{Drastic environmental change from Step 2 to Step 3}

After second proto-life could expand the habitat globally on Hadean surface environment, the biggest and most critical environmental change was the encounter with toxic ocean. The Earth has initiated the plate tectonics between $4.37 \mathrm{Ga}$ and $4.20 \mathrm{Ga}$ when ocean appeared through ABEL Bombardment [22], promoting the breakup and amalgamation of continents through time. Therefore, second proto-life had a fate to meet toxic ocean necessarily over time (Fig. 34).

From the viewpoint of planetary formation theory, Hadean ocean was too toxic. Heavy metals from meteorites were dissolved in ocean water to make it ultra-acidic, and chlorine from carbonaceous chondrite was also dissolved in ocean, which made Hadean ocean ultra-saline. Such a harmful ocean could never grow a life. Second proto-life, encountered with toxic ocean, were killed without exception at initial stage, and mass extinction repeatedly occurred. However, this process necessitates the second proto-life to evolve to third proto-life.

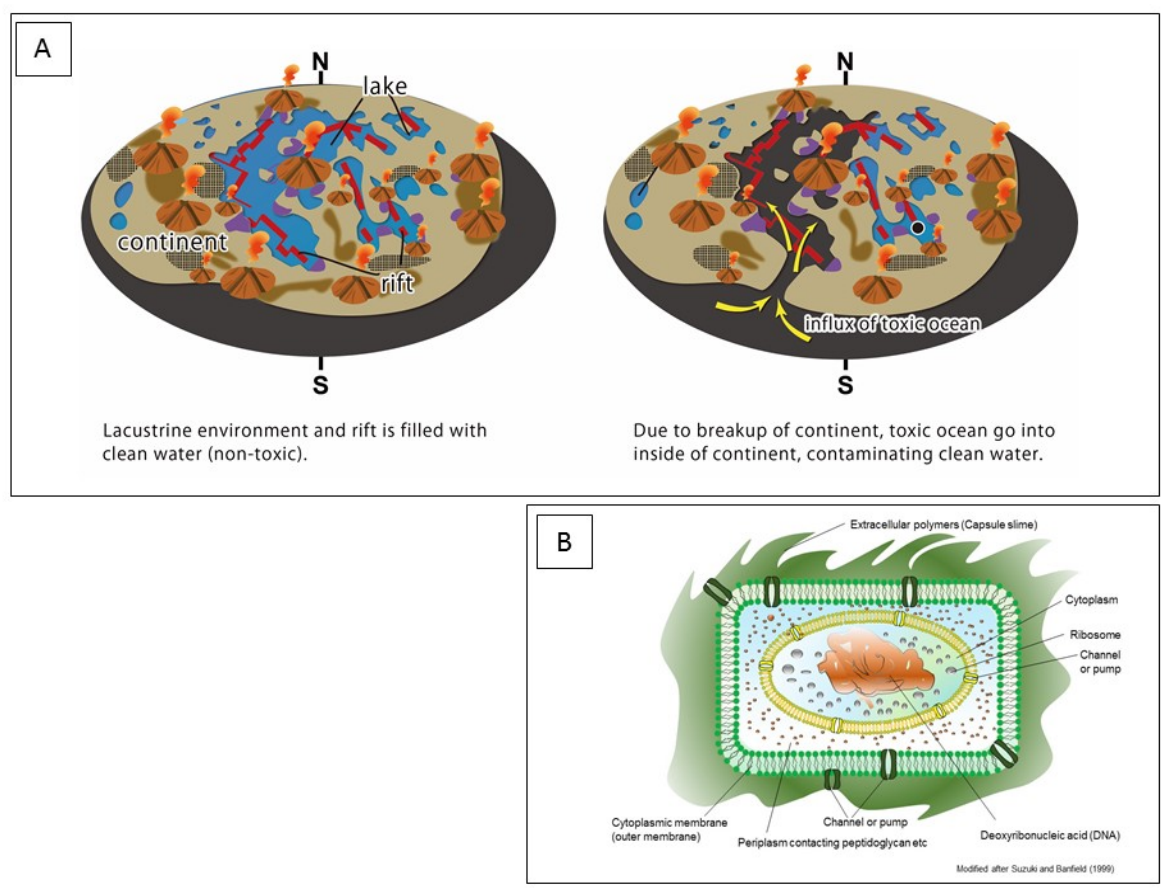

Fig 34 (Top)Drastic environmental change from clean water in lake (left) to influx of toxic ocean by continental rifting of primordial supercontinent. Invasion of toxic ocean caused mass extinction, and biological response must have occurred during the severe survival time until death. (Bottom) A schematic sketch of prokaryotes (modified after [65]). Note there are the three barriers for DNA by cell wall, outer lipid bi-layer membrane, and inner membrane. Also at least two kinds of aquaporins connected with cell wall holes. Numbers of ribosomes (protein factory) which is responsible for production of individual functional proteins surrounding DNA control tower. 


\subsubsection{Biological response from Step 2 to Step 3}

As a result of time-consuming adaptive evolution, second proto-life evolved into more robust life to survive this environment. One of the biggest change is assumed to be the formation of cell wall, which could wrap their body by strong cell wall to resist toxic ocean, and also encapsulated necessary functions (metabolism and self-replication) within it. Such membrane also should have developed the pump function, especially for sodium $(\mathrm{Na})$. $\mathrm{Na}$ is less contained in continental rock minerals, but abundant in ocean as $\mathrm{NaCl}$. Too much $\mathrm{Na}$ is poisonous for life function, as proto-life was born in the environment with less $\mathrm{Na}$, so $\mathrm{Na}$ pump is assumed to be completed in this period.

At the same time, third proto-life needs to control membrane and metabolism within one cell, which means ectosymbiont cannot work to survive anymore. This is why genetic code was well developed in this third stage, and endosymbiont appeared to enable the shift from RNA world to more sophisticated DNA world.

This is the appearance of third stage proto-life, presumably by $4.1 \mathrm{Ga}$. And this is presumably first prokaryote, being with the right conditions for three definitions; (1) membrane, (2) metabolism, and (3) self-replication. Probably, this first life, e.g. our oldest ancestor, have incidentally had 20 kinds of amino acids to form their body, which is still remaining in modern life forms including human being.

After the appearance of third proto-life, primordial continent was broken and carried into deep mantle due to tectonic erosion driven by plate tectonics. After huge continent as the mother of life was lost, landmass to supply nutrients is limited to small island arcs. So, third protolife must live in difficult time. However, toxic ocean had been gradually cleaned up through water rock interaction associated with a series of process; weathering, erosion, and transportation, which continuously progressed since the formation of ocean. By around 4.0Ga, $\mathrm{pH}$ of ocean was expected to turn to almost neutral and heavy metals dissolved in ocean was removed from seawater to be metallic ore at the bottom of ocean (Fig 35). This situation is backed in evidence by the presence of carbonate rocks formed on the 3.8Ga seafloor in Isua, Greenland [66], and 4.03.9Ga rocks from Labrador in Canada [67]. On the other hand, salinity of ocean was still high, ca. more than 5 times of present salinity until 635Ma [68]. Therefore, it was risky for third proto-life to invade into ocean, however, it was possible to live around brackish-water regions near the river mouth.

Fig. 36 provides a brief summary of the evolution of proto-life as a response of rapid environmental change twice after the birth first stage of ectosymbionts in underground cave. The first stage is dominated by metabolism with semi-permeable membrane helped by ribozyme, followed by source energy change from nuclear reactor to the Sun, hence associated with extensive membrane evolution at second stage, but still ectosymbionts in bio-films. The third stage is the completion of prokaryotes as strongly protected cell life from the surrounding toxic ocean. Also noted that the first-stage proto-life has continuously been transported to the surface by geyser system to help survival of Earth’ s life until 2.2Ga at least. 


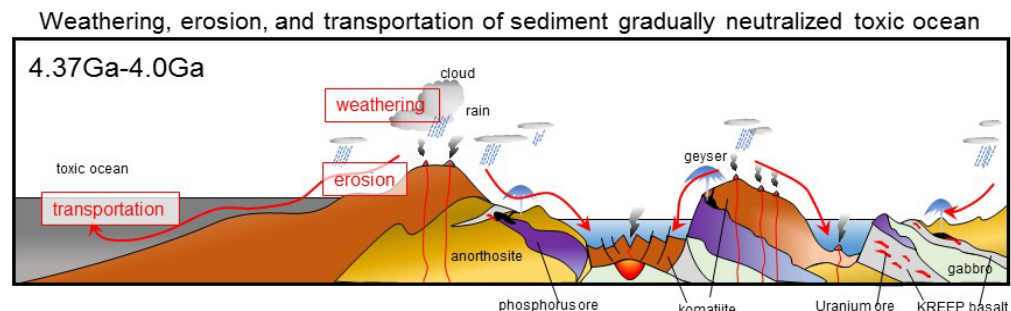

Highly acidic ocean was neutralized by around $4.0 \mathrm{Ga}$

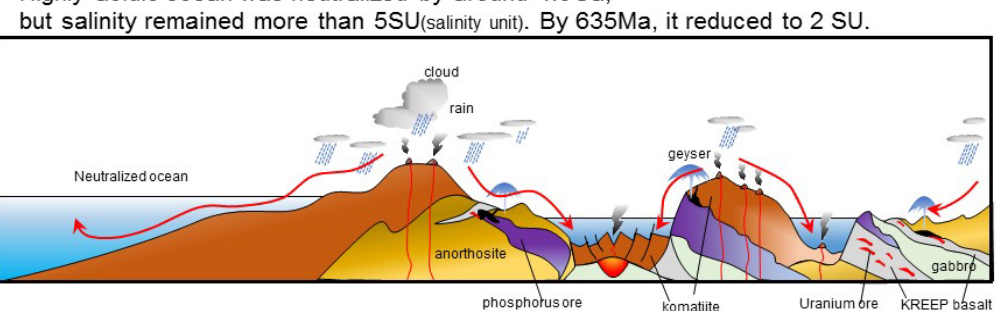

Fig 35 Cleanup of the toxic primordial ocean through time. The Hadean ocean was toxic to life (ultra-high acidity, more than 5 times modern salinity, and enrichment in heavy metals). Water rock interactions associated with a series of process; and weathering, erosion, and transportation, continuously progressed following the formation of ocean. By around 4.0Ga, the $\mathrm{pH}$ of ocean probably became almost neutral and the heavy metals that were initially dissolved in the ocean water were removed form metallic ores at the ocean. However, salinity remained higher until about 635Ma.
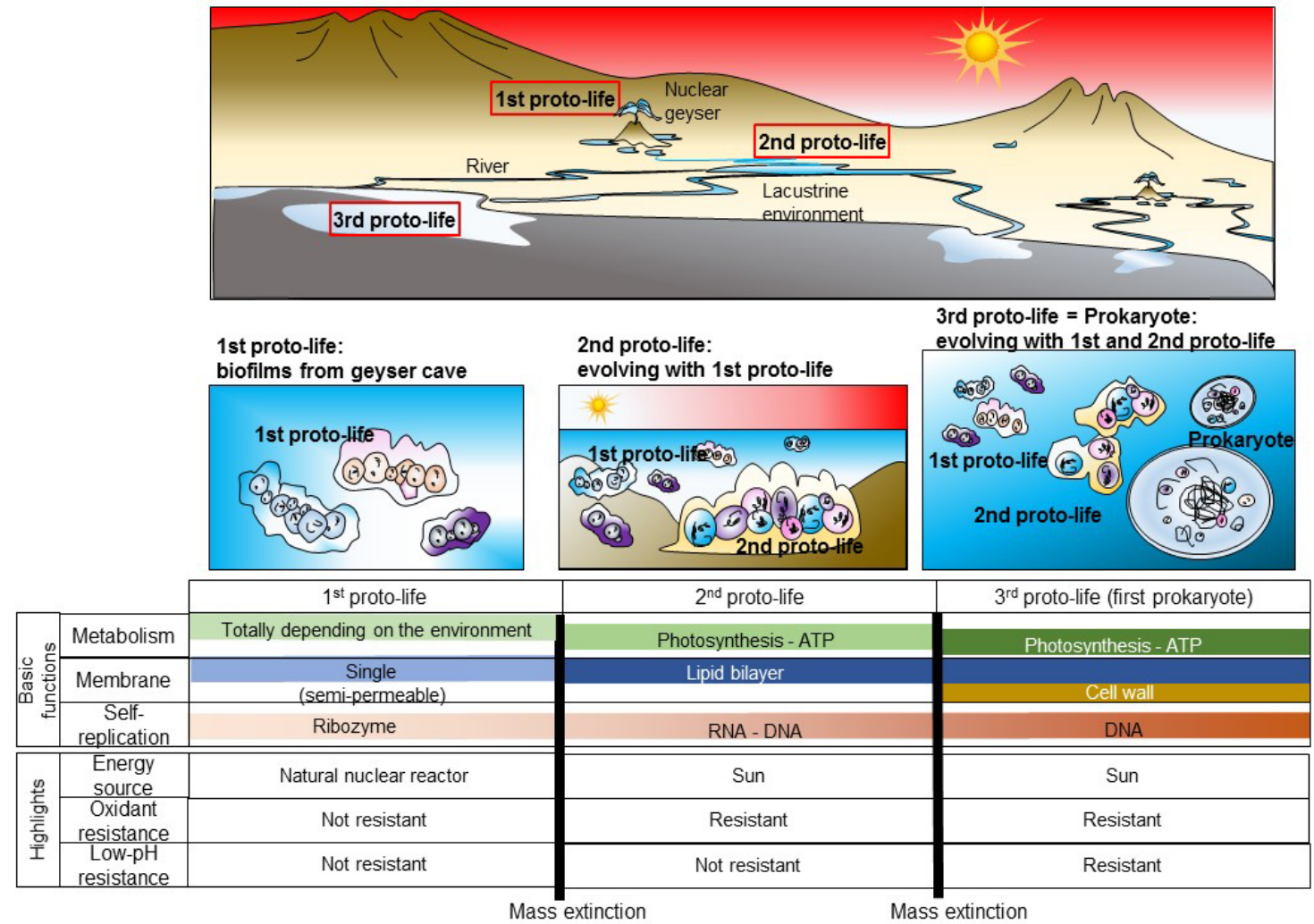

Fig 36. A summary of three-step evolution of proto-life on the Earth. The evolution of protolife is a response toward rapid environmental changes, which occurred twice after the birth of first proto-life, which probably lived as ectosymbionts in an underground cave. The first stage was dominated by metabolism with a semi-permeable membrane, helped by ribozymes. 
This was followed by the environmental change to the second stage, which was the change in source energy from a nuclear reactor to the Sun. This produced more extensive membrane evolution, but these still maintained the form of ectosymbiotic bio-films. The third stage was the appearance of prokaryotes, which strongly protected cellular life from the surrounding toxic ocean. This three-step proto-life evolution was enabled by a continuous supply of BBLs and proto-life by nuclear geyser system.

\section{Evolution of the Earth's life}

The research for the origin and evolution of life is typical interdisciplinary science, requiring the combination of biology, geology, planetary science, paleontology, molecular biology and many other research fields. To understand and summarize complex earth's life history, we should focus rather more important events in the history that are extracted from miscellaneous events. So, which events can be the representative events of earth's history.

\subsection{The biggest 20 Events in the Earth History}

Fig 37 shows 20 biggest events through earth's history. The criterion to extract those events is that the event is single and unique phenomenon to become a turning point for the earth's history. Therefore, repeating events should not be extracted, such as the formation of supercontinent through amalgamation and dispersion of continent. The collision of continent such as Indian continent against Asia to form Himalayan mountain belt at 50Ma is local and not global event, hence such an event is not listed up as one of the biggest events.

Event 1 (4.56Ga) is the formation of the solar system, as the initial event to lead to the birth of the earth. Event 2 (4.56Ga within 1 million years after the appearance of proto-planetary disc) is the birth of the Earth to start earth's history. Event 3 (4.37-4.20Ga) is the formation of atmosphere and ocean by ABEL Bombardment, which enabled the earth to be a habitable planet. Event 4 (4.20Ga) is the appearance of strong geo-magnetosphere, which protect birthplace of primordial life from super-flare of young violent Sun. Event 5 (4.20-4.10Ga) is the emergence of first life, which is the beginning of life's history. Event 6 (4.0Ga) is the loss of primordial continent, which means the loss of "mother of earth's life" that had supplied nutrients to life. Event 7 (4.10-3.5Ga) is the birth of $\mathrm{O}_{2}$ producing cyanobacteria, which is another important event to make life evolve to more complex life. Event 8 (2.7Ga) is the mantle overturn, which could be one of the critical situation to turn to be Venus state. Event 9 (2.4-2.2Ga) is the appearance of snowball earth, which is caused by starburst. Event 9 (2.2Ga) is the birth of Eukaryote, leading to the emergence of multicellular life. Event 10 (700-600Ma) is the drastic change in the surface environment due to combination of (1) decrease of geo-magnetic intensity due to change from bipolar to quasi-quadrupole, (2) the increase in the landmass, (3) return flow of seawater into mantle. The combination of three different environmental factors changed the earth's surface environment drastically, and life had to evolve to adapt it. Event 11 (635-542Ma) is the birth of the Ediacaran fauna and flora and its mass extinction. The appearance of Ediacaran fauna and flora is critical as the evolution of life. Event 12 (540Ma) is the Cambrian explosion, which is well known that presently existing 35 phyla appeared. Event 13 (250Ma) is the mass extinction of Paleozoic organisms, one of the biggest mass extinction in Phanerozoic time to enable further 
evolution of life. Event 14 (7Ma) the birth of human being at African Rift Valley, leading to the formulation of civilized society. Event 15 (in 200 years future) is the birth of self-replicating artificial life, that will be able to explore the universe through space and time. Event 16 (in 400 million years) is the death of $\mathrm{C} 4$ plant due to low $\mathrm{CO}_{2}$ content less than $40 \mathrm{ppm}$, which will affect animal. Event 17 (in 1 billion years) is the termination of plate tectonics, making the Earth as Venus state, resulting in the termination of all life. Event 18 (in 1 billion years) is the loss of ocean as the result of Venus state. Event 19 (in 5 billion years) is the collision between the Milly Way Galaxy and Andromeda Galaxy. Event 20 (in 8 billion years) is disappearance of the Earth, the end of the earth's history.

From the biological perspective, more significant key events are from Event 9 to Event 13, including the expansion of body size by 1 million times to evolve into eukaryote, metazoan and plant. These events are closely related to the drastic environmental changes, represented by the snowball earth, driven by starburst in the universe. Snowball earth is somehow misunderstood as the event of cold period continuing over 200 million years. However, geological evidences do not indicate Snowball period is long-continued glacier period, rather caused intense fluctuation in surface temperature from frozen level to extremely hot level. In frozen period, oxygen producing photosynthesis is severely damaged, resulting in the reduction of atmospheric oxygen down to Archean level which caused mass extinction of life requiring oxygen.

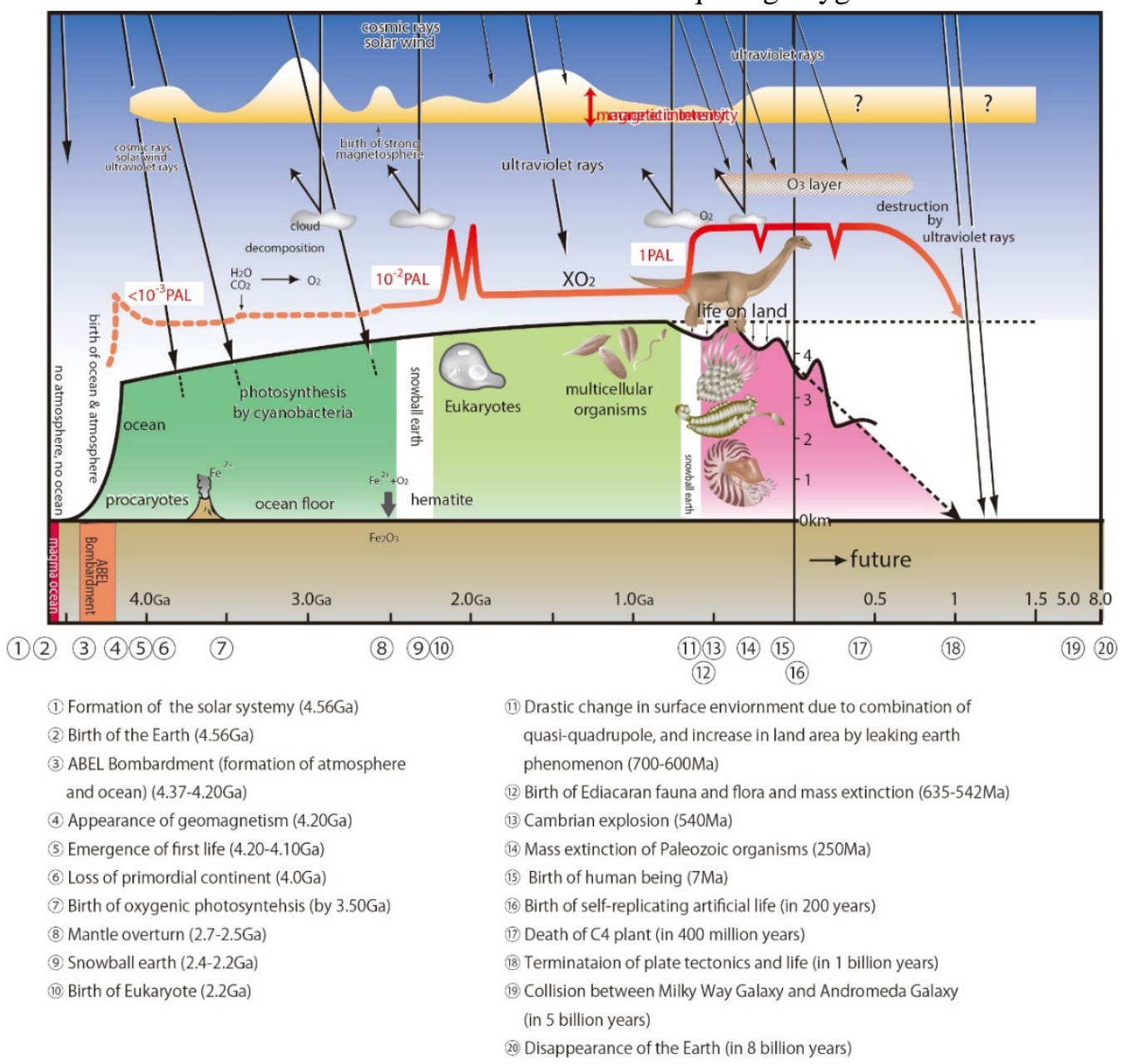

Fig 37. 20 biggest events of the earth’s history. 


\subsection{The proposal of Humanozoic Eon}

After the birth of life in middle-late Hadean time, two revolutional changes occurred in life's history, e.g. (1) at 2.3-2.0Ga, $1 \mu \mathrm{m}$ prokaryote evolves to $1 \mathrm{~mm}$ eukaryote, and (2) at 0.80.5Ga, eukaryote evolves to $1 \mathrm{~m}$ metazoan and plant [69]. Through these two periods, size of living organism became one million times larger than before (Fig. 38). Then, at 7Ma, human being finally appeared.

Human being is one of species of primate, and closely related to monkey, biologically. Yet, the development of human is surprisingly remarkable and extremely faster than other biological evolution, except the periods of punctuated equilibria at 2.3-2.0Ga and 0.8-0.5Ga since the birth of life at 4.0Ga. Hence, the birth of human being at $7 \mathrm{Ma}$ could be evaluated to be outstanding evolutionary event. In addition, the development of human brain is more significant in biological evolution. Humans had the ability to produce many different tools to create other tools, and spread to all over the world within short period after the emergence. And now human is able to involve in even space exploration. Human being is essentially standing out for the development of brain. Therefore, we propose the new eon to emphasize the appearance of human being (and brain). We propose the Humanozoic Eon by redefining geological time, particularly the Quaternary period, and regards the Humanozoic Eon as well as Hadean, Archean, Proterozoic, and Phanerozoic Eon.

Beyond the concept of traditional geological time table, the development of human brain is significant. Revolutional development was initiated by utilization of $\mathrm{Ca}^{2+}$ ion within a cell to transmit information, and connected to further development of neuron, vertebrate, eye, and brain. Such evolutionary development could be a turning point to the age of artificial intelligence, i.e., self-replicating robot in near future. It may be the time of the end of the Humanozoic Eon.

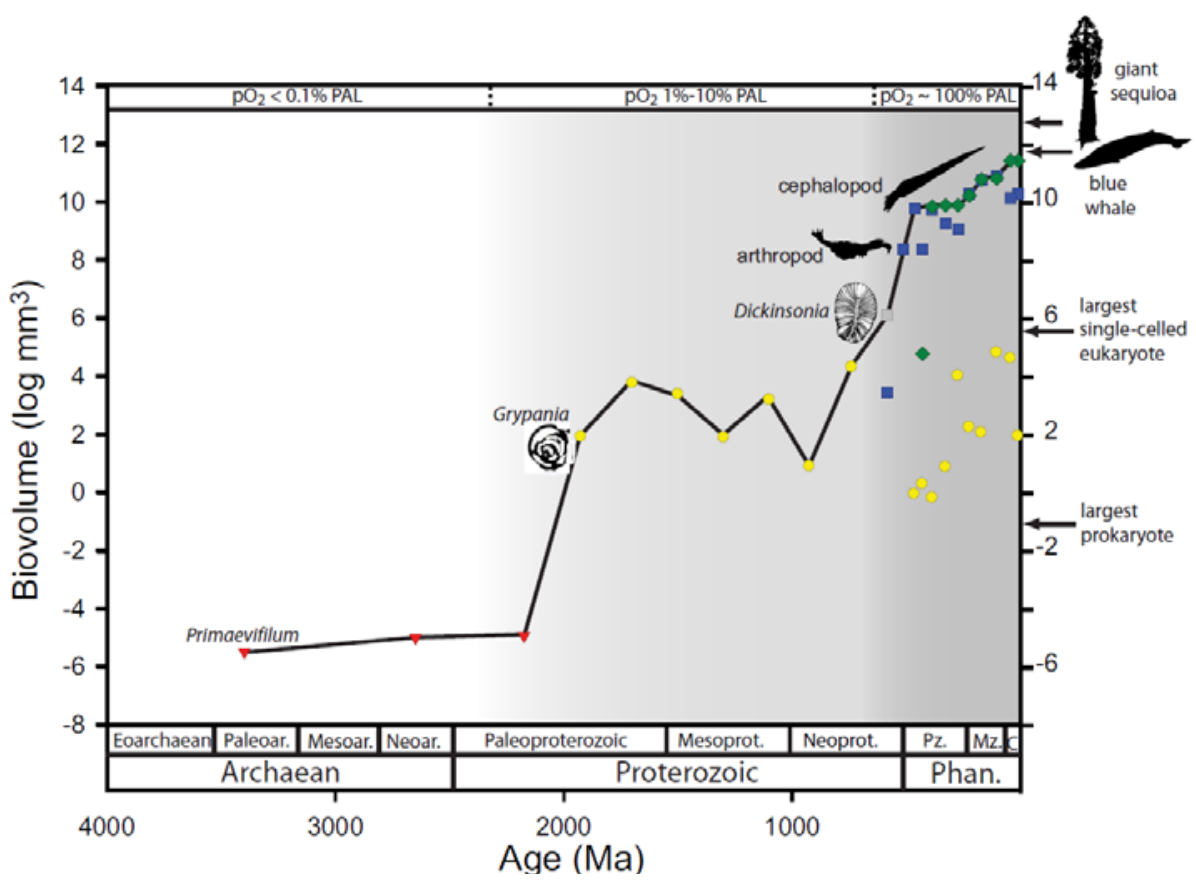

Fig. 38 Life history through time based on fossil records of life [69]. Size of living organism drastically changed with two steps. First change (2.3-2.0Ga) is from prokaryotes to eukaryote, 
and second change (0.8-0.5Ga) is from eukaryote to large multicellular life such as metazoans, fungi, plants, with respect to fossils. Each change caused the expansion of volume one million times. Both periods correspond to the increase in oxygen level as shown on the top of column, $\mathrm{O}_{2}<0.1 \mathrm{PAL}$ in the Archean, 1-10\% PAL in the Proterozoic, and 1PAL in the Phanerozoic.

\subsection{Accelerated Evolution of life through time}

Late professor Motoo Kimura is a Japanese molecular biologist, who introduced the neutral theory of molecular evolution. Including him, molecular biologists has been investigating the biological evolution based on laboratory experiments of mutation. According to their experimental result, life's evolution from primordial life to human being would spend over 15 billion years (15Gyr), which is longer than the cosmic age (13.8 Gyr). Earth's life evolved from $1 \mu \mathrm{m}$ across microorganism up to human being within 4.0 billion years ( $4 \mathrm{Gyr}$ ). Hence, evolutional speed is about 4 times faster than simple estimation by molecular biologists. What caused the speed up of the mutation rate?

Mutation-driven drastic evolution has been well recorded as fossils through Earth's history, specifically, the emergence of eukaryote at ca. 2.0Ga, and that of metazoan and plant at Cambrian time at $0.54 \mathrm{Ga}$ (Fig. 38). It should be pointed out that remarkable environmental fluctuation occurred right before the emergence of new organism (Fig. 37, Fig. 38). Such anomalous environmental change has been called "Snowball Earth [37][38]", and people thought the correlation between snowball earth state and acceleration of life's evolution.

Snowball earth is characterized by glaciers covering even equatorial regions which was well documented by paleo-magnetic measurements. Most people have imagined that entire earth was covered by glacier during snowball earth period continuing for a few hundred millions of years, however, it is not right according to geological records. Snowball period includes intense fluctuation in temperature between hot period and frozen period with several times, and as a whole of snowball period, warm periods dominate rather than glacial periods. Traditionally, researchers interpreted the decrease in atmospheric $\mathrm{CO}_{2}$ caused snowball state, and the earth reverted to normal state due to greenhouse gas effect of $\mathrm{CO}_{2}$ once $p \mathrm{CO}_{2}$ re-increased. They thought decrease and increase of $p \mathrm{CO}_{2}$ is driven by mantle dynamics and plate tectonics. However, as seen in the case of Marinoan snowball period, the length of Marinoan is only a few million years. It is impossible to explain the mechanism to decrease and increase $p \mathrm{CO}_{2}$ by plate tectonics, because plate motion speed is $10 \mathrm{~cm} /$ year at largest $(100 \mathrm{~km} / 1$ million year), which is too short to make $\mathrm{CO}_{2}$ circulated between atmosphere and mantle through plate tectonics. It means the change in $p \mathrm{CO}_{2}$, expected as the cause of snowball state, has no relation to plate movement.

Alternatively, starburst could be the best to explain the snowball event, which is caused by the collision between dwarf galaxy and the Milky Way Galaxy, considering chronological coincidence between them (Fig. 39)[70][71]. Age frequency distribution of star formation through universal history indicates the peak of star formation at 4.5-4.0Ga, 2.3Ga, and 0.8-0.6Ga (see a summary by [71][72]). The cause-and-effect of cold-warm climate fluctuation could be ideally explained by the radiation of galactic cosmic ray (GCR) which is 1,000 times stronger than radiation in normal period.

Snowball earth caused by extensive radiation could also explain global mass extinction, which should have affected the production of free oxygen by photosynthesis. When global mass 
extinction occurred, oxygen producing photosynthetic bacteria became extinct, resulting in the decrease of $\mathrm{pO}_{2}$. After snowball state was over, photosynthetic bacteria came back first, followed by re-establishment of new ecosystem under recovered $\mathrm{pO}_{2}$ without glaciers.

Through the repetition of up-down of $\mathrm{pO}_{2}$ during snowball event, new genes must have been prepared within genes of older type of organism which was available in anoxic conditions. Those organisms remained in subsurface environment during high $\mathrm{pO}_{2}$ period, however, they could return to the surface environment during snowball state due to extreme reduction in $\mathrm{pO}_{2}$. Then they evolved to adjust themselves to new environment with more oxidized condition $\left(10^{2}\right.$ $10^{3}$ times more than before in terms of PAL) (Fig. 38). We think an ultimate cause of acceleration of life's evolution could be the starburst in the Universe.

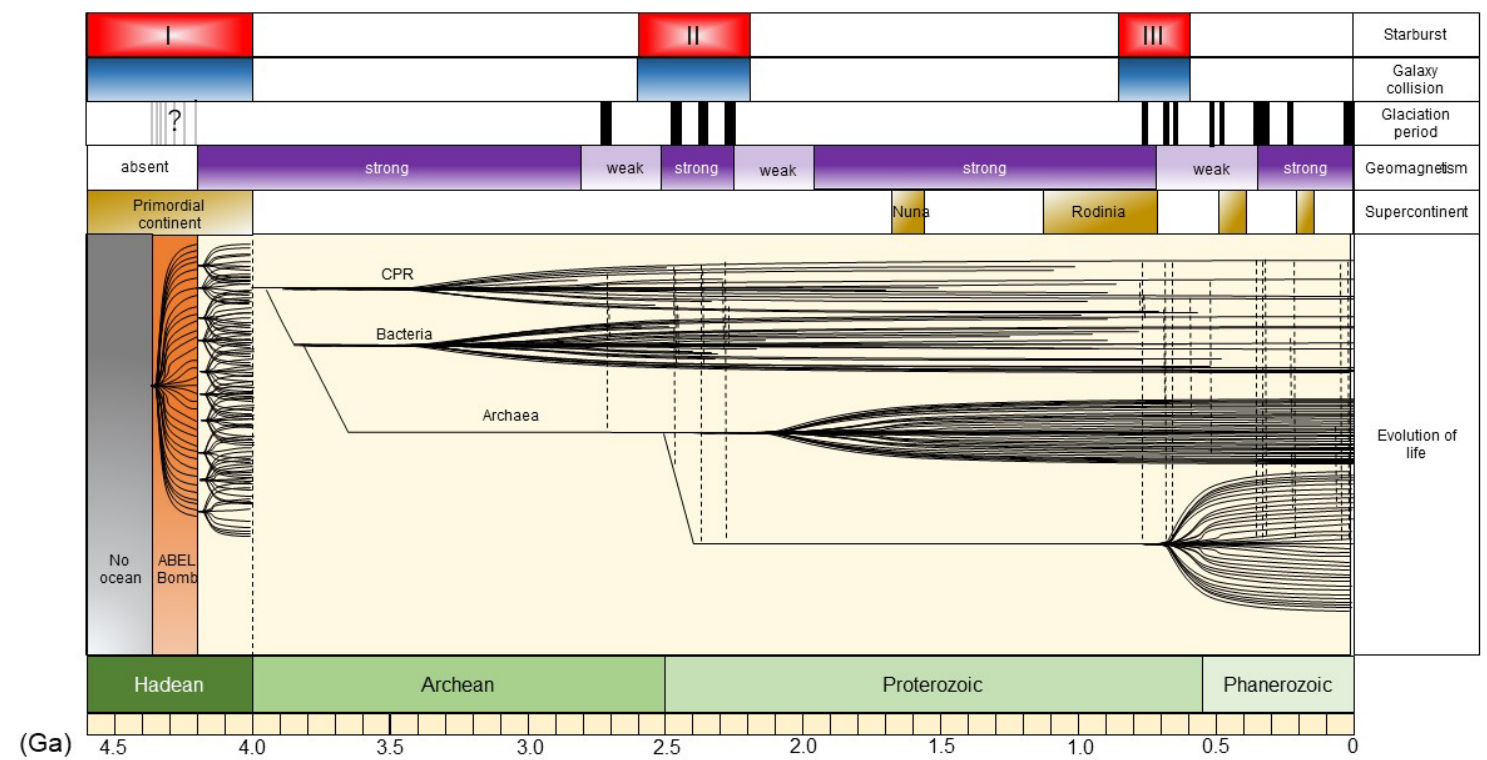

Fig. 39. The relationship between starburst, snowball earth, and evolution of life. Punctuated equilibria for the evolving life on the Earth could be the result of starburst in the universe. Starburst events are shown on the top of the column, which occurred at 4.6-4.0Ga. 2.7-2.2Ga, and 0.8-0.5Ga. Evolution of life is schematically illustrated as tree of life, (1) birth of life with extensive mass extinction in the middle-late Hadean, (2) birth of eukaryote at 2.0Ga right after the snowball event over 200-300 Myr long, and (3) birth of metazoans and plant during 0.8-0.5Ga before the Cambrian explosion of life. Note the time-correspondence of starburst and snowball events, which may have caused the explosive evolution of life by radiation-induced mass extinction. Increased poisonous oxygen selectively injured the G(guanine), one of nucleobases. This may suggest the uni-directional evolution of terrestrial life and refuse accidental evolution for the final emergence of our human being.

\section{Toward the establishment of Astrobiology}

Astrobiology is one of the new research fields to investigate how life begin and evolve in the universe. However, we have never ever known other life than earth's life. Therefore, to develop Astrobiology, our knowledge completely depends on whether we understand earth's life. For deep understanding, it is important for us to know the universality and specialty of earth's life. Based 
on such information, we will be able to further consider what is universal life including the origin and evolution.

For example, the universality of earth's life is that main constituent elements are $\mathrm{C}, \mathrm{H}, \mathrm{O}$, and $\mathrm{N}$. This is common for all types of life on earth. How about universal life? A few decades ago, Carl Sagan and some other scientists discussed the possibility of life utilizing silicon ( $\mathrm{Si}$ ), instead of carbon (C). They thought Si can replace $\mathrm{C}$ because $\mathrm{Si}$ and $\mathrm{C}$ belong to the same group in the periodic table. However, their idea was denied. In the stability field of liquid water (in the case of earth, $0-100^{\circ} \mathrm{C}$ under $1 \mathrm{bar}$ ), the kind of chemical compounds centering on silicon is less than 100. In addition, minerals and organic compounds cannot form compounds using carbon and silicon in arbitrary proportion. Therefore, silicon cannot be the centre of organic compounds, indicating no possibility of life consisting of $\mathrm{Si}, \mathrm{H}, \mathrm{O}$, and $\mathrm{N}$. This is the universality of life in the universe.

Clues to understand how planet evolves to be habitable come from the earth's history. Therefore, the understanding of how the earth formed under which conditions, how the surface environment evolved, is a key to unravel the history to be or evolve to a habitable planet. Fig 40 shows the 43 conditions to become a habitable planet, which are categorized to four groups. First group lists up planetary requirements to be life emerging planet, Second group shows nine requirements for the birth place (discussed details in section 4), Third group shows requirements to keep planetary condition to be life-sustaining, and Forth group is requirements to evolve into planet with civilization. In following part, we briefly introduce each requirement.

\section{Conditions to evolve to a habitable planet}

\begin{tabular}{|c|c|}
\hline \multicolumn{2}{|c|}{$\begin{array}{l}\text { 1st Group: Planetary requirements to be life } \\
\text { emerging planet }\end{array}$} \\
\hline 1) & Chemical composition of central star \\
\hline 2) & Mass of central star \\
\hline 3) & Circular orbit \\
\hline 4) & $\begin{array}{l}\text { Birth of gas giants (supplier of asteroids and } \\
\text { guardian from comets) }\end{array}$ \\
\hline 5) & Mass of planet (between Mars and super-earth) \\
\hline 6) & Appearance of satellite \\
\hline 7) & Inclination of rotational axis \\
\hline 8) & Birth of rocky planet \\
\hline 9) & Existence of $\mathrm{Fe}_{3} \mathrm{P}$ \\
\hline 10) & Within liquid water zone \\
\hline 11) & Secondary accretion of life component \\
\hline 12) & $\begin{array}{l}\text { Formation of bimodal lithosphere to initiate } \\
\text { plate tectonics }\end{array}$ \\
\hline 13) & $\begin{array}{l}\text { Initial mass of ocean to expose landmass to } \\
\text { supply nutrient and to operate plate tectonics }\end{array}$ \\
\hline 14) & Cleansing of ocean \\
\hline 15) & Initial volume of life constituent elements \\
\hline 16) & Balance of organic and $\mathrm{H}_{2} \mathrm{O}$ \\
\hline 17) & $\begin{array}{l}\text { Long-term existence of huge primordial } \\
\text { continent }\end{array}$ \\
\hline 18) & Removal of atmospheric $\mathrm{CO}_{2}$ \\
\hline 19) & Appearance of magnetosphere \\
\hline
\end{tabular}

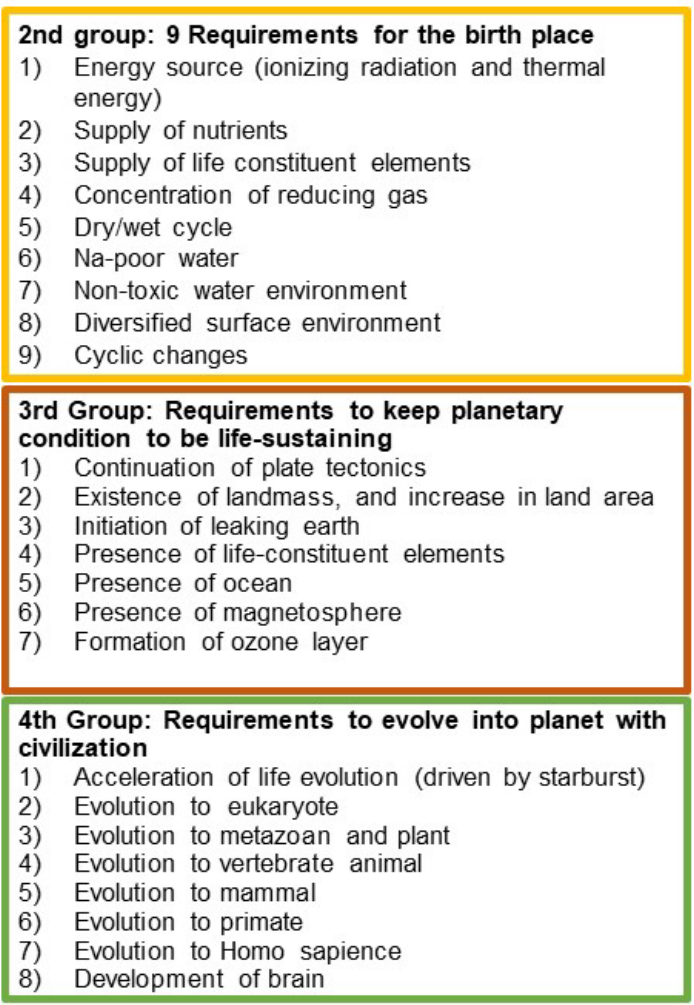

Fig 40 Conditions to evolve to a habitable planet. There are four groups to become a planet with civilization. First group picks up planetary requirements to be life emerging planet. Second group 
is nine requirements for the birth place of life on the planet (stated in section 4). Third group includes requirements to keep planetary condition to be life-sustaining, and Forth group lists up requirements to evolve into planet with civilization. This is working hypothesis to go forward to establish Astrobiology.

\subsection{First group: Planetary requirements to be life emerging planet}

\subsubsection{Chemical composition of central star}

According to the observational facts of exoplanets and central stars, there is great diversity of chemical composition of stars, which controls the chemical composition of planets. For example, if the ratio $\mathrm{C} / \mathrm{O}$ of central star is bigger than 0.8 , planets cannot have water due to insufficient amount of oxygen. In that case, carbon planet appears. In other words, chemical composition of central star determines whether a planet has water or not.

\subsubsection{Mass of central star}

Central starts are categorized into F-type ( $\left.>2 \mathrm{M}_{\mathrm{E}}\right)$, G-type (1.0 $\left.\mathrm{M}_{\mathrm{E}}\right)$, K-type $\left(0.8 \mathrm{M}_{\mathrm{E}}\right)$, and $\mathrm{M}$ type $\left(0.2-0.3 \mathrm{M}_{\mathrm{E}}\right)$, based on the mass with the comparison against solar mass. F-type stars evolve fast with nucleosynthesis from hydrogen to elements of higher atomic numbers over time. In 10 million years after its formation, F-type star undergoes a supernova explosion to release heavy elements in the universe, and neutron star remains. G-type star (the Sun) does not synthesize elements heavier than Fe in its center, and not undergo a supernova explosion. In the final stage, star evolves into white dwarf. K-type or M-type star do not have nuclear fusion reactions since its formation.

If the mass of central star is large like F-type stars, lifetime of central star becomes shorter in proportion to the size, indicating there is insufficient time for life to evolve on a planet, even if life is born. In addition, if the mass is larger, the mass of rocky planet tends to be larger as well. If so, a planet (Super-Earth) has long magma ocean period due to greenhouse effect of thick atmosphere, suggesting less possibility to have water on its surface.

If the mass of central star is smaller, electromagnetic ray, wind of central star, and energy irradiation are weak. Therefore, too much volatiles are captured by a planet, resulting in failure to be a habitable planet.

\subsubsection{Circular orbit}

If a planet has a circular orbit, fluctuation of surface temperature of a planet is not large during the revolution. If a planet in an elliptical orbit, temperature difference between summer and winter becomes larger, suggesting the difficulties for life to survive. In other words, a planet with a circular orbit has more possibility to become habitable.

\subsubsection{Birth of gas giants (supplier of asteroids and guardian from comets)}

Gas giants has an important role to supply icy asteroids to inner rocky planets by gravitational scattering. Without gas giants, there is no mechanism to supply volatiles to inner 
planets, resulting in the failure to create habitable planets. At the same time, gas giants protect inner planets from invasion of comets from outer solar system. If gas giants did not guard, inner rocky planets would be covered by too much water, which also foil the creation of habitable planet. Collision between the earth and comets is potential events even on present earth. Good example is the comet Shoemaker-Levy 9, which collided with the Jupiter in 1994. The source of large comets is the Kuiper belt or further region.

\subsubsection{Mass of planet (between Mars and super-Earth)}

The size of planet is critical for the evolution of planet. If the mass is small like Mercury and Mars, volcanic activity cannot continue longer because the planet cools down faster. As a result, material circulation stops in early stage of planetary evolution. On the other hand, if the mass is too large, more volatiles (atmospheric and oceanic components) are captured to cause greenhouse effect, resulting in failure to have ocean on the planet.

\subsubsection{Appearance of satellite}

Satellite can produce tidal force, which generate dry/wet cycle on the surface of the planet if there is landmass and ocean.

\subsubsection{Inclination of rotational axis}

Inclination of rotational axis produces four seasons on a planet, which make the change in temperature more moderate. If there is no inclination of rotational axis, there is no season. Equatorial regions are always heated while polar region is always frozen, causing large difference in temperature between north and south

\subsubsection{Birth of rocky planet (first step of "Two-step formation”)}

To evolve into a habitable planet, planet must be born without atmosphere or ocean, as discussed in ABEL model. Reductive planet can have phosphorus that is not combined with oxygen. Such reductive environment makes it possible to promote chemical reaction leading to first metabolism through ABEL Bombardment (secondary accretion of icy asteroids as listed in 6-1-11.

\subsubsection{Existence of Fe3P (schreibersite)}

The presence of phosphorus is critical to enable life's activity as represented by metabolism. Phosphorus is accumulated in the continental crust through the solidification of magma ocean of the planet. However, to utilize phosphorus for life, phosphorus must be kept under reducing environment at the initial stage. If phosphorus is present with volatiles (under oxidizing environment) from the initial stage, phosphorus does not react with other material anymore. If phosphorus was present under reducing environment, then liquid water is supplied, it produces struvite $\left(\mathrm{NH}_{4} \mathrm{MgPO}_{4}-6 \mathrm{H}_{2}\right)$, and phosphate compound is precipitate. 


\subsubsection{Within liquid water zone}

The distance from the central star is critical to have liquid water on the planetary surface. To have liquid water, its surface temperature must be between 0 to $100^{\circ} \mathrm{C}$, and the planet must locate at such distance.

\subsubsection{Secondary accretion of life component (second step of “Two-step formation”)}

Accretion of life constituent elements by icy asteroids is very significant event to create habitable planet. Without secondary accretion of these elements, life never emerge on the planet.

\subsubsection{Formation of bimodal lithosphere to initiate plate tectonics}

It is expected stagnant lid tectonics is operated after the formation of planet and before bombardment of icy asteroids. Even if the planet is bombarded by asteroids, if bimodal lithosphere (oceanic plate and continental plate) did not appear, plate tectonics does not start. To form bimodal lithosphere, huge asteroid needs to bombard the planet to destroy stagnant lid on the planetary surface.

\subsubsection{Initial mass of ocean to expose landmass to supply nutrient and to operate plate tectonics}

When the initial mass of ocean is converted to the thickness of ocean, it must be $4 \pm 1 \mathrm{~km}$ (approximately $0.02 \mathrm{wt} \%$ of the mass of earth) in the case of earth. If the thickness is over this value, the land cannot be exposed to supply necessary nutrients for life. if the thickness is less than this value, plate tectonics cannot begin.

\subsubsection{Cleansing of ocean}

Primordial ocean is too toxic because metallic elements of carbonaceous chondrite are dissolved. Chemical composition of primordial ocean is thought to be extreme high $\mathrm{pH}(\mathrm{pH}<0.1)$, enriched in heavy metals, and high saline (more than 8 times of present sea). So neutralization through water-rock interaction is necessary to make the planet habitable.

\subsubsection{Initial volume of life-constituent elements}

Major life constituent elements $\mathrm{C}, \mathrm{H}, \mathrm{O}$, and $\mathrm{N}$. To emerge life, adequate amount of these elements must be supplied. For example, initially given carbon amount of the earth is estimated equivalent to about 400 bars $\mathrm{CO}_{2}$. If this amount was half, it is assumed that earth's life ended 2 billion years ago. The same thing is applied to $\mathrm{H}, \mathrm{O}$, and $\mathrm{N}$.

\subsubsection{Balance of organics and $\mathrm{H}_{2} \mathrm{O}$}

Total chemical composition of supplied icy asteroids determine the balance of life constituent elements. If too much carbon is given, extra carbon remains in atmosphere to make a planet Venus state, resulting in the failure in making habitable planet. 


\subsubsection{Long term existence of huge primordial continent}

Continent (landmass) supplies necessary nutrients for life through the process of weathering, erosion, and transportation, driven by the Sun through climate system. If nutrients were not supplied, life could not emerge. It means the exposure of landmass is critical for life. At the same time, exposure of continent must be maintained long time to support life's emergence and evolution. Also, huge sized continent is a key to sustain long time.

Through the interaction between fine grained mineral with larger surface area and liquid water, elements of mineral dissolve in water as the form of ion, which can be effectively utilized by life. This interaction depends on the surface area of mineral, so grain refining of mineral is key. In other words, water-rock interaction between seawater and ocean floor is not effective like the process of weathering, erosion, and transportation by climate system.

\subsubsection{Removal of atmospheric $\mathrm{CO}_{2}$ into mantle}

Carbon in the atmosphere is the cause of greenhouse gas effect, leading a planet to Venus state. Therefore, removal of carbon is a key to maintain planetary habitability. $\mathrm{CO}_{2}$ can be fixed to rock as the form of carbonate rock, which can be carried into mantle through tectonic erosion along subduction zone. Total amount of atmospheric $\mathrm{CO}_{2}$ must be less than 5bar through the earth history, otherwise the planet turns to Venus state due to greenhouse gas effect.

\subsubsection{Appearance of magnetosphere}

The planetary surface is dangerous for life due to influx of high energy particles such as cosmic rays and UV. To protect surface environment from such dangerous factors, magnetosphere is necessary.

\subsection{Second group: Nine requirements for the birth place}

After planetary requirements are satisfied, there is a possibility to emerge life, however, birthplace have another nine requirements, that are discussed in details in section 4 . These requirements are 6.2.1 energy source (ionizing radiation + thermal energy), 6.2.2. supply of nutrients, 6.2.3 supply of major constituent elements CHON, 6.2.4 concentration of reducing gas, 6.2.5 dry/wet cycle, 6.2.6 Na-poor water, 6.2.7 non-toxic water environment, 6.2.8 diversified environments (ocean, $\mathrm{pH}$, salinity, heavy metals, atmosphere, temperature, pressure, continent, varied geology) and 6.2.9 cyclic change. For the details, see section 4 .

\subsection{Third group: Requirements to keep planetary condition to be life-sustaining}

Even if life is born on the planet, there are requirements to keep the habitability. Such planetary requirements are listed here in this group. Listed requirements are still part of working hypothesis and need modification and upgrade by discussions in detail. However, at least 7 requirements of planetary condition have to be satisfied to be life-sustaining planet. 


\subsubsection{Continuation of plate tectonics}

Plate tectonics plays an important role to keep steady-state surface environment of rocky planet. Therefore, continuation of plate tectonics is necessary requirement. To continue the operation of plate tectonics, the presence of appropriate amount of ocean is a key. For this condition, initial amounts of $\mathrm{H}_{2} \mathrm{O}$ and $\mathrm{CO}_{2}$ is important. If $\mathrm{H}_{2} \mathrm{O}$ is too short, the amount of ocean is less than requirement, and if $\mathrm{CO}_{2}$ is too much, ocean evaporates due to greenhouse gas effect. Particularly in the stage of mantle overturn, large amount of $\mathrm{CO}_{2}$ is released to atmosphere, which can turn the planet Venus-like. Plate tectonics can buffer $p \mathrm{CO}_{2}$.

\subsubsection{Existence of landmass, and increase in land area}

The existence of huge landmass is required in the First group, and also necessary in the Third group as well to be life-sustaining planet. This is because landmass is the supplier of nutrient for life, and also accumulate $\mathrm{pO} 2$ with time. Landmass contributes to increase free oxygen, because sediment bury organic matter to prevent their oxidation that results in accumulation of free oxygen. In other words, larger landmass can accumulate more free oxygen in atmosphere.

\subsubsection{Initiation of leaking earth}

It is the fate of surface water (ocean) to be transported into mantle with the cooling of the planet. Once the temperature of subduction zone gets below $650^{\circ} \mathrm{C}$, hydrated minerals become stable even in the mantle, therefore, surface water can be carried to inner earth as the form of hydrous mineral. This is the phenomenon of leaking earth [73]. If leaking earth begin, decrease in ocean amount causes huge landmass on the surface of the earth.

\subsubsection{Presence of life-constituent elements}

To sustain life, the supply of life-constituent elements is critically important. If the total amount of life-constituent elements is too small, lifetime of living organism on the planet would be short and cannot evolve to larger or more complicated one, e.g., if the Earth had had half of current life components at initial stage at 4.0Ga, we may have not emerged on the Earth. Instead, life may have been ended at ca. 2.0Ga.

\subsubsection{Presence of ocean}

For life, the presence of ocean is important anytime, because the existence of ocean make it possible to operate plate tectonics, and supply water (clean water without salt) for life through climate system. Lifetime of ocean depends on the size of planet, which is the fate of cooling planet. If planetary size is small like Mars, such planet cools down faster, and ocean disappear earlier because leaking phenomenon occur earlier than the case of larger size planet. Subduction of oceanic plate transports surface ocean water into deep mantle, which make dry planet at the end. 


\subsubsection{Presence of magnetosphere}

Birth of strong geomagnetism was necessary requirement on the surface of rocky planet when primordial life emerged on the planet. But the condition must have continued long time over 4.0Gyr. Mars has lost strong dynamo after $600 \mathrm{Myr}$ since Mars was born. Venus remains no strong dynamo.

\subsubsection{Formation of ozone layer}

Ozone layer cuts the short wavelength of light such as UV, which damages DNA of metazoans on landmass. To prevent such damages, ozone layer is necessary as well as magnetosphere. The birth of ozone layer depends on the content of free oxygen in atmosphere. To accumulate atmospheric free oxygen, it depends on the biomass of cyanobacteria and plant on the surface of continents and continental shelf, although the amount of autotroph may depend on ecosystem. Therefore, timing of appearance of ozone layer may not be simple as a function of increase in landmass.

\subsection{Forth group: Requirements to evolve into planet with civilization}

In Forth group, we list up biological requirements to evolve into planet with civilization. Main problem, derived from the concept of evolution, is a biological complexity, which is totally different from physical, chemical, and geological phenomenon. Biological factors are much more complex than other environmental factors. One of the most complex manner in biology is the ecosystem. Predator-prey ecological system is extremely complex, hence, accidental survival is in common. Outer forcing to ecosystem such as nearby supernova, GCR radiation by starburst may have extensively modified the evolutionary history through time. However, we cannot yet evaluate individual evolution scheme after mass extinction, i.e., reconstruction of new ecosystem with newly appeared evolving life. So listed requirements in this group are also imperfect and still working hypothesis. However, at least nine requirements could be listed.

\subsubsection{Acceleration of life evolution (driven by starburst)}

From the viewpoint of molecular biology, evolution from primordial life to human being needs $15 \mathrm{Gyr}$, however, only $4 \mathrm{Gyr}$ was spent to evolve to human being. It means the acceleration of life evolution occurs at some points in the evolutionary history. As explained in Section 5, mutation-driven drastic evolution has been well recorded as fossils through Earth's history, specifically, the emergence of eukaryote at ca. 2.0Ga, and that of metazoan and plant at Cambrian time at $0.54 \mathrm{Ga}$ (Fig. 38). It should be pointed out that remarkable environmental fluctuation occurred right before the emergence of new organism. Such anomalous environmental change has been called "Snowball Earth", and it is caused by starburst.

\subsubsection{Survival over 2 Gyr to evolve to eukaryote}

After the birth of primordial life in the middle-late Hadean, prokaryotes must survive at least 2 billion years, which remained no significant evolutionary event on the earth. However, this 
period seems to be very sensitive time in spite of no strong environmental damage. If huge asteroid bombarded the earth in this period to form a local magma pond, then all ecosystem may have been destroyed. To evolve to eukaryote, prokaryote must survive such events. Is it accidental or not? Why and how was prokaryote surviving such a long time? Those questions are still remained.

In addition, the evolution to eukaryote means the emergence of endosymbiotic life (intracellular symbiont in a large cell ca. $1 \mathrm{~mm}$ across) at 2.0Ga, which was explained by Lynn Margulis [74]. The genome-level synthesis or unravelling of this revolutionary mechanisms remains unsolved.

\subsubsection{Evolution to metazoan and plant}

At 2.0Ga, one of the biggest surprising evolution of life occurred, i.e., the birth of eukaryote. This revolutionary process still remains as a big puzzle, although increase in $p \mathrm{O}_{2}$ occurred and it becomes 2-3 order of magnitude higher than before. How many functions were necessary to make it possible for this evolution is largely unsolved yet.

\subsubsection{Evolution to vertebrate animal}

Increase of $\mathrm{pO}_{2}$ is poisonous for life, because oxygen attacks DNA, in particular, it selectively damages the base pair of guanine. During the snowball period from the Ediacaran to the end of the Cambrian time (635-485Ma), 8 times of mass extinction repeatedly occurred. Vertebrate emerged at 540Ma in the failed rift of South China craton with abundant supply of phosphorous ores, which was one of the largest P-ores over the world. Five distinct time intervals are recognized in this period, indicating environmental change proceeded in a small rifted continental margin, and the jungle law continued to lead the appearance of new ecosystem. As a result, multi-organisms' symbionts (large multicellular life living symbiotically with other various living organism as a single life, e.g. the most developed one is human) were born during Cambrian explosion.

\subsubsection{Evolution to mammal}

At the end of Paleozoic Era, the largest mass extinction occurred after Ordovician time when ca. $96 \%$ of large metazoans were killed. The mechanism of mass extinction is still controversial, but at least a consensus is present that the environmental change occurred under super-anoxia, Presumably the collision of solar system against dark cloud occurred this drastic environmental change. At first, an accidental decrease of $\mathrm{pO} 2$ caused extensive mass extinction. Right after the mass extinction, first mammal was emerged. The process toward the emergence of mammal should have been a survival race with adjustment to low- pO2 environment, and first mammal is assumed to appear with mouse size. The process to emerge mammal has been clarified through genomic approach in details by Professor Norihiro Okada, a Japanese biologist.

\subsubsection{Evolution to primate}

Probably, first primate emerged at ca. 100Ma at the triple junction of rift system at Antarctica-India-Africa (still connected with South America) on Gondwana centered at South 
Pole. Details have not yet clarified, however, the process of divergence of monkey will be a key to unravel when, where, and how monkey emerged by combining geological evolution and genomic records.

\subsubsection{Evolution to Homo sapience}

The first human being appeared at 7Ma, presumably related to the African rift valley, although the fossil locality is outside of the African rift valley. The increase in brain size is a key to evolve to us, Homo sapience. Volume of brain has been measured and the result seems to suggest the stepwise increase with three times, indicating mutation-induced rapid evolution. The trigger of stepwise increase of brain size seems to be extensive rift volcanism enriched in radiation-bearing elements.

\subsubsection{Development of brain}

The development of function to transport $\mathrm{Ca} 2+$ ion in the cell, and cell communication is a key to lead to the emergence of multi-cellular organisms evolving into vertebrates, then further develop neuron, eye, and brain, from fish to human being at the end. This sequential evolution can be explained by the uni-directional evolution. Because the base pair of guanine is selectively damaged by increasing free oxygen. However, details are still remained undemonstrated in laboratory.

\subsection{Probability of life-sustaining planets in our Galaxy}

The Drake equation has long been used to estimate the life in the universe as we have introduced discussion in [35]. However, what are essential requirements for a habitable planet, birthplace of life, or the origin and evolution of life, is our fundamental questions to this big mystery, i.e. the life in the universe. Since then, we have investigated in great details about the requirements for the origin and evolution of life up to the building of a civilization on the planet.

We listed up 41 requirements from the planetary conditions to be habitable, to biological conditions for having civilization. They are still working hypothesis and need to modify or upgrade to make it better and more reliable. The difficulty to list up those requirements is there are possible variables with each condition that we have not listed above. For example, the presence or absence of ocean is one of important requirements for habitable planet, and the probability is $1 / 2$. Even if there is an ocean on the planet, there are some variables with it to be a habitable planet. First, the amount of ocean is critical. If ocean is sufficient enough to cover all continental landmass, life cannot be born nor evolving due to insufficient supply of nutrients even if plate tectonics is operated. On the other hand, if ocean is too small in amount less than below the crest of mid-oceanic ridge, plate tectonics would not operate, because of no extensive hydration of mid-oceanic ridge basalt (MOB). If plate tectonics is not operated, a planet evolves into Venus state and cannot be habitable. Therefore, the amount of ocean is a critically important factor to determine the life-sustaining habitable planet, but there are many variables with it. Another variable of ocean is the thickness, which must be $4 \pm 1 \mathrm{~km}$ in the case of Earth-size planet, however, such detailed condition is difficult to categorize. Because the amount is changing 
through time. Considering the condition of ocean alone, it has various variables, e.g. thickness, $\mathrm{pH}$, salinity, and change in amount through time.

In general, the estimation of probability is simply give from the answer of yes or no, or judgement of presence or absence. If there are 50 requirements for life-sustaining planet, the probability of the presence of life-sustaining planet is $(1 / 2)^{50}$, while $2^{50}$ corresponds to the number of planets moving around a single central star in our Milky Way Galaxy. Beside the Milly Way Galaxy, more galaxies should be present. If so, life might be present somewhere in the universe as far as can be evaluated from the probability.

However, as we listed the requirements, it cannot be simply calculated by probability. Requirements have to be satisfied as well as possible variables, and they have the constrains of permutation and combination. After all the requirements, variables, permutation and combination are satisfied, life can be emerged and evolve as the Earth did successfully. We are made aware that the probability to emerge and evolve life is extremely small, and the probability of the planet having civilization in the Universe is reduced more drastically.

\section{Conclusion}

This paper summarized the history of each study fields briefly, and introduced new models or new proposal to push forward to reach to the goal of the research.

1 Origin of solar system: a new model was introduced, which incorporated chemical differentiation of rock-forming materials, magneto-rotational instability through the growing proto-planetary disc, in addition to N-body numerical simulation.

2 Origin of the Earth; a new model (ABEL model) was introduced. ABEL model proposed the Earth was formed by anhydrous enstatite chondrite, and born as dry planet at 4.53Ga. After 4.37Ga, icy asteroids bombarded the earth to supply with not only $\mathrm{H} 2 \mathrm{O}$ but also life components, resulting in the formation of ocean and atmosphere. This bombardment event (ABEL Bombardment) made the habitable planet Earth.

3 Proposal of carbon cycle through time: a new model of carbon cycle is proposed from the origin of carbon and circulation from atmosphere to mantle, through plate tectonic and volcanism. In addition, we proposed carbonate compensation depth (CCD) could work as the function of pCO2 in a large sense.

4 The origin and evolution of Earth's life: we listed up nine requirements for the birthplace of life based on comprehensive review of previous research. And we also selected 20 big events of the Earth's history to understand significant events through history. It is important to emphasize that earth's life evolved with two steps; (1) from prokaryotes to eukaryotes at 2.0Ga, and (2) to metazoans and plant by $0.54 \mathrm{Ga}$. In these two period, evolution of life was accelerated by starburst.

5 Toward the establishment of Astrobiology: we proposed a working hypothesis to discuss how the planet must emerge and evolve under various kinds of requirements, with four categorized requirements. In addition to requirements, there are variables of each requirement. 
Also permutation and combination of requirements must be satisfied to emerge and evolve to start life on the planet. The calculation of probability of life based on the number of requirement is easy, however, substantive estimation of probability of life in the universe has more difficulties and the probability of the planet having civilization in the Universe might be extremely small.

\section{Acknowledgement}

This research was supported by a Grant-in-Aid for Scientific Research on Innovative Areas, Grant Number 26106002, 26106004, 26106006: Hadean Bio-Science, and also by the Ministry of Education and Science of the Russian Federation, Project no. 14.Y26.31.0018. The authors thank Ms. Reiko Hattori for technical assistance in completing this paper. The illustrations were prepared with the support of Ms. Shio Watanabe.

\section{References}

[1] V.S. Safronov, Evolution of the protoplanetary cloud and formation of the Earth and the planets, the National Aeronautics and Space Administration and the National Science Foundation, Washington, D.C. by Israel program for Science Translations, 1969.

[2] V.S. Safronov, Evolution of the Protoplanetary Cloud and the Formation of the Earth and the Planets, Soviet Astronomy, 16 (1972) 183.F. Baggins, Quantum effects of the One Ring, JHEP 01 (3021) 006 [hep-th/2001033]

[3] C. Hayashi, K. Nakazawa, Y. Nakagawa, Formation of the Solar System, in: D.C. Black, M.S. Matthews (Eds.) Protostars and Planets II, The University of Arizona Press, Tucson, 1985, pp. 11001153.

[4] E. Kokubo, S. Ida, Orbital Evolution of Protoplanets Embedded in a Swarm of Planetesimals, Icarus, 114 (1995) 247-257.

[5] S. Ida, E. Kokubo, T. Takeda, N-Body Simulations of Moon Accretion, in: M.Y. Marov, H. Rickman (Eds.) Collisional Processes in the Solar System, Springer Netherlands, Dordrecht, 2001, pp. 203222.

[6] K.J. Walsh, A. Morbidelli, S.N. Raymond, D.P. O'Brien, A.M. Mandell, A low mass for Mars from Jupiter/'s early gas-driven migration, Nature, 475 (2011) 206-209.

[7] Y. Abe, T. Matsui, Early evolution of the Earth: Accretion, atmosphere formation, and thermal history, Journal of Geophysical Research, 91 (1986) E291-E302.

[8] J.F. Kasting, Runaway and moist greenhouse atmospheres and the evolution of Earth and Venus, Icarus, 74 (1988) 472-494.

[9] Y. Imaeda, T. Ebisuzaki, Tandem planet formation for solar system-like planetary systems, Geoscience Frontiers, 8 (2017) 223-231.

[10] F.E. DeMeo, B. Carry, The taxonomic distribution of asteroids from multi-filter all-sky photometric surveys, Icarus, 226 (2013) 723-741.

[11] F.E. DeMeo, B. Carry, Solar System evolution from compositional mapping of the asteroid belt, Nature, 505 (2014) 629-634.

[12] Y. Abe, Earth evolution of the terrestrial planets, Journal of Physics of the Earth, 43 (1995) 515-532. 
[13] A. Kouchi, T. Kudo, H. Nakano, M. Arakawa, N. Watanabe, S.I. Sirono, M. Higa, N. Maeno, Rapid growth of asteroids owing to very sticky interstellar organic grains, Astrophysical Journal, 566 (2002) L121-L124.

[14] C. Hayashi, Structure of the solar nebula, growth and decay of magnetic-fields and effects of magnetic and turbulent viscosities on the nebula, Supplement of the Progress of Theoretical Physics, (1981) 35-53.

[15] K. Öberg, I. , R. Murray-Clay, E. Bergin, A. , The Effects of Snowlines on C/O in Planetary Atmospheres, The Astrophysical Journal Letters, 743 (2011) L16.

[16] K. Schwarz, R. , E. Bergin, A. , The Effects of Initial Abundances on Nitrogen in Protoplanetary Disks, The Astrophysical Journal, 797 (2014) 113.

[17] M. Javoy, E. Kaminski, F. Guyot, D. Andrault, C. Sanloup, M. Moreira, S. Labrosse, A. Jambon, P. Agrinier, A. Davaille, C. Jaupart, The chemical composition of the Earth: Enstatite chondrite models, Earth and Planetary Science Letters, 293 (2010) 259-268.

[18] R.N. Clayton, Oxygen Isotopes in Meteorites, in: Treatise on Geochemistry, Elsevier, 2003, pp. 129-142.

[19] A.N. Krot, K. Keil, C.A. Goodrich, E.R.D. Scott, M.K. Weisberg, Classification of meteorites, in: A.M. Davis (Ed.) Meteorites, Comets and Planets: Treatise on Geochemistry, Elsevier BV, Amsterdam, The Netherkands, 2005, pp. 83-128.

[20] F. Robert, Isotope geochemistry - The origin of water on Earth, Science, 293 (2001) 1056-1058.

[21] S. Maruyama, M. Santosh, S. Azuma, Initiation of plate tectonics in the Hadean: Eclogitization triggered by the ABEL Bombardment, Geoscience Frontiers, 9 (2018) 1033-1048.

[22] S. Maruyama, T. Ebisuzaki, Origin of the Earth: A proposal of new model called ABEL, Geoscience Frontiers, 8 (2017) 253-274.

[23] B.L. Jolliff, M.A. Wieczorek, C.K. Shearer, C.R. Neal, New views of the Moon, Mineralogical Society of America Geochemical Sciety, 2006.

[24] E.A. Whitaker, The lunar Procellarum basin. In multi-ring basins: formation and evolution, in: Proceedings of Lunar and Planetary Science Conference, 1981, pp. 105-111.

[25] M.D. Hopkins, S.J. Mojzsis, A protracted timeline for lunar bombardment from mineral chemistry, Ti thermometry and U-Pb geochronology of Apollo 14 melt breccia zircons, Contributions to Mineralogy and Petrology, 169 (2015) 1-18.

[26] J.M. Dohm, S. Maruyama, Habitable Trinity, Geoscience Frontiers, 6 (2015) 95-101.

[27] D. Nesvorný, Young Solar System's Fifth Giant Planet?, The Astrophysical Journal Letters, 742 (2011) L22.

[28] R. Cloutier, D. Tamayo, D. Valencia, Could Jupiter or Saturn Have Ejected a Fifth Giant Planet?, The Astrophysical Journal, 813 (2015) 8.

[29] X. Yang, F. Gaillard, B. Scaillet, A relatively reduced Hadean continental crust and implications for the early atmosphere and crustal rheology, Earth and Planetary Science Letters, 393 (2014) 210-219.

[30] S.A. Wilde, J.W. Valley, W.H. Peck, C.M. Graham, Evidence from detrital zircons for the existence of continental crust and oceans on the Earth 4.4 Gyr ago, Nature, 409 (2001) 175-178.

[31] S. Azuma, S. Yamamoto, H. Ichikawa, S. Maruyama, Why primordial continents were recycled to the deep: Role of subduction erosion, Geoscience Frontiers, 8 (2017) 337-346. 
[32] I.H. Campbell, S.R. Taylor, No water, no granites - No oceans, no continents, Geophysical Research Letters, 10 (1983) 1061-1064.

[33] A.B. Ronov, Common tendencies in the chemical evolution of the earth's crust, ocean and atmosphere, Geochemistry International, 1 (1964) 713-737.

[34] S. Maruyama, J.G. Liou, From snowball to Phanerozoic Earth, International Geology Review, 47 (2005) 775-791.

[35] S. Maruyama, M. Ikoma, H. Genda, K. Hirose, T. Yokoyama, M. Santosh, The naked planet Earth: Most essential pre-requisite for the origin and evolution of life, Geoscience Frontiers, 4 (2013) 141165.

[36] T. Tashiro, A. Ishida, M. Hori, M. Igisu, M. Koike, P. Méjean, N. Takahata, Y. Sano, T. Komiya, Early trace of life from 3.95 Ga sedimentary rocks in Labrador, Canada, Nature, 549 (2017) 516.

[37] P.F. Hoffman, D.P. Schrag, Snowball earth, Scientific American, 282 (2000) 68-75.

[38] J.L. Kirschvink, Late Proterozoic Low-Latitude Global Glaciation: The Snowball Earth, in: J.W. Schopf, C. Klein, D.D. Maris (Eds.) The Proterozoic Biosphere: A Multidisciplinary Study, Cambridge University Press, 1992, pp. 51-52.

[39] C. Darwin, On the origin of species, John Murray, Albemable Street, London, 1859.

[40] A.I. Oparin, The origin of life on the earth, Academic Press, New York, 1957.

[41] D. Deamer, The First Living Systems: a Bioenergetic Perspective, Microbiology and Molecular Biology Reviews, 61 (1997) 239-261.

[42] S. Arrhenius, Worlds in the making: the evolution of the universe, Harper, 1908.

[43] J.D. Sutherland, The Origin of Life-Out of the Blue, Angewandte Chemie International Edition, 55 (2016) 104-121.

[44] J.L. Kirschvink, B.P. Weiss, Mars, panspermia, and origin of life: Where did it all begin? , Journal of Geography, 112 (2003) 187-196.

[45] J.B. Corliss, J.A. Baross, S.E. Hoffman, An hypothesis concerning the relationship between submarine hot springs and the origin of life on Earth, Oceanologica Acta, 4 (1981) 59-69.

[46] D.S. Kelley, J.A. Karson, D.K. Blackman, G.L. Fruh-Green, D.A. Butterfield, M.D. Lilley, E.J. Olson, M.O. Schrenk, K.K. Roe, G.T. Lebon, P. Rivizzigno, A.T.S.P. the, An off-axis hydrothermal vent field near the Mid-Atlantic Ridge at 30[deg] N, Nature, 412 (2001) 145-149.

[47] A.Y. Mulkidjanian, A.Y. Bychkov, D.V. Dibrova, M.Y. Galperin, E.V. Koonin, Origin of first cells at terrestrial, anoxic geothermal fields, Proceedings of the National Academy of Sciences of the United States of America, 109 (2012) E821-E830.

[48] T. Ebisuzaki, S. Maruyama, Nuclear geyser model of the origin of life: Driving force to promote the synthesis of building blocks of life, Geoscience Frontiers, 8 (2017) 275-298.

[49] S.L. Miller, A Production of Amino Acids Under Possible Primitive Earth Conditions, Science, 117 (1953) 528-529.

[50] J.L. Bada, A. Lazcano, Prebiotic soup - Revisiting the Miller experiment, Science, 300 (2003) 745746.

[51] S.L. Miller, H. Urey, Organic compound synthesis on the primitive Earth, Science, 130 (1959) 245251. 
[52] S.L. Miller, J.L. Bada, SUBMARINE HOT SPRINGS AND THE ORIGIN OF LIFE, Nature, 334 (1988) 609-611.

[53] D. Deamer, Membranes and the Origin of Life: A Century of Conjecture, Journal of Molecular Evolution, 83 (2016) 159-168.

[54] B. Damer, D. Deamer, Coupled Phases and Combinatorial Selection in Fluctuating Hydrothermal Pools: A Scenario to Guide Experimental Approaches to the Origin of Cellular Life, Life, 5 (2015) 872.

[55] W.F. McDonough, S.S. Sun, The composition of the Earth, Chemical Geology, 120 (1995) 223-253.

[56] M.M. Hanczyc, S.M. Fujikawa, J.W. Szostak, Experimental models of primitive cellular compartments: Encapsulation, growth, and division, Science, 302 (2003) 618-622.

[57] J.-F. Lambert, Adsorption and Polymerization of Amino Acids on Mineral Surfaces: A Review, Origins of Life and Evolution of Biospheres, 38 (2008) 211-242.

[58] P.A. Monnard, D.W. Deamer, Membrane self-assembly processes: Steps toward the first cellular life, Anatomical Record, 268 (2002) 196-207.

[59] D. Deamer, Membranes, Murchison, and Mars: An Encapsulated Life in Science, Astrobiology, 12 (2012) 616-617.

[60] E. Ochiai, Life and metal elements, Kyoritsu Shuppan CO., Ltd., Tokyo, 1991.

[61] E. Ochiai, Bioinorganic chemistry, Academic Press, 2008.

[62] J.A. Tarduno, R.D. Cottrell, W.J. Davis, F. Nimmo, R.K. Bono, A Hadean to Paleoarchean geodynamo recorded by single zircon crystals, Science, 349 (2015) 521-524.

[63] Y. Kato, T. Kano, K. Kunugiza, Negative Ce Anomaly in the Indian Banded Iron Formations: Evidence for the Emergence of Oxygenated Deep-Sea at 2.9-2.7 Ga, Resource Geology, 52 (2002) 101-110.

[64] T. Komiya, T. Hirata, K. Kitajima, S. Yamamoto, T. Shibuya, Y. Sawaki, T. Ishikawa, D. Shu, Y. Li, J. Han, Evolution of the composition of seawater through geologic time, and its influence on the evolution of life, Gondwana Res., 14 (2008) 159-174.

[65] Y. Suzuki, J. Banfield, Geomicrobiology of Uranium, in: P.C. Burns, R. Finch (Eds.) Uranium: Mineralogy, Geochemistry and the Environment, Mineralogical Society of America, Washington, DC, 1999, pp. 393-432.

[66] T. Komiya, S. Maruyama, T. Masuda, S. Nohda, M. Hayashi, K. Okamoto, Plate tectonics at 3.8-3.7 Ga: Field evidence from the Isua Accretionary Complex, southern West Greenland, Journal of Geology, 107 (1999) 515-554.

[67] T. Komiya, S. Yamamoto, S. Aoki, K. Koshida, M. Shimojo, Y. Sawaki, K. Aoki, S. Sakata, T.D. Yokoyama, K. Maki, A. Ishikawa, T. Hirata, K.D. Collerson, A prolonged granitoid formation in Saglek Block, Labrador: Zonal growth and crustal reworking of continental crust in the Eoarchean, Geoscience Frontiers, 8 (2017) 355-385.

[68] T. Saito, Estimate of secular change in seawater salinity through Earth history, in: Department of Earth and Planetary Sciences, Tokyo Institute of Technology, Tokyo, 2015.

[69] J.L. Payne, A.G. Boyer, J.H. Brown, S. Finnegan, M. Kowalewski, R.A. Krause, S.K. Lyons, C.R. McClain, D.W. McShea, P.M. Novack-Gottshall, F.A. Smith, J.A. Stempien, S.C. Wang, Two-phase increase in the maximum size of life over 3.5 billion years reflects biological innovation and environmental opportunity, Proceedings of the National Academy of Sciences of the United States of America, 106 (2009) 24-27. 
[70] Maruyama, M. Santosh, Models on Snowball Earth and Cambrian explosion: A synopsis, Gondwana Res., 14 (2008) 22-32.

[71] R. Kataoka, T. Ebisuzaki, H. Miyahara, S. Maruyama, Snowball Earth events driven by starbursts of the Milky Way Galaxy, New Astronomy, 21 (2013) 50-62.

[72] R. Kataoka, T. Ebisuzaki, H. Miyahara, T. Nimura, T. Tomida, T. Sato, S. Maruyama, The Nebula Winter: The united view of the snowball Earth, mass extinctions, and explosive evolution in the late Neoproterozoic and Cambrian periods, Gondwana Res., 25 (2014) 1153-1163.

[73] S. Maruyama, Y. Sawaki, T. Ebisuzaki, M. Ikoma, S. Omori, T. Komabayashi, Initiation of leaking Earth: An ultimate trigger of the Cambrian explosion, Gondwana Res., 25 (2014) 910-944.

[74] L. Sagan, On the origin of mitosing cells, Journal of Theoretical Biology, 14 (1967) 225-IN226. 